University of Rhode Island

DigitalCommons@URI

Open Access Dissertations

1975

\title{
MECHANISM AND CHARACTERISTICS OF DRUG-INDUCED AGGRESSION
}

Gerald Gianutsos

University of Rhode Island

Follow this and additional works at: https://digitalcommons.uri.edu/oa_diss

\section{Recommended Citation}

Gianutsos, Gerald, "MECHANISM AND CHARACTERISTICS OF DRUG-INDUCED AGGRESSION" (1975). Open Access Dissertations. Paper 149.

https://digitalcommons.uri.edu/oa_diss/149

This Dissertation is brought to you for free and open access by DigitalCommons@URI. It has been accepted for inclusion in Open Access Dissertations by an authorized administrator of DigitalCommons@URI. For more information, please contact digitalcommons-group@uri.edu. 


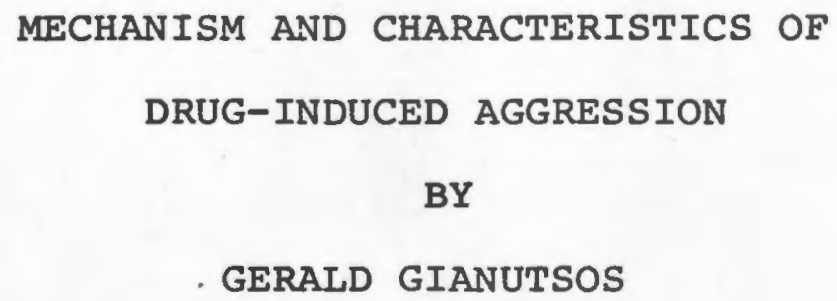

A DISSERTATION SUBMITTED IN PARTIAL FULFILLMENT OF THE REQUIREMENTS FOR THE DEGREE OF DOCTOR OF PHILOSOPHY

IN

PHARMACOLOGY

(PHARMACEUTICAL SCIENCES)

UNIVERSITY OF RHODE ISLAND

1975 
DOCTOR OF PHILOSOPHY DISSERTATION

OF

GERALD GIANUTSOS

Approved :

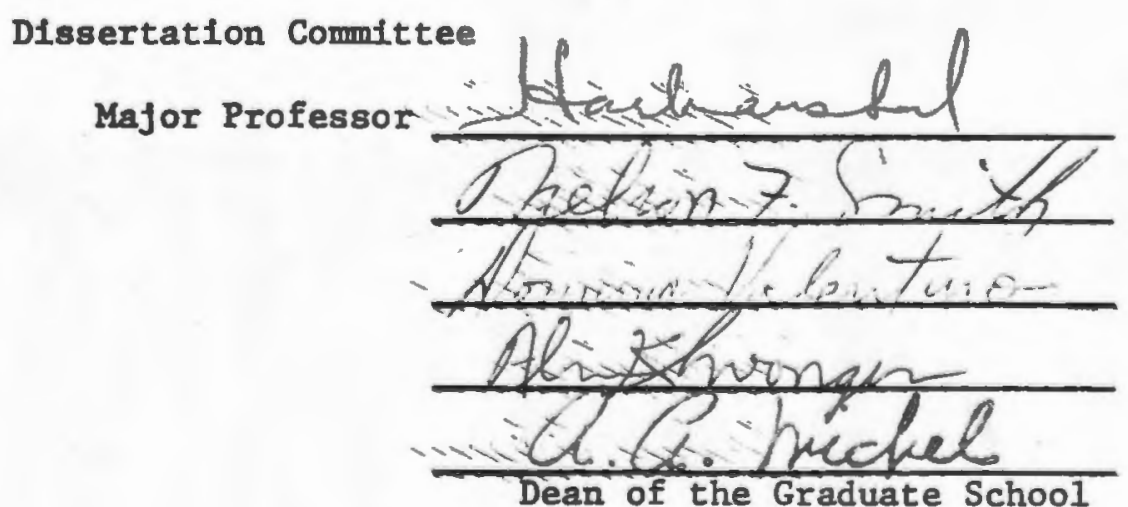

UNIVERSITY OF RHODE ISLAND

1975 
MECHANISM OF DRUG INDUCED AGGRESSION 


\begin{abstract}
Gerald Gianutsos, Ph.D.: Mechanism and Characteristics of Drug-Induced Aggression.
\end{abstract}

This research investigated the pharmacological alteration of drug-induced aggression in naive, morphine-dependent and chronically haloperidol treated rats. Naive rats were treated with apomorphine $(1.25-20 \mathrm{mg} / \mathrm{Kg})$ and aggregated in groups of four for aggression. It was determined that 20 $\mathrm{mg} / \mathrm{Kg}$ of apomorphine produced maximal aggression, as measured by number of attacks, duration of aggressive posturing and number of vocalizations. Doses less than $5 \mathrm{mg} / \mathrm{kg}$ were without any effect. The neuroleptics, haloperidol and oxyperomide, the narcotic, morphine, and the cholinergic agonist, pilocarpine all reduced apomorphine-induced aggression in a dosedependent manner. Centrally acting anti-cholinergic drugs partially reversed the blockade of aggression produced by all the drugs except morphine which was preferentially antagonized by naloxone, a narcotic antagonist. Aggression was elicited by sub-threshold doses of apomorphine when combined with clonidine; large doses of dexetimide, an anticholinergic; or when administered three days after an injection of $\mathrm{p}$-chloroamphetamine $(12 \mathrm{mg} / \mathrm{Kg})$. None of these drugs were capable of eliciting aggression by themselves. Amphetamine potentiated the apomorphine-induced aggression, but 
failed to elicit aggression with sub-threshold doses of apomorphine unless combined with cyproheptadine.

In morphine-dependent rats, aggression was observed during withdrawal produced by withholding of injections, but not in withdrawal induced by naloxone. The aggression - which was observed at 72 hours and at 30 days of withdrawal - was reduced by morphine, haloperidol or by lesions of the dopaminergic nigro-striatal bundle, and enhanced by small doses of apomorphine. Apomorphine was also capable of eliciting aggression when administered at four hours of withdrawal, with or without naloxone. The 72 hour withdrawal aggression was similar to apomorphine-induced aggression in naive rats since it was dose-dependently increased by dexetimide or clonidine and decreased by pilocarpine. However, in contrast to the effect in naive rats, anticholinergic drugs failed to reverse the blockade of aggression produced by haloperidol in morphine dependent rats.

Following chronic treatment with haloperidol, rats demonstrated signs of dopaminergic supersensitivity as shown by enhanced apomorphine- or amphetamine-induced stereotypy, increased spontaneous hyperactivity and a shift to the left of the dose-response curve for amphetamine stimulation and for apomorphine-induced reduction in striatal dopamine turnover. In addition, the rats exhibited an increased sensitivity to the stimulation of activity produced by dexetimide and a decrease in the depression of activity produced by pilocarpine. Although there was no spontaneous aggression after discontinuation of chronic halperidol, the threshold 
dose of apomorphine required to elicit aggression was dramatically reduced. Amphetamine failed to produce aggression after chronic haloperidol, in contrast to the effect normally seen after chronic morphine.

The results of this study demonstrated the requirement of central dopaminergic stimulation for drug-induced aggression, and suggested that the aggression was antagonized by the activity of acetylcholine and serotonin and possibly facilitated by norepinephrine. In addition, it suggested that morphine and haloperidol produce an anti-aggression action by different mechanisms, possibly involving a cholinergic component in the case of haloperidol. Finally, the research provided evidence that the dopaminergic supersensitivity following chronic treatment with morphine may be qualitatively or quantitatively different from the supersensitivity following chronic treatment with haloperidol, since spontaneous and amphetaminestimulated aggression are noted only in the former case. It was proposed that morphine interferes with cholinergic and/or serotonergic compensatory mechanisms and that these contribute to the aggression. 


\section{ACKNOWLEDGEMENTS}

The author wishes to express his gratitude to his wife, Adeline, and to his parents, Mr. and Mrs. Costas Gianutsos, for their understanding, patience and inspiration.

The guidance provided by Dr. Harbans Lal, and the many helpful suggestions and criticisms offered by members of the author's committee and the faculty of the Department of Pharmacology and Toxicology of the University of Rhode Island during these studies are sincerly appreciated. The author is also grateful for the help and understanding provided by his fellow students in the Department of Pharmacology and Toxicology, especially to Martin Hynes, III, Richard Drawbaugh, Stephen Micsic, Chejerla Reddy and Dr. Robert Numan who provided invaluable assistance in certain aspects of this work.

In addition, the author would like to acknowledge the financial support provided by an NDEA Fellowship, a Univers1ty of Rhode Island Fellowhip and a Teaching Assistantship from the Department of Pharmacology and Toxicology, without which these studiés would have never been possible. 
TABLE OF CONTENTS

PAGE

ABSTRACT............................. I1

ACKNOWLEDGEMENTS ....................... v

TABLE OF CONTENTS..................... v1

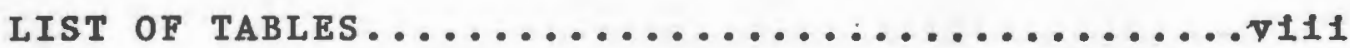

LIST OF FIGURES....................... $x$

CHAPTER

I INTRODUCTION....................... 1

II LITERATURE SURVEY.................. 4

A. AGGRESSION ............................ 4

1) General Aspects................. 4

2) Models of Aggression............ 7

B. DOPAMINE IN THE CENTRAL NERVOUS SYSTEM.. 12

1) Dopam1ne Pathways.............. 12

2) Dopamine Release and Turnover...... 19

3) Behavioral Effects of Dopamine..... 21

4) Effects of Drugs on Dopamine Levels and Turnover...................... 26

C. DOPAMINE INTERACTIONS IN THE CNS...... 33

1) Acetylcholine................. 34

2) Serotonin.................. 37

D. DOPAMINERGIC SUPERSENSITIVITY....... 39

1) Leston Induced Supersensitivity.... 41

2) Drug Induced Supersensitivity......4 43 
III EXPERIMENTAL..................... 46

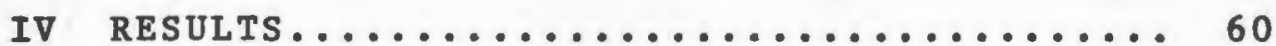

A) APOMORPHINE INDUCED AGgRESSION....... 60

1) Effect of Anti-Dopaminergic Drugs.. 60

2) Effect of Drugs Affecting Acety1choline.................... 66

3) Effect of Amphetamines......... 73

B) MORPHINE WITHDRAWAL AGgRESSION....... 78

1) 72 Hour Withdrawal Aggression..... 78

2) Elicited Withdrawal Aggression.... 87

3) Protracted Aggression.......... 95

C) CHRONIC HALOPERIDOL.............. 97

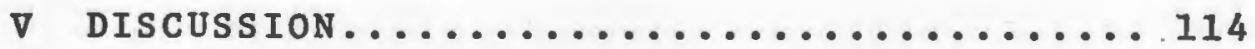

A) APOMORPHINE INDUCED AGGRESSION....... 116

1) Role of Dopamine.............116

2) Cholinergic-Dopaminergic Interact-

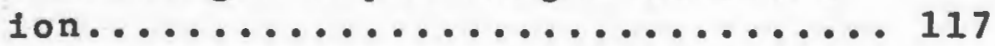

3) Serotonergic-Dopaminergic Interac-

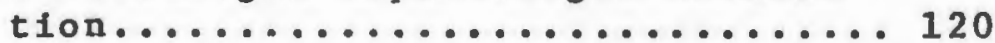

4) Effect of Clonidine............ 123

B) MORPHINE WITHDRAWAL AGgRESSION....... 125

1) Elicited Aggression............ 126

2) Protracted Aggression........... 128

C) CHRONIC HALOPERIDOL................ 129

D) COMPARISON OF HALOPERIDOL AND MORPHINE. 133

VI SUMMARY AND CONCLUSIONS............. 141

VII BIBLIOGRAPHY.................. 145 


\section{LIST OF TABLES}

TABLE

PAGE

1 Dose Ranges and Pretreatment Times for Drugs Used.............................. 48

2 Schedules of Chronic Drug Treatments........ 50

3 Effects of Neuroleptics on Apomorphine Induced

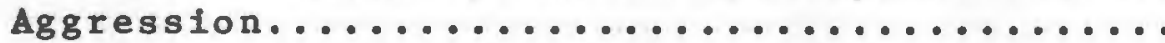

4 Effect of Morphine on Apomorphine Induced

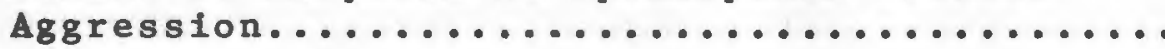

5 Reversal of Neuroleptic Induced Blockade of Apomorphine Induced Aggression by Dexetimide..

6 Effect of Pilocarpine Plus Oxyperomide on Apomorphine Induced Aggression..............

7 Blockade of Apomorphine Induced Aggression by

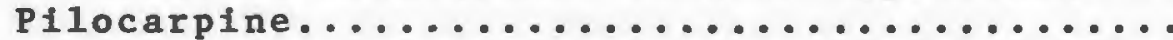

8 Effect of Anticholinergics on Pilocarpine Induced Blockade of Apomorphine Induced

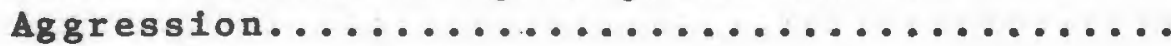

9 Effect of Dexetimide on Apomorphine Induced Aggression........................

10 Effect of Amphetamine on Apomorphine Induced

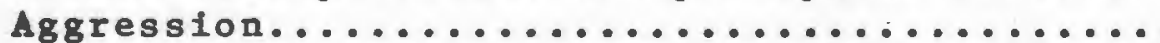

11 Effect of Clonidine on Apomorphine Induced Aggression.........................

12 Effect of Amphetamine Plus Cyproheptadine on Apomorphine Induced Aggression............

13 Effect of Different Schedules of Addiction on 72 Hour Morphine Withdrawal Aggression.......

14 Locomotor Activity of Rats During Morphine

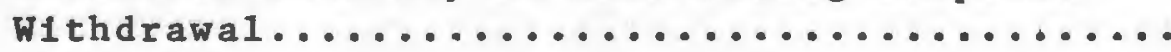

15 Effect of Apomorphine or Haloperidol on 72 Hour Morphine Withdrawal Aggression.......... 
16 Effect of Brain Lesions on 72 Hour Morphine Withdrawal Aggression..................

17 Effect of Dexetimide on Haloperidol Induced Blockade of Morphine Withdrawal Aggression....

18 Effect of Dexetimide on 72 Hour Morphine Withdrawal Aggression.....................

19 Effect of Clonidine on Morphine Withdrawal

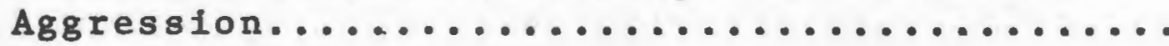

20 Precipitated Narcotic Withdrawal Four Hours After Terminal Morphine Injection...........

21 Elicitation of Withdrawal Aggression in Morphine Dependent Rats Four Hours After Morphine Injection.........................

22 Effect of Apomorphine or Naloxone on 72 Hour Morphine Withdrawal Aggression.............

23 Effect of Apomorphine and Brain Lesions on Morphine Withdrawal Aggression............

24 Apomorphine Induced Stereotypy in Rats After Chronic Treatment with Haloperidol..........

25 Amphetamine Induced Stereotypy in Rats After Chronic Treatment with Haloperidol...........

26 Apomorphine Induced Aggression Following Chronic Haloperidol Administration.......... 100

27 Failure of Amphetamine to Induce Aggression in Rats Chronicaliy Treated with Haloperidol..... 103

28 Effect of Pentobarbital on Locomotor Activity in Rats After Chronic Treatment with Haloper-

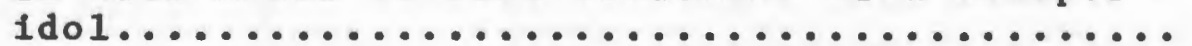

29 Effect of Chronic Haloperidol Treatment on

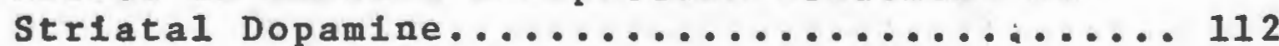

30 Effect of Brain Neurotransmtters in Drug

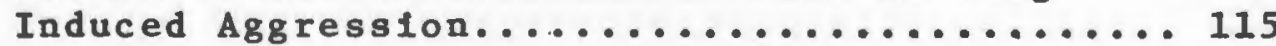




\section{LIST OF FIGURES}

NUMB E R

PAGE

1A Aggressive Postures of Rats During Drug Induced Aggression: Rearing............... 54

1B Aggressive Postures of Rats During Drug Induced Aggression: Dominant-Submissive Posture. 55

2 Dose Related Elicitation of Aggression by Apomorphine in Naive Rats...............6 61

3 Dose Related Elicitation of Aggression by Apomorphine in p-Chloroamphetamine (PCA)

Treated Rats.........................

4 Dose Related Reduction of 72 Hour Morphine Withdrawal Aggression by Pilocarpine........

5 Effect of Amphetamine on Locomotor Activity in Normal and Chronic Haloperidol Treated Rats 105

6 Effect of Amphetamine, Apomorphine or AlphaMethy1-p-Tyrosine (MPT) on Locomotor Activity in Normal and Chronically Haloperidol Treated

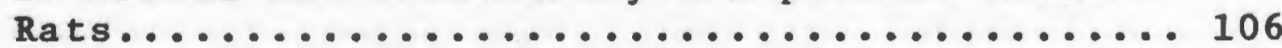

7 Effect of Dexetimide on Locomotor Activity in Normal and Chronic Haloperidol Treated Rats 108

8 Effect of Pilocarpine on Locomotor Activity in Normal and Chronic Haloperidol Treated Rats 109

9 Effect of Apomorphine on Striatal Dopamine Turnover in Normal Rats and After Chronic

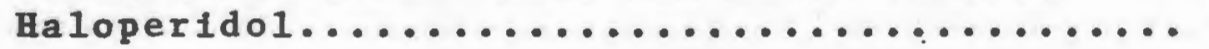




\section{INTRODUCTION}

Drugs are capable of producing a variety of behavioral changes in laboratory animals. Under the appropriate conditions, drugs can elicit aggressive behavior. Over the past several years, aggression has been reported after the administration of several different types of drugs, most notably. apomorphine (Senault, 1970) and amphetamine (Chance, 1948). In addition, aggression has been reported during narcotic withdrawal (Boshka et a1., 1966; Lal et a1., 1971), which. is intensified by treatment with either apomorphine or amphetamine (Puri and Lal, 1973a).

The mechanism underlying drug-induced aggression is not well established. Apomorphine is believed to directly stimulate dopamine receptors in the brain (Ernst, 1967; Anden et al., 1967). Amphetamine is believed to release both norepinephrine (Car1sson et a1., 1966; Carr and Moore, 1969) and dopamine (Besson et al., 1971; Chiueh and Moore, 1973), but its behavioral effects are generally regarded as the result of dopaminergic stimulation (Van Rossum and Hurkmans, 1964; Costa et a1., 1972; Thornburg and Moore, 1973a). Therefore, a working hypothesis may be formulated which states 
that a hyperstimulation of dopamine neuronal systems may be responstble for aggression. A study of the types of drugs which both increase and decrease the degree of aggression may provide some insight into the mechanisms involved in this type of behavior and a method for comparing different types of drugs.

Haloperidol and morphine share a number of behavioral effects (see Lal et al., 1975a), Including an ant1-aggressive action in fighting elicited by shock (Lal et al., 1975a), DOPA + amphetamine (Lal et a1., 1972b) or morphine withdrawal (Purt and Lal, 1973a). The two drugs also both produce an acceleration of dopamine turnover (Puri et al., 1973). Yet, there are obvious differences between. the two drugs.

Dopamine's behavioral effects are modulated by activity of other neurotransmitters. For instance, amphetamine induced stereotypy is decreased by cholinergic (Arnfred and Randrup, 1968) or serotonerglc (Welner et al., 1973) activity. These types of interactions are rarely studied In drug-induced aggression.

The objectives of this research, therefore, are threefold. First, the research will examine the role of brain dopamine indrug-induced aggression. Secondly, it w111 investigate the interaction between dopamine and acetylcholine and serotonin in this behavior, and thirdly, it w111 compare and contrast haloperidol and morphine after both acute and chronic treatment. 
The significance of this research is manifold. The primary significance will be the determination of the role of brain dopamine in the expression of drug-induced aggression.

Secondly, this research will provide information relevant to the interaction between dopamine and acetylcholine and serotonin in the CNS, especially in the control of drug-induced aggression.

Thirdly, this research will examine similarities and differences between morphine and haloperidol after both acute and chronic treatment. Since only the former produces physical dependence (though both share many behavloral actions, see above), this research may provide information relevant to drug addiction.

Lastly, this research may have practical significance by serving as a potential model for schizophrenia research. It has been suggested that schizophrenia may be due to a hyperactivity of dopamine neuronal systems in the CNS (Rlawans et al., 1972a; Matthysse, 1973). It is proposed here, that a similar hyperactivity may be the cause underlying the drug-induced aggression in rodents. If so, the drug-induced aggression may serve as a useful tool for studying brain changes which may be related to schizophrenia and serve as a test for screening new potential therapeutic agents. 
II. LITERATURE SURVEY

\section{A. AGGRESSION}

\section{1) General Aspects}

Violence is a well recognized component of human society. However, fighting is not restricted to humans, but is found in a wide variety of animals. Because of the ubiquity of this behavior, it has long.attracted the attention of psychologists, psychiatrists, ethologists, sociologists and other investigators in the behavioral sciences. In recent years, it has also been studied by pharmacologists who have used aggression to provide information on the complex workings of the brain, to gain Insight into the actions of centrally acting drugs and to attempt to rationally develop drugs for the treatment of psychopethological disorders.

Aggression has been defined by Lorenz (1966) as

"the fighting instinct in beast and man which is directed against members of the same species." This behavior, in the view of Valzelli (1967), is directed towards removing or overcoming what is menacing the physical or psychologi- 
cal integrity of the organism. Aggression is such a widespread phenomenon, that Scott (1958) concluded that it is not an accident of evolution but rather a necessary and useful part of an animal's life. Aggression is necessary, Lorenz (1966) concluded, to establish territoriality, for the selection of the strongest member of a species, and for the defense of the young.

Collias (1944) investigated the role of aggression in the ecological pattern of living systems and observed that a great deal of fighting in vertebrates is associated with territoriality. In addition, he observed that fighting in animal groups tends to become organized into social dominance hierarchies which has the net effect of greatly reducing the amount of fighting and that one of the major physlological factors connected with fighting in vertebrates is the male sex hormone.

Considerable attention has been focused on further delineating the variables underlying aggressive behavior. The physiological mechanisms responsible for aggression are very complex and involve interactions between neural, hormonal and sensory factors, as well as equally complex psychological factors. Tor example, it is believed that aggression is strongly stimulus bound. As an 1llustration, it is known that rats will kill mice, but not rat pups; male mice will attack other males, but will not attack females; attacks precipitated by stimulation of the 
hypothalamus of the cat will be directed at a live rat, but not at a stuffed rat (see Moyer, 1968). Furthermore, it is well recognized that animals respond to postures of their opponents which results in inhibition of aggression. In addition, other psychological factors such as success at fighting influence aggression. Successful, experienced animals are much more likely to fight than inexperienced ones or animals which have lost a battle (Scott, 1962). Thus it is clear that aggresion is an extremely complex behavior and any hypothesis which purports to explain aggressive behavior would have to be equally complex.

Moyer (1968) has classified aggression into seven categories. These are predatory, inter-male, fear-induced, irritable, territorial defense, maternal and instrumental. These types of aggression were differentiated on the basis of stimulus situations which elicit the behavior. Moyer pointed out that different neuroanatomical loci, neural mechanisms and topographical patterns may accompany the different types of aggression, so that a global explanation encompassing all types of aggression may be an insurmountable task. Therefore, it is not surprising that a drug may affect different types of aggression in different ways. Some of these methods used to study the effects of drugs on aggression are presented in the next section. 
2) Models of Aggression

There is a starting variety of methods by which aggression may be studied in the laboratory. The most widely used procedures are aggression produced by a painful stimulation (Tedesch1 et al., 1959; Ulrich and Azrin, 1962), prolonged social Isolation of mice (Yen et al., 1959) or the administration of drugs. Some other frequently utilized models for the study of aggression include mouse killing (muricide) by rats (Kar11, 1956); frog kiliing (ranacide) by rats (Bernstein and Moyer, 1970); hyperemotionality Induced by lesions of the septum (Brady and Nauta, 1953); rage responses following intracerebral injections of chemicals (see Myers, 1975); aggression during extinction of an operant task (Azrin et a1., 1966); and the introduction of a strange rat into the residence of another (Miczek, 1974). It is probable that the models each have a different physiological basis. The characteristics of the most popular models will be briefly described.

In the isolation paradigm, male mice are housed singly for a period of at least three weeks (Yen et a1., 1959). The aggression occurs spontaneously when the isolated mouse is exposed to another mouse. The mice become progressively more aggressive with increasing duration of isolation and progressively less aggressive as the size of the group in which they live Increases (Welch and Welch, 1970). The isolated mice are more sensitive to the effects of CNS 
stimulants and less sensitive to the effects of cNs depressants (Lal et al., 1972a). Th1s type of aggression has been extensively utilized for the testing of drugs and is blocked by a wide variety of pharmacological substances (Janssen et a1., 1960; Valze111, 1967) apparently with 11ttle select1vity. The isolation reportedly produces a decrease in the turnover of brain serotonin and norepinephrine and an increase in the turnover of brain dopamine (Valzell1, 1970).

In pain-induced aggression, two animals are enclosed In an area from which they cannot escape and a painful stimulus, usually an electric shock, is delivered to the animals. The aggression occurs in females as well as males, but is not directed towards inanimate objects in the case of rats (Ulrich and Azrin, 1962). This procedure has also been used for screening drugs (Tèdeschi et al., 1959). Pain-induced aggression appears to be primarily related to the activity of brain catecholamines, especially norepInephrine (E1chelman, 1973).

Pharmacological investigation of aggression may also be carried out in fighting that occurs as a result of the prior administration of a drug. Several types of drugs are capable of producing aggression in laboratory animals, especially apomorphine (Senault, 1970) and amphetamines (Lal et $\underline{\text { a1. }}$ 1970; Hasselager et a1., 1972). Aggression also occurs during withdrawal following chronic treatment with narcotics (Boshka et al., 1966; Lal et al., 1971). The apomorphine-induced and morphine withdrawal aggression 
will be treated more fully below. The drug-induced aggression paradigm appears to be related to dopaminergic activity In the CNS

a) Apomorphine-Induced Aggression- Large doses of apomorphine, a dopamine receptor agonist (Anden et a1., 1967), produce aggression In rats (Senaul, 1970; McKenzie, 1971). The aggression is directed only towards a similarly treated rat and is not observed when a non-treated rat or a mouse is put into contact with an apomorphine treated rat (Mckenzie, 1971). The aggression occurs with increased frequency in older ( 84 day old) rats and is absent in rats less than 49 days of age (McKenzie, 1971).

This effect is seen only in male rats (Mckenzie, 1971). Castration or hypophysectomy decreases, while large doses of testosterone increase the degree of aggression (Senaul, 1972).

When lesions are made in the amygdala or the substantia nigra of rats, apomorphine-induced aggression is reduced. In contrast, lesions which destroy the septum or olfactory bulb enhance the degree of aggression but fail to produce aggression in normally non-aggressive rats (Senault, 1973).

The effect of various drugs on apomorphine-induced aggression have been studied. Neuroleptics and anxiolytics reduce the degreee of aggression (Senault, 1970) as do the alpha-adrenergic blocker, phenoxybenzamine (Senaul, 1974); the beta-adrenergic blocker, propranolol (Butter- 
worth et al., 1975); and the anticholinergic, atropine (Senault, 1970; D1abac, 1973). A slight decrease in the aggression is produced by 5-hydroxytryptophan (Senaul, 1974). The aggression is increased by L-DOPA, MAO Inhibitors (Senault, 1974), reserpine (McKenzie, 1971) and to some extent by clonidine (Senault, 1974; Butterworth et a1., 1975). A sensitization to the effect of apomorphine has been shown following withdrawal from narcotics (Puri and La1, 1973a) or treatment with 6-hydroxydopamine (Elchelman and Thoa, 1973). It has been reported that little if any effect on apomorphine-induced aggression is produced by antidepressants (D1abac, 1973), PCPA or alpha-m-dopa (Senault, 1974).

Lasty, it has been noted that ET-495, another drug believed to stimulate dopamine receptors (Corrodi et al., 1972) also produces aggression (Senault, 1974).

b) Morphine Withdrawa1 Aggression - Rats can be made dependent on narcotics and will exhibit a number of behavloral changes during withdrawal from these drugs (Martin et 스., 1963). Dependent rats undergoing withdrawa1 from morphine are hyperirritable and, when placed together, will show vigorous fighting (Boshka et a1., 1966). The aggressIon is blocked by continued treatment with morphine, but emerges when drug administration is discontinued. The aggression reaches its maximum approximately three days after withdrawal has been initiated (Thor et a1., 1970; Puri and Lal, 1973a). The fighting consists of vocaliza- 
tions, aggressive postures, biting and other forms of attack and often leads to severe injury or death of some of the rats (Lal, 1975). Abstinence from other narcotics, such as etonttazene (Florea and Thor, 1968), methadone (Singh, 1973) or fentanyl (Lal et al., 1975b) also results in withdrawal aggression, but spontaneous aggression is not noted after chronic treatment with amphetamine, alcohol or barbiturates (Puri and Lal, 1974b). Morphine withdrawal aggression has also been reported in mice (Weissman, 1973) and guinea pigs (Goldstein and Schulz, 1973). Rage and diffi-. culty in handling has also been reported during narcotic withdrawal in monkeys (Seevers and Deneau, 1963).

The aggression differs from natural aggression in that posturing by the subordinate animal which usually leads to cessation of aggression, does not inhibit fighting during withdrawal, and a withdrawn rat will attack a dead rat (Crabtree and Moyer, 1973). Some aggression, although to a lesser degree, is shown by females in morphine withdrawal (Crabtree and Moyer, 1973). Older rats are more responsive than younger ones (Davis and Khalsa, 1971).

The aggression occurs spontaneously during withdrawal but can be markedly increased by directly (Puri and Lal, 1973a) or indirect1y (Thor, 1969; Lal et a1., 1971) acting dopamine receptor stimulants. These observations first suggested that dopamine supersensitivity develops during narcotic addiction (PurI and Lal, 1973a). Small doses of d- or 1-amphetamine potentiate the aggression and are near- 
1y equipotent in this regard (Lal et al., 1971). Hydroxyamphetamine, which has only a peripheral action, does not

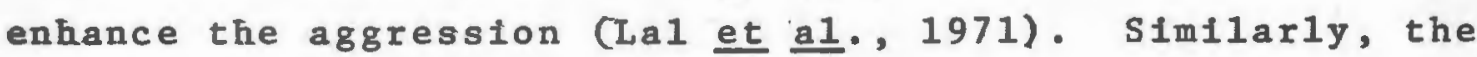
aggression is markedly enhanced by small doses of apomorphine or L-DOPA and is decreased by dopamine receptor blockade by haloperidol or by inhibition of dopamine synthesis by alpha-methy1-p-tyrosine (Puri and Lal, 1973a). Apomorphine also induces aggression in morphine dependent mice (Iorio et all., 1975). These results strongly suggest the Involvement of brain dopamine in morphine addiction and withdrawal. In addition, morphine withdrawal aggression is also enhanced by extracts of Cannabis sativa (Carlini and Gonzalez, 1972).

\section{B. DOPAMINE IN THE CENTRAL NERVOUS SYSTEM}

\section{1) Dopamine Pathways}

Dopamine, like other central neurotransmitters, has an uneven distribution in the CNS. The discovery of high levels of dopamine in the basal ganglia by Bertler and Rosengren (1959) gave rise to the idea that dopamine has a function of its own, Independent of being a precursor of norepinephrine. Dopamine is distributed in the basal ganglia, the limbic system, the hypothalamus and the cortex. The existence of dopamine fiber pathways in the CNS has been demonstrated through studies employing lesions, stimulating electrodes, blochemical and histochemical techniques. Based upon these studies, the following dopaminergic path- 
ways have been described:

a) Nigro-neostriatal Dopamine neurons

b) Mesolimbic Dopamine neurons

c) Tubero-infundibular Dopamine neurons

a) Nigro-Neostriatal Dopamine Neurons - The nigro-neostriatal system seems to originate mainly in the pars compacta of the substantia nigra (Anden et a1., 1964). Support for this comes from fluorescence microscopy and the high dopamine content observed in this area (Hornykiewicz, 1966). Unilateral pars compacta lesions result in a 60 per cent lowering of the dopamine level in the corpus striatum of the operated side when compared with the unoperated side (Faul1 and Laverty, 1969). The caudate nucleus and putamen show a falrly strong green to yellow fluorescence due to the high dopamine content. This fluorescence was reduced in animals with lesions of the substantia nigra. A clear correlation was found between the fluorescence reduction and the extent of destruction of the pars compacta (Anden et al., 1964). Some cell bodies are also found in the zona reticulata and the pars lateralis of the substantia nigra, which also belong to the nigroneostriatal dopamine system (Fuxe et a1., 1970). Recent1y, studies after the removal of the nucleus caudatus putamen suggest that the cell bodies of the ventrolateral part of the midbrain tegmentum belong to this uncrossed neuron system, in as much as they show marked reduction in fluorescence Intensity and signs of atrophy after such 
operations (Fuxe et al., 1970). There is now a virtually complete picture of the distribution of these dopamine fibers. Upon leaving the pars compacta of the substantia nigra, most of the nigro-neostriatal dopamine fibers become aggregated in a bundle which ascends just medially and dorso-medial to the ventral part of the crus cerebri. At the level of the posterior part of the median eminence, the bundle turns to the ventrolateral part of the crus cerebri and enters and diverges into the retrolenticular part of the internal capsule. Running rostrally and dorsally in the Internal capsule, the fibers then ascend in the fibers of the Internal capsule to innervate the neostriatum (Anden et a1., 1965).

Blochemical and histochemical investigations have yielded some quantitative data on the unilateral nigroneostriatal dopamine system in the rat. The number of neurons making up this system is 3500 on the average. There are about $1.2 \times 10^{-10}$ grams of dopamine per neuron with terminals contalning 50 times more dopamine than the cell bodies. There are approximately 500,000 varicosities In the terminals, each with an average diameter of $0.4 \mathrm{u}$, containing $2.5 \times 10^{-16}$ grams of dopamine and has a dopamine concentration of around 8000 ug/gr wet weight. One dopamine cell body of the substantia nigra, with a mean diameter of $30 u$, contains $2.5 \times 10^{-18}$ grams and has a dopamine concentration of from 60 to $200 \mathrm{ug} / \mathrm{gr}$ (Anden et a1: $1966 \mathrm{~d}$ ). 
These data imply that dopamine is a neurotransmitter of the nigro-neostriatal pathway. There is evidence to Indicate that dopamine may function as an inhibitory neurotransmitter at the terminals of the nigro-striatal pathway. Bloom and coworkers (1965) demonstrated that dopamine has primarily an inhibitory action when applied microIontophoretically to caudate neurons. Most of the neurons that respond to dopamine are inhibited by exogenous dopamine applied to the caudate nucleus of anesthetized and decerebrated cats (McLellan and York, 1967; York, 1970). Following the application of dopamine iontophoretically from multibarrel micropippettes near caudate cells, the rate of discharge of 50 to 60 per cent of these neurons $1 s$ depressed, while the spike rate of approximately 10 per cent of the cells is facilitated. Electrical stimulation of the substantia nigra evokes depressant and facillatory responses from individually recorded caudate neurons (Connor, 1968; 1970).

b) Meso Limbic Dopamine Neurons - The mesolimbic dopamine neurons have their cell bodies in the area surrounding the nucleus interpeduncularis and fibers from these cell bodles terminate in the tuberculum olfactorlum, nucleus accumbens, the dorsolateral part of the nucleus interstitiata striae terminalis and in the nucleus amygdaloideus centralls (Anden et a1., 1966b). These areas have been shown to contain large quantities of dopamine which is 
not associated with norepinephrine synthesis (Koslow et al., 1974). A dopamine sensitive adenylate cyclase has also been found in the tuberculum olfactortum, nucleus accumbens and amygdala (Clement-Cormier et a1., 1974). These cyclase systems are considered to resemble the "dopamine receptor" (Kebabian et al., 1972). Dopaminergic fibers of this system run medially to the nigrostriatal dopamine fibers, wheras cranlally they lie mainly ventral to the nigro-striatal system (Anden et a1., 1966b).

The mesolimbic dopamine neurons probably contain less dopamine than do nigro-striatal neurons. This is probably because the terminal network of each mesoIimbic neuron is much smaller than that of the nigroneostriatal dopamine neurons (Anden et al., 1966c; Fuxe et à1., 1970).

c) Tubero-Infundibular Dopamine Neurons - The tuberoInfundibular dopamine neurons have their cell bodies mainly localized in the anterior part of the nucleus annuatus and anterfor periventricular nuclei. The axons of this system run ventrally toward the lateral border of the median eminence (Fuxe, 1963; Fuxe and Hokfelt, 1966; 1969). In the external layer of the median eminence, the axons give rise to a densely packed plexus óf dopaminergic nerve terminals, which exerts an axo-axonic influence in the layer (Hokfe1t, 1967). 
This very short dopaminergic intrahypothalamic system regulates the discharge of the releasing and inhibiting factors from the median eminence (Fuxe et al., 1970). The release of doapmine in the median eminence acts locally on terminals storing luteinizing hormone releasing factor (LHRF) to inhibit the release of LHRF from the median eminence. This system also participates in mediating the negative feedback action of estrogen and testosterone on gonadotropic secretion, because estrogen and testosterone markedly Increase the turnover of tubero-infundibular dopamine In neurons of castrated rats, resulting in increased release of dopamine in the area (Fuxe et a1., 1967; 1969). The blockade of ovulation by synthetic estrogens and their derIvatives may at least be partly mediated via activation of this neuron system (Fuxe and Hokfelt, 1969). This system is also highly sensitive to prolactin, which markediy increases the turnover of dopamine in tubero-infundibular neurons (Fuxe and Hokfelt, 1969).

d) Cortical Dopamine Neurons - In addition to the well defined tracts described above, large quantities of dopamine have also been found in the cortex of varlous species (Bertler and Rosengren, 1959). It appears that most of the dopamine found in the cortex of the rat is not localized In noradrenergic terminals. Lesions of the dorsal noradrenergic system or combined lesions of the dorsal and 
ventral noradrenergic systems, which both significantly decrease cortical levels of norepinephrine, did not induce a parallel reduction of cortical dopamine content (Thierry et al., 1973b). These fingings strongly suggest the existence of dopaminergic neurons in the cortex. Further evidence for the existence of dopaminergic terminals In the rat cortex is provided by the fact that cortical synaptosomes have the ability to synthesize ${ }^{3} \mathrm{H}-\mathrm{dopamine}$ from ${ }^{3}$ B tyrosine (Thierry et a1., 1973a). The destruction of ascending noradrenergic pathways which abolishes the In vitro synthes ${ }_{1}$ s of ${ }^{3}$ H-norepinephrine did not affect the synthesis of $3 \mathrm{H}$-dopamine (Thierry et al., 1973a). In addition, a specific dopamine reuptake process has been demonstrated in the cerebral cortex of normal rats and in rats whose ascending noradrenergic pathways have been selectively destroyed (Tassin et a1., 1974). The dopamine cells in the cortex have recently been visualized by histofluorescence techniques (Hokfelt et al., 1974). The dopamine was shown to be distributed throughout the limbic cortex, but was not present in the neocortex (Hokfelt et a1., 1974). Part of the dopamine terminals in the cortex originate in the $A 9$ and $A 10$ areas of the substantia nigra (LIndvall and Bjorklund, 1974). A dopamine-sensitive adenylate cyclase has also been found in the cortex (Von Hun-. gen and Roberts, 1273). 
2) Dopamine Release and Turnover, in the CNS

Uolng a push-pull cannula, Mclennan (1964) demonstrated the resting release of dopamine from the caudate nucleus, which was estimated to occur at the rate of $1 \mathrm{ng} / \mathrm{m} 1 \mathrm{n}$. Electrical stimulation of the substantia nigra produced an Increase in dopamine output in the putamen (McLennan, 1965) and an increase in dopamine and its metabolite, homovanilIIc acid (HVA) in the lateral ventricle of the cat (Portig and Vogt, 1969). A frequency and intensity related release of labelled dopamine from the caudate nucleus was also demonstrated after stimulation of the nigro-striatal bundle or the caudate (Von Volghtlander and Moore, 1971a; 1971b). Similar results were shown when caudate dopamine stores were specifically labelled by radioactive tyrosine Chiueh and Moore, 1973). Electrode placements more medial or lateral in the hypothalamus falled to induce dopamine release (Chiueh and Moore, 1973). These results clearly implicate dopamine as the neurotransmitter in the nigrostriatal pathway.

The release of dopamine can be further enhanced by potassium or by drugs such as amphetamine (Besson et al., 1971). The amphetamine induced release is prevented by lesions of the nigro-striatal bundle (Von Volghtlander and Moore, 1973a).

Lesioning of the nigro-striatal bundle produces a gradual degeneration of dopamine terminals and a marked reduction of dopamine levels in the striatum (Poirer and 
Sourkes, 1965; Moore et al., 1971; 01tsman and Harvey, 1972). However, inhibition of the firing of the nigrostriatal bundle by lestons or administration of gammahydroxybutyrate causes an Immediate increase in the levels of caudate dopamine (Walters et a1., 1973).

The effect of drugs on the release and utilization of brain dopamine is usually indirectly determined after assessIng the drug's effect on dopamine turnover. The turnover of dopamine refers to the overall rate at which the dopamine stores are replaced in a given tissue. The turnover of rat brain dopamine has been estimated to occur at the rate of $0.21 \mathrm{ug} / \mathrm{g} / \mathrm{hr}$, with a turnover time of 3.6 hours (Neff and Costa, 1966). The turnover rate can be Influenced by a variety of physlological situations and can also be affected by drugs (see section B.4). The overall rate of catecholamine formation is governed by the activity of tyrosine hydroxylase (Levitt et al., 1965), the first enzyme in the synthetic pathway. The synthesis of new dopamine is regulated by a complex process involving end-product inhibition (Udenfriend et a1., 1959); activity of post-synaptic receptors (Carlsson and Lindquist, 1963); activity of pre-synaptic autoreceptors (Roth et a1., 1975); and brain tyrosine concentrations (Wurtman et al., 1974). Drugs may interact at any point, but drug effects are generally considered to occur by Increasing or decreasing dopamine receptor stimulation. In general, a drug which Increases dopamine receptor activity would decrease dopa- 
mine turnover, while a drug that decreases dopamine receptor activity would Increase dopamine turnover.

3) Behavioral Effects of Dopamine

Activity of dopaminergic neurons in the cNS is responstble for the regulation of numerous behaviors. These include motor effects (catalepsy, Parkinsonism, locomotor actIvity); reward mechanisms (self-administration, self-stimulation); consummatory behaviors; and bizarre behaviors (stereotypy, aggression, schizophrenia). These effects will be briefly described.

a) Motor Functions - The degeneration of the nigro-striatal pathway causes the motor dysfunctions associated with Parkinson's Disease (Hornykiewlcz, 1966). This degeneration leads to akinesia, rigidity and tremors in human patients. It is possible to restore normal motor function in Parkinsonian patients by treatment with L-DOPA (Cotzias et al., 1967) which markedly elevates the level of brain dopamine (Everett and Borcherding, 1971). In animals, the deficiency of striatal dopamine leads to an immobility termed catalepsy. This can be accomplished by large lestons of the mesencephalic-diencephalic areas of the brain which disrupt dopamine activity in the neostriatum (Anden et al., 1966e). or by the administration of neuroleptic drugs either systemically (Janssen et a1., 1965) or directly Into the caudate-putamen or globus pallidus Costall et a1., 1972). 
Dnilateral lesions of the nigro-striatal pathway or the corpus striatum are known to produce asymmetries in movement and posture (Potrer and Sourkes, 1965; Anden et a1., 1966b). The difference between the two sides of the brain may be further aggravated by treatment with drugs that release dopamine from the non-lestoned side. Such animals show a pronounced rotational behavior (Anden et a1., 1966b). The rotational behavior is further 1inked to the differences in dopamine levels on the two sides of the brain by the finding that unilateral striatal injections of dopamine causes the rats to turn or slowly rotate away from the side where dopamine was injected (Ungerstedt, et a1., 1969). Spontaneous rotations towards the intact side are seen 24 to 34 hours after a lesion of the nigro-striatal dopamine system. The direction of the rotation as well as the time point of its occurence is indicative of a degeneration release of dopamine from the lesioned side (Ungerstedt, 1971a). In a chronically lesioned animal, there is a striking difference between the effects of dopamine-releasing drugs and dopamine receptorstimulating drugs. Amphetamine causes the animal to rotate towards the lesioned side, apomorphine causes it to rotate towards the intact side (Ungerstedt, 1971a).

Intrastriatal injections of dopamine produce motor hyperactivity in rats (Benkert and Kohler, 1972). Sim1larly, large doses of L-DORA combined with a peripheral aromatic acid decarboxylase inhibttor produce an increase 
In spontaneous locomotor activity which is associated with a seven-fold Increase in brafn dopamine levels, while norepinephrine remains unchanged (Butcher et a1., 1972).

In addition, the locomotor stimulation produced by amphetamine is believed to be due to release of dopamine CVan Rossum and Hurkmans, 1964; Thornburg and Moore, 1973a; Hollfster et al., 1974). Depletion of brain norepinephrine by inhibition of dopamine-beta-hydroxylase (Thornburg and Moore, 1973a) or treatment with 6-hydroxydopamine (Hollister et a1., 1974) falled to alter the amphetamine-induced stimulation, while selective dopamine depletion did reduce the amphetamine effect.

b) Reward Mechanisms - Reward systems are usually thought of as being noradrenergic (Stein, 1968), but recent evidence has suggested a major role for dopamine as well. In add1tion to the traditional sites of electrode placement, self-stimulation behavior may also be maintained from electrodes placed in the substantia nigra (Arbuthnott et a1., 1970) or the nucleus accumbens (Ph1llips et al., 1975), both of which are Important dopaminergic sites. Self-stimulation from the lateral hypothalamus is blocked by the dopamine receptor blockers, haloperidol and pimozide (Wauquier and Niemegeers, 1972; Lippa et a1., 1973), but not by phentolamine, a noradrenergic receptor blocker, or by the inhtbition of norepinephrine synthesis with FLA-63 (utppa et al., 1973). Furthermore, depletion of dopamine 
by 6-hydroxydopamine depressed brain self-stimulation, while simflar treatments which deplete norepinephrine were Ineffective (Cooper et al., 1974). The action of amphetamine in enhancing self-stimulation was similarly affected by 6-hydroxydopamine treatment (Cooper et al., 1974). Lastly, It was shown that $d-$ and 1 - amphetamine were equipotent in enhancing self-stimulation from dopaminergic sites while d-amphetamine was more potent in noradrenergic sttes (PhI111ps and PIbIger, 1973; Ph1111ps et al., 1975). These differences in potencies closely parallelled the $\underline{\text { in }}$ vitro effect of amphetamine in releasing norepinephrine or dopamine (Azzaro and Rutledge, 1973).

In addition, the self-administration of amphetamine is apparently dependent on dopaminergic mechanisms since low doses of dopamine receptor blockers selectively increase lever pressing for amphetamine (analagous to the effect seen after decreasing the dose of amphetamine in the self-administered solution), while higher doses produce extinction (Yokel and Wise, 1975). Lastly, apomorphine, a direct. dopamine agonist, is also self-administered by rats (Baxter et a1., 1974).

c) Consummatory Behavior - Aphagia and adipsia result from the destruction of dopamine fibers coursing through the lateral hypothalamus by electrolytic lesions or 6-hydroxydopamine treatment (Ungerstedt, 1971b). This behavior is correlated with biochemical and histochemical evidence of 
decreased dopaminergic input to the striatum (Ungerstedt, 1971b; Zigmond and Strtcker, 1972; G1Ick et a1., 1974; Hynes et a1., 1975). Stmilar destruction of noradrenergic fibers falled to produce these defictts in eating and drinking (Ungerstedt, 1971b).

d) BIzarre Behaviors - Injections of drugs which Increase brain dopaminergic activity, such as apomorphine, DOPA or amphetamine, result in a compulsive gnawing behavior (Harnack, 1874; Randrup and Udsen, 1963; Ernst, 1965) termed stereotypy. This behavior consists of repetitive sniffing, Ilcking and chewing of the cage. This behavior is a1so noted after direct infection of apomorphine into the striatum (Smelik and Ernst, 1966) or the olfactory tubercles (McKenzie, 1972).

Various dopaminergic structures have been reported to be the site responsible for stereotypy on the basis of studies Involving lestons and local injections. These Include the striatum (Sme11k and Ernst, 1966; Fog et a1., 1970; Ungerstedt et a1., 1969); the olfactory tubercles (McKenzle, 1972); and varlous other portions of the mesolimbic dopamine system (Costall and Naylor, 1973).

It is interesting to note that recent theories concerning the etiology of schizophrenla have suggested that It is the result of dopaminergic hyperactivity in the striatum (Klawans et al., 1972a); the IImblc system (Matthysse, 1973); or the cortex (Hokfelt et al., 1974). 
The blockade of stereotypy has been used as a screening procedure for detecting anti-psychotic actiytty of drugs (Janssen et a1., 1965).

The hypothesis put forward in this thesis is that drugInduced aggression is also the result of dopaminergic hyperactivity. Apomorphine and amphetamine generally produce aggression in rats and mice, respectively (see section II. A.2). Apomorphine is believed to directly stimulate dopamine receptors (Anden et al., 1967), while amphetamine releases dopamine (Besson et al., 1971). ET-495, another

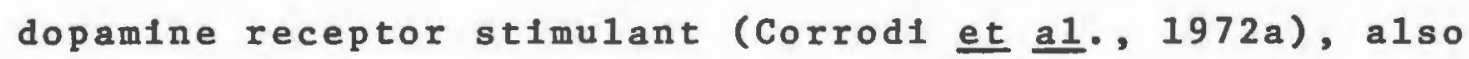
produces aggression in rats (Senault, 1974). Similarly, DOPA administration results in a substantial increase in brain dopamine and elicits fighting, while similar treatments which ralse norepinephrine are ineffective in producing fighting (Benkert et al., 1973a). A more detalled discussion of the relevant data is found in section $\nabla$.

4) Effects of Drugs on Dopamine Levels and Turnover

This research is primarily concerned with the actions of apomorphine, haloperidol and morphine. All of these drugs have profound effects on brain dopamine, which are important in the determination of their mechanisms of action. These effects will be examined in this section a) Apomorphine - Apomorphine is believed to directiy stimulate dopamine receptors. This conclusion is based on be- 
havioral experiments in whtch apomorphine-induced stereotypy was unaffected by depletion of dopamine by alphamethyl-p-tyrosine (MPT) (Ernst, 1967) or by 6-hydroxydopamine lesions of the substantia nigra (Price and Fibiger, 1974). These treatments abolished the stereotypy produced by amphetamine (Ernst, 1967; Price and FIbiger, 1974), which is believed to release dopamine from pre-synaptic terminals (Besson et al., 1971; Chlueh and Moore, 1973). Neurochemically, apomorphine decreases the turnover of striatal dopamine. The drug decreases the incorporation of c14 tyrosine into $\mathrm{c}^{14}$ dopamine (Persson, 1970; Nyback etal., 1970), decreases the disappearance of dopamine after MPT administration (Anden et al., 1967; Puri et a1.; 1973), decreases the rate of formation of homovanillic acid (Roos, 1969) and decreases the accumulation of DOPA after decarboxylase inhibition by NSD 1025 (Koe, 1974). These biochemical changes are blocked by prior administration of neuroleptics (Anden et a1., 1967; Anden and Bedard, 1971; Lahti et a1., 1972). Recent1y, apomorphine was also shown to decrease the turnover of dopamine in cortical areas (Scatton et a1., 1975).

In experiments where histofluorescence was measured, apomorphine retarded the reduction in dopamine fluorescence which normal1y occurs after MPT (Anden et al., 1967). Small doses of apomorphine also depress the firing rate of dopamine cells (Bunney et a1., 1973a), presumably by a feedback mechanism. These effects are 1ikewise blocked 
by haloperidol while the effects on firing rate are unaffected Бy MPT.

These results have been Interpreted as due to a decrease in activity of dopamine neurons as a compensatory mechanismsfor receptor stimulation by the apomorphine CAnden et a1., 1967; Lahtt et a1., 1972; Puri et a1., 1973). Although apomorphine can inhibit tyrosine hydroxylase (Goldstein et al., 1970), the doses required In vitro are substantially higher than necessary to produce functional changes.

b) Haloperidol - Haloperidol, and related anti-psychotic drugs, are belleved to block dopamine receptors. The behavioral consequences of this effect are the induction of catalepsy, ptosis and inhibition of operant avoldance and brain self-stimulation (Fielding and Lal, 1974).

Neurochemically, haloperidol increases the turnover of dopamine in the striatum (Anden et a1., 1970a), the meso-1imbic areas (Anden et a1., 1970a) and the cortex (Scatton et al., 1975). This is accomplished without a1tering the levels of dopamine in the brain (Anden et al., 1966a). There is also no change in brain dopamine levels after chronic haloperidol treatment (Gyorgy et a1., 1969; Puri and Lal, 1974a; Hyttel, 1974). Tolerance to the dopamine turnover enhancing effect of haloperidol has been reported after chronic treatment (Asper et a1., 1973), but Purt and Lal (1974a) falled to observe this phenomenon, although they did find that morphine dependent rats 
were tolerant to the effects of haloperidol. Haloperidol increases the synthesis of labelled dopamine from radioactive tyrosine (Nyback et al., 1970), Increases the depletion of brain dopamine after the administration of MPT (Neff and Costa, 1966; Corrod1 et a1., 1967), Increases the rate of accumulation of the dopamine metabolttes, homovanillic acid and 3,4-dihydroxyphenylacetic acid (Anden et a1., 1966a; Roos, 1965) and 3-methoxytyramine and normetanephrine (after MAO blockade) (Carlsson and Lindquist, 1963) and increases the accumulation of DOPA after NSD 1025 (Cegrell et a1., 1970). The haloperidol induced increase in dopamine depletion following MPT requires intact nigro-striatal fibers for the effect to occur (Anden et al., 1971). In addttion, haloperidol reduces the stimulation of adenyl cyclase caused by dopamine (Clement-Cormier et al., 1974) and increases the firing rate of dopamine cells (Bunney et al., 1973b). The Interpretation of these results has been that haloperidol blocks dopamine receptors and this causes a compensatory activation of dopamine neurons to increase the concentration of dopamine in the synaptic cleft (Carlsson and Lindquist, 1963). However, haloperidol falled to alter the In vivo efflux of labelled dopamine Into the ventricle of the cat Con Voightlander and Moore, 1973b). It has also been proposed that halopertdol may block the pre-synaptic coupling between 
nerve impulses and transmitter release (Seeman and Lee, 1975). Recent evidence suggests that the increased firing of the dopamine neuron produced by the neuroleptics enhances the affinity of tyrosine hydroxylase for its pteridine cofactor (Zivkovic et al., 1974).

c) Morphine - Morphine is aiso believed to decrease the effect of dopamine in the CNS. Morphine does not alter the steady state level of dopamine in the rat (Gunne et a1., 1969; Purt et a1., 1973) or cat (Moore et a1., 1965), although a transient increase in dopamine levels occuring at two and four hours after drug administration has been reported in the rat (Clouet and Ratner, 1970). Morphine causes a decrease in dopamine levels in the mouse (Takagi and Nakama, 1966; Rethy et a1., 1971) and an Increase in levels in the monkey (Segal et al., 1972).

The exact relationship between dopamine and narcotic drugs may not be defined by the measurements of dopamine content of nervous tissue since these reflect only gross changes and may not reveal local changes or alterations In the turnover of dopamine.

Morphine increases the conversion of $\mathrm{c}^{14}$ tyrosine to labelled dopamine in the rat (C1ouet and Ratner, 1970; Costa et al., 1973). The $\mathrm{c}^{14}$ dopamine reachès maximum concentrations in the striatum one hour after morphine administration (Clouet and Ratner, 1970). Morphine also increases the turnover of dopamine in the mouse (Smith 
et a1., 1970; Loh et al., 1973), an effect which is blocked Ej the narcotic antagonist naloxone (Smith et al., 1972). Morphine also causes an Increase in the depletion of dopamine in the rat brain after inhibition of catecholamine synthesis by MPT (Gunne et a1., 1969; Puri et a1., 1973). This depletion was determined by histofluorescence to occur In the dopamine terminals of the striatum, the nucleus accumbens and the olfactory tubercles (Gunne et al., 1969). In addition, morphine increases the concentration of the dopamine metabolites, homovanillic acid and 3,4-dihydroxyphenylacetic acid (Kuschinsky and Hornykiewicz, 1972; Fuku1 and Takag1, 1972; Kuschinsky, 1973). Thts effect is also blocked by naloxone, while the corresponding increase in homovanillic acidproduced by chlorpromazine is unaffected by naloxone (Kuschinsky and Hornykiewicz, 1972). Lastly, morphine increases cyclic AMP formation by a dopamine sensitive adenylate cyclase (Pur1 et al., 1975).

The mechanism by whtch morphine enhances dopamine turnover is not well established. Morphine does not alter either in vitro (C1ouet et a1., 1973) or in vivo (Cicero et al., 1973) tyrosine hydroxylase, nor does it alter the affinity of tyrosine hydroxylase for its cofactor, substrate or end product ( $C_{1}$ cero et al., 1973). Purt and coworkers (1973) proposed that morphine blocks dopamine receptors and the increased turnover reflects a compensatory increase In neuronal activity analagous to the effect of neuroleptics. Consistent with this hypothesis is the 
observation that the increased synthesis of new dopamine produced by: morphine is assoclated with an increased release of dopamine into an incubation medium from striatal slices (Gauchy et a1., 1973). Methadone has also been proposed to act via post synaptic dopamine receptor blockade (Sasame et a1., 1972). Alternatively, it has been suggested that morphine produces a functional deficiency of dopamine by diverting newly synthesized dopamine from storage sites to sites of catabolism (Kuschinsky and Hornykiewlcz,1972). After chronic treatment with morphine, there is a slight increase in the dopamine content of the brain in rats (S1oan et a1., 1963; Johnson et a1., 1974), but dopamine levels remain unchanged after prolonged treatment in dogs (Gunne, 1963) or monkeys (Segal et al., 1972). Although most researchers report that a tolerance develops to the effect of morphine on brain dopamine turnover Cunne et al., 1969 ; Smith et a1., 1972 ; Costa et a1., 1973; Puri and Lal, 1974a), 1t has also been reported that morphine continues to increase the synthesis of dopamine after chronic treatment (Johnson et a1., 1974). This effect may be associated with the increase in tyrosine hydroxylase activity which reportedly occurs during chronic morphine treatment (Reis et a1., 1970). However, decreased tyrosine hydroxylase activity has also been reported in rats implanted with morphine pellets (Branchey et a1., 1974). 
During morphine withdrawal, brain dopamine was decreased in dogs, 72 hours after withdrawal was initiated (Gunne, 1963). In rats, brain dopamine levels appear to remain unchanged during withdrawal (Maynert and Rlingman, 1962; Puri and Lal, 1974a), although a decrease in levels, relative to inflated levels during addiction, has been reported (Sloan et al., 1963). In contrast to these results, which were obtained in animals which were withdrawn by withholding of morphine injections, abstinence precipitated by naloxone administration reportedly increases the level of brain dopamine in rats and mice (Iwamoto et al., 1973). The turnover of brain dopamine also appears to remain unchanged during morphine withdrawal (Puti and Lal, 1974a) although decreased dopamine turnover has also been reported in rats (Gunne et al., 1969) and mice (Rosenman and Smith, 1972). In addition, caudate tyrosine hydroxylase activity 18 reportedly elevated at 48 hours of withdrawal in rats (Reis et al., 1970) and decreased at 36 hours of withdrawal in mice (Marshall and Smith, 1974).

\section{DOPAMINE INTERACTIONS IN THE CNS}

The effects of dopamine in the CNS are modulated by activity of other brain neurotransmitters. The complexity of the brain demancs that activity in one area will have consequences in another area, so that it is foolhardy to Investigate the actions of one transmitter as if it existed 
Independently. These delicate equilibria are important aspects of the normal functioning of the brain and drug interference with the normal balance of transmitter function may be an essential component of the drug's action. The most widely studied of dopamine's interactions are with acetylcholine and serotonin.

\section{1) Acetylcholine}

The concept of an interaction between dopamine (DA) and acetylcholine ( $\mathrm{ACh}$ ) developed from the clinical observations that Parkinsonism could be relieved either by increasing dopamine activity or by decreasing cholinergic activity (Klawans, 1968). Subsequently, considerable behavioral and neurochemical evidence has been gathered to support the idea of a reciprocal balance between $\mathrm{ACh}$ and DA.

Catalepsy, which is-produced by drugs which decrease dopaminergic activity in the brain, is also produced by cholinergic drugs (Costall et al., 1972), while the neuroleptic-induced catalepsy is reversed by anticholinergics (Morpurgo and Theobald, 1964). Similarly, the ant1cholinergics enhance, while cholinergics block, the stereotypy produced by dopamine receptor stimulation (Arnfred and Randrup, 1968; Schee1-Kruger, 1970; Klawans et a1., 1972b). In addition, anticholinergic drugs are reported to reverse the neuroleptic-induced blockade of methylphen1date stereotypy (Fjalland and Moller-Nielsen, 1974a). 
Likewise, the amphetamine-induced locomotor stimulation is enhanced by scopolamine (Fibiger et a1., 1970) and inhibited by tremorine (Mennear, 1965)., while the locomotor stimulation produced by anticholinergics is blocked by reducing the synthesis of dopamine (Thornburg and Moore, $1973 \mathrm{~b})$.

Neurochemicaliy, dopaminergic stimulation appears to reduce the release of $\mathrm{ACh}$ while cholinergic stimulation appears to increase the turnover of DA. Some of the experiments which have demonstrated these effects are summarized here. Dopamine released via stimulation of the nigro-striatal bundle blocks the release of $\mathrm{ACh}$ (Stadler et al., 1974). Similarly, apomorphine, amphetamine or L-DOPA increases the level of $A C h$ in the striatum (Sethy and Van Woert, 1974). The Increase in ACh levels produced by apomorphine (Guyenet et al., 1975) or ET-495 (Ladinsky et a1., is blocked by neuroleptics but is not blocked by alphamethy 1-p-tyrosine (Ladinsky et al., 1974) or lesions of the nigro-striatal bundle (Guyenet et al., 1975), suggesting that the effect is mediated via dopaminergic receptor stimulation. Similarly, neuroleptic drugs increase the release of $\mathrm{ACh}$ with a resultant decrease in levels in tbe

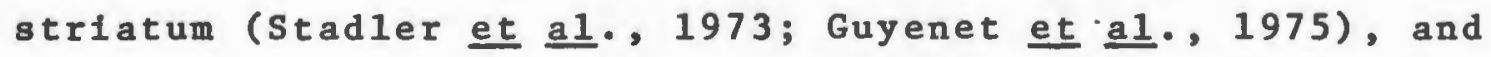
Increase ACh turnover (Trabucchl et a1., 1974). Promethazine, a phenothiazine related to chlorpromazine which has little or no DA receptor blocking activity, does not alter ACh levels (Stadler et al., 1973). This effect is noted in 
the striatum, but not in other dopaminergic areas (Lloyd et a1., 1973), nor is it noted in the hippocampus, which receives a rich cholinergic input but does not contain dopamine terminals (Rommelspacher and Kuhar, 1975). These results are poorly correlated with the direct anticholinergic activity of the neuroleptics. (Rommelspacher and Kuhar, 1975) again suggesting that the effect is mediated by dopamine. These results have been interpreted to mean that striatal ACh is under an inhibitory influence of DA. However, lesions of the nigro-striatal pathway did not affect striatal ACh levels (Butcher and Butcher, 1974; Guyenet et a1., 1975). In an analagous manner, cholinergic drugs increase striatal dopamine turnover (Corrodi et a1., 1967a) and the rate of formation of homovanillic acid (HVA) (Ahtee and Kaariainen, 1974). Similarly, anticholinergics reduce the turnover of striatal dopamine (Bowers and Roth, 1972; Corrodi et a1., 1972a) and reduce the concentration of HVA (0'Keefe et al., 1970). However, intraventricular infusion of atropine increases striatal HVA (Bartholini and Pletscher, 1971).

of considerable interest is the additional interaction between $\mathrm{ACh}$ and $\mathrm{DA}$ in which anticholinergics have been reported to inhibit the increase in DA turnover produced by the neuroleptics (o'Keefe et al., 1970; Anden, 1972; Bowers and Roth, 1972). It appears that this effect is $11 \mathrm{mited}$ to the neuroleptic induced increase in striatal dopamine turnover, since the increase in turnover in limbic areas is un- 
affected by anticholinergics (Anden and Bedard, 1971; Anden, 1972).

\section{2) Serotonin}

Behavioral evidence supporting an interaction between serotonin and DA has grown in recent years, although the evidence is not as strong as in the case of ACh (previous section). In general, increasing serotonergic activity opposes the effect of dopaminergic stimulation.

Lycke and coworkers (1969) found that depressing the level of serotonin by parachlorophenylalanine (PCPA), an inhibitor of serotonin synthesis (Koe and Weissman, 1966), increased the excitation produced by DOPA and resulted in aggression in their mice. Similarly, PCPA enhances the stimulation produced by amphetamine (Mabry and Campbell, 1973), while blocking serotonin receptors enhanced the stimulation produced by apomorphine (Grabowska and Michaluk, 1974). Breese and coworkers (1974) further investigated this relationship and observed thatpargyline reduced the stimulant effect of amphetamine and that this was correlated with an increase in serotonin levels. PCPA reversed the inhibition. Similarly, destruction of serotonin neurons with 5,6-dihydroxytryptamine likewise potentiated the amphetamine response. PCPA was unable to alter the inhibition of amphetamine-induced stimulation produced by 6-hydroxydopamine (Breese et a1., 1974), suggesting that the serotonin effect is indirect. 
Further evidence for an interaction between DA and serotonin has been provided by studies which measured stereotypy produced after DA agonists, but these results have been contradictory. Decreasing serotonergic activity has been reported to increase the stereotypy produced by either amphetamine or apomorphine (Weiner et a1., 1973; 1975). However, it has also been reported that decreasing serotonergic stimulation has no effect (Breese et al., 1974) and even decreases the stereotypy (Costall and Naylor, 1975) Induced by these DA agonists.

It has also been reported that the catalepsy induced by neuroleptics is antagonized by PCPA or by.the destruction of raphe neurons (Kostowsk1 et a1., 1972), lending further support to an interaction.

The evidence thus suggests that activation of dopaminergic neurons leads to a compensatory increase in the activity of serotonergic neurons which results in a reduction of the effect of the initial dopamine stimulation (Grabowska and Michaluk, 1974; Cools, 1974). 


\section{DOPAMINERGIC SUPERSENSITIVITY}

Supersensitivity refers to the phenomenon in which the amount of a substance required to produce a given biological response is less than normal. This implies a shift in the dose response curve for an agonist to lower agonist concentrations. Such a shift in the dose response curve is considered the major criterion for supersensitivity (Trendelenburg, 1966). Evidence for the concept of supersensitivity was provided by experiments in the peripheral nervous system. In early experiments, it was shown that spinal motor neurons became more reactive to a variety of stimuli following transection of the spinal cord or destruction of sensory. nerve fibers (Cannon and Rosenblueth, 1949). Supersensitivity in the periphery is considered to be of two types. In the first type, termed denervation supersensitivity, physical removal of the pre-junctionsl nerve terminals leads to an enhanced effect of the neurotransmitter due to loss of the re-uptake function of the nerve terminal (Langer and Trendelenburg, 1966). In decentralization supersensitivity, the neurotransmitter fails to reach the target organ and leads to an actual increase in the sensitivity of the receptor (Langer et a1., 1967). This type of supersensitivity was demonstrated by the enhanced response of the cat nictitating membrane to norepinephrine following removal of the afferent nerves to the superior cervical ganglion (Langer et a1., 1967). The time course of each type of supersensi- 
tivtey te different, with denervation supersensitivity requiting a shorter period of time to develop. The actual mollecular mechanism by which supersensitivity occurs is momawr, but several suggestions have been made. There could tre a change in the post-junctional element so that it ecturIIy becomes more sensitive to the transmitter (Thesleff, $I \mathscr{G Q})$ : the mechanism inactivating the transmitter could change sa that it is removed from its site of action more stowly (Trendelenburg, 1963); or pre-junctional elements could trecease their capacity to deliver transmitter or change their recovery process to repetitive stimilation (Sharplese and Jaffe, 1969). Many of these changes have been demonatrated in disused or denervated peripheral structures.

In the central nervous system, the term supersensitivity is ladgely applied to any procedure which results in an exaggerated response to an agonist. This has been studied, tn dapaminergic brain areas, after elther the destruction of treurons which supposedly synapse with dopamine receptors or after the administration of drugs which decrease the aval1ability of dopamine for its receptors. In both cases, an erhanced response to stimulation by dopamine and related eganists is presumed to occur as a compensatory adaptation to the lack of ytimulation as a result of the effect of the lestar ar the drug. It should be noted that supersensitivity has been used to explain the development of toler- 
ance to and physical dependence on drugs (e. g. Jaffe and Sharpless, 1968; Collier, 1966; Sharpless and Jaffe, 1969; Puri and La1, 1973a), since withdrawal phenomena seem to represent rebound effects which are opposite in character to those produced by the drug itself. The characteristics of the two methods of producing supersensitivity in the CNS are described below.

\section{1) Lesion Induced Supersensitivity}

Intracerebral injections of 6-hydroxydopamine produce a degeneration of catecholamine containing nerve terminals In the CNS (Breese and Traylor, 1970; Uretsky and Iversen, 1970). Following this treatment, rats exhibit a marked 1ncrease in locomotor activity in response to L-DOPA (Uretsky and Schoenfeld, 1971) or apomorphine (Schoenfeld and Uretsky, 1972) as well as enhanced apomorphine-induced stereotypy (Iversen and Creese, 1975) and ET-495 induced hypothermia (Reid, 1975). Similarly, destruction of the substantia nigra results in enhancement of apomorphineinduced stereotypy, while the stereotypy produced by amphetamine is blocked (Iversen and Creese, 1975).

Unilateral destruction of dopaminergic nigro-striatal fibers or terminals provides an interesting model for the study of dopaminerglc supersensitivity (Ungerstedt, 1971a; Von Voightlander and Moore, 1973c). After such lestons, animals circle away from the side of the lesion in response to apomorphine and towards the side of the lesion in response 
to amphetamine, presumably because apomorphine has more of an effect on the lesioned (supersensitive) side: An injection of 6-hydroxydopamine into the striatum, which induces this behavior, markedly decreases the concentration of dopamine but has little effect on norepinephrine or serotonin (Von Voightlander and Moore, 1973c). In addition, the dose response curve for eliciting the turning by apomorphine or L-DOPA gradually shifts to the left over the course of 30 days (Thornburg and Moore, 1975). Similar1y, the rate of apomorphine-induced circling is well correlated with the reduction of forebrain dopamine (Thornburg and Moore, 1975).

Following lesions of the substantia nigra, an enhancement of striatal dopamine-stimulated adenylate cyclase has been reported (Mishra et a1., 1974) which would provide neurochemical substantiation for the supersensitivity. Furthermore, caffeine and theophyl11ne enhanced the turning response to apomorphine in unilaterally lesioned rats, but falled to alter turning by themselves or that produced by amphetamine (Fuxe and Ungerstedt, 1974) which was Interpreted as due to a preferential effect of these compounds on cyclic AMP formed in the lesioned (supersensitive) side. However, it has äiso been reported that there is no difference in caudate dopamine-stimulated adenylate cyclase after destruction of pre-synaptic nerve terminals by 6-hydroxydopamine (Von Voightlander et al., 1973). Further 
evidence for denervation supersensitivity is provided by Fibiger and Grewal (1974) who found that in rats with unilateral substantia nigra lesions, the effect of apomorphine in Increasing striatal acetylcholine levels was greater on the lesioned side compared with the non-lesioned side, although the response to haloperidol was unaffected by the lesion. In addition, it is interesting to note that the dopamine cells which do not degenerate after 6-hydroxydopamine treatment have a higher rate of dopamine turnover than cells on the non-lesioned side (Agid et a1., 1973), which may represent another type of compensation for reduced dopamine stimulation on the lesioned side.

\section{2) Drug Induced Supersensitivity}

Changes in behavior during and after chronic administration of drugs has long been recognized. Boyd (1960) noted a tolerance to the depressant effect of chlorpromazine after 30 weeks of treatment without a cross tolerance to pentobarbita1. Furthermore, he noted an increase in 10comotor activity during "withdrawal" of the drug. Similarly, Moore (1968) reported a tolerance to the depressant effect of alpha-methyl-p-tyrosine (MPT) during chronic feeding of mice, despite the fact that catecholamine levels remained depressed. Similarly, daily treatment with reserpine led to enhanced locomotor activity when the drug was discontinued which was correlated with an increase in norepinephrine stimulated adenyl cyclase (Williams and Pirch, 1974). 
Subsequently, it was noted that exaggerated responses to dopamine agonist drugs could be ellcited following chronic treatment with drugs which would normally block their effect in nalve rats. The stereotypy produced by amphetamine, apomorphine or methylphenidate was augmented following the cessation of repeated treatment with neuroleptics in rats (Schelkunov, 1967; Tarsy and Baldessarini, 1973), m1ce (Fjalland and Moller-Nlelsen, 1974b) and guinea-pigs (Klawans and Rubovits, 1972). This effect was also noted following chronic MPT, but was not seen following chronic treatment with the non-neuroleptics, pentobarbital or diazepam (Tarsy and Baldessarini, 1973), which do not affect CNS dopamine. Interestingly, it has been reported that this effect also falls to develop following chronic treatment with the novel neuroleptic, clozapine (Sayers et a1., 1975), a drug which does not block apomorphine stereotypy in naive rats (Sti1le et a1., 1971).

Similarly, amphetamine stimulation of locomotor activity was enhanced following chronic MPT, but the stimulation produced by methylphenidate or pipradol, which is not blocked by MPT in nalve animals, was unaffected following chronic MPT (Dominic and Moore, 1969). Concomitant administration of L-DOPA along with MPT, which would bypass the Inhibition of catecholamine synthesis and prevents the depletion of dopamine produced by the MPT, blocked the development of supersensitivity. (Gudelsky et al., 1975). 
Recenty, it was shown that supersensitivity following chronic haloperidol could also be demonstrated neurophyslologically (Yarbrough, 1975), such that a larger proportion of caudate cells were inhibited by dopamine following chronic haloperidol treatment. However, there is apparenty no change in striatal dopamine-sensitive adenylate cyclase activity in mice chronically treated with neuroleptics, although behavioral evidence of supersensitivity was present (Von Volghtlander et a1., 1975).

Purl and Lal (1973a) proposed that a dopaminerglc supersensitivity also develops during chronic treatment with narcotics. This suggestion was based on experiments involving aggression during morphine withdrawal in which normally ineffective doses of apomorphine or amphetamine stimulated the aggression (Lal et al., 1971; Puri and La1, 1973a). Subsequently, it was also shown that the reduction in striatal dopamine turnover produced by apomorphine could be elicited with ordinarily ineffective doses in morphine withdrawn rats (Puri and La1, 1973b). 
III. EXPERIMENTAL

\section{A. Anima1s}

Male, hooded rats of the Long-Evans strain were obtalned from Charles River Breeding Farms, Wilmington, Massachusetts and were used in this study. The rats weighed 275-350 g at the start of experiments involving chronic drug treatment. Rats used for apomorphine-induced aggression weighed 375-475 g. The animals were housed: in a room with thermostatica11y controlled constant temperature $\left(70^{\circ} \mathrm{F}\right.$ or $21^{\circ} \mathrm{C} \pm 1^{\circ} \mathrm{C}$ ) and an alternating period ( 12 hours) of $11 \mathrm{ght}$ and dark ( 7 AM to 7 PM, 11ght). They were allowed free access to food and water at all times unless otherwise stated. Rats used for chronic morphine treatment were housed in individual cages; all others were housed in standard colony cages.

\section{B. Drugs}

Drugs used in this study were: apomorphine hydrochlorIde (Mallinckrodt Chemical Works), morphine sulfate (Merck \& Co.), halaperidol (Janssen Pharmaceutica and McNeil Laboratories), amphetamine sulfate (Smith, Kline \& French), p110carplne hydrochlortde (Mallinckrodt Chemical Works), dexetImIde (R16470) (Janssen Pharmaceut1ca), Isopropam1de (ZR79) (Janssen Pharmaceutica), naloxone hydrochloride (Endo Lab- 
-ratromiex), atropine sulfate (Mallinckrodt Chemical Works), Fentaberfital sodium (Abbott Laboratories), cyproheptadine (Lierck,. Sharpe. \& Dohme), clonidine hydrochloride (BoeringerIngeIfre-im) and alpha-methyl-p-tyrosine (MPT) methyl ester Hydrachloride (Aldrich Biochemicals). All drugs were freshIF preprared and administered by the intraperitoneal route, except in those experiments in which more than two drugs were used. In these, the first drug was administered subcutareously. All drugs were dissolved in distilled water except haloperidol and oxyperomide which were dissolved in 0.3\% tartaric acid and cyproheptadine which was solubilized with the ald of two drops of Tween 20. The doses and pretreatment times for the drugs are shown in Table 1.

\section{Chronic Drug Treatment}

\section{I) Eorphine Addiction}

Hatg were made dependent on morphine by infecting them with gystematically increasing doses of morphine sulfate three times a day. The starting dose of $15 \mathrm{mg} / \mathrm{kg} /$ infection (45 mg/kg/day) was increased by $15 \mathrm{mg} / \mathrm{kg} /$ injection daily for nine days until a maintenance dose of $135 \mathrm{mg} / \mathrm{kg} / \mathrm{infection}$ (405 mg/kg/day) was reached. The rats were maintained at this dose for at least five days. On the last morning, a final $\pm n f e c t i o n$ of $135 \mathrm{mg} / \mathrm{kg}$ was administered, after which ro further morphine was injected. This was considered zero time of withdrawal. This is the usual addiction schedule 
TABLE 1

DOSE RANGES AND PRE TREATMENT TIMES

FOR DRUGS USED

\begin{tabular}{|c|c|c|c|}
\hline Drug & $\begin{array}{l}\text { Dose Range } \\
\text { (mg/Kg) }\end{array}$ & Time & $\begin{array}{l}\text { Waited Before } \\
\text { (minutes) }\end{array}$ \\
\hline d-amphetamine & $0.1-16$ & & 60 \\
\hline 1-amphetamine & $2-32$ & & 60 \\
\hline apomorphine & $0.5-20$ & & 10 \\
\hline atropine & $2.5-10$ & & 30 \\
\hline clonidine & $0.06-0.50$ & & 30 \\
\hline cyproheptadine & $2-8$ & & 45 \\
\hline dexetimide & $0.32-20$ & & 40 \\
\hline haloperidol & $0.16-10$ & & 120 \\
\hline isopropamide & $2.5-5$ & & 30 \\
\hline morphine & $5-135$ & - & 40 \\
\hline MPT & $100-300$ & & 240 \\
\hline naloxone & $1-16$ & & 10 \\
\hline oxyperomide & $1.25-5$ & & 40 \\
\hline pentabarbital & $5-20$ & & 15 \\
\hline pilocarpine & $1.25-10$ & & 15 \\
\hline
\end{tabular}


utilized in this study. In early pilot experiments, other schedules were also employed. In these procedures, Injectlons were given every 12 hours and the terminal dose was $200 \mathrm{mg} / \mathrm{kg} / \mathrm{day}$. In the first schedule, a starting dose of $10 \mathrm{mg} / \mathrm{kg} / \mathrm{injection}$ was increased by $10 \mathrm{mg} / \mathrm{kg} / \mathrm{injection} \mathrm{each}$ day for 10 days. This is referred to as the short, low dose schedule. In the other, the starting dose of $5 \mathrm{mg} / \mathrm{kg} / \mathrm{Injec-}$ tion was increased by $5 \mathrm{mg} / \mathrm{kg} / 1 \mathrm{njection} \mathrm{dally}$ for 20 days. This is referred to as the long, 1ow dose schedule. These treatment schedules are 111 ustrated in Table 2 .

\section{2) Chronic Haloperidol}

Rats were infected with haloperidol twice dally beginning with a dose of $2.5 \mathrm{mg} / \mathrm{kg} / 1 \mathrm{nj} e c t i o n$. This dose was Increased by $2.5 \mathrm{mg} / \mathrm{kg} / 1 \mathrm{njection}$ every fifth day unt 11 the terminal dose of $10 \mathrm{mg} / \mathrm{kg} / \mathrm{injection}(20 \mathrm{mg} / \mathrm{kg} / \mathrm{day})$ was reached. This dose was malntalned for four days. On the following morning, a final injection of $10 \mathrm{mg} / \mathrm{kg}$ was administered after which no further haloperidol was injected and this was considered as zero time of withdrawal. This schedule is also 11lustrated in Table 2.

\section{Brain Lesions}

Under ether anaesthesia, bilateral electrolytic lesions were made with a monopolar, stalniess steel electrode with a $0.5 \mathrm{~mm}$ non-insulated tip. A current of either 2 mA for 30 seconds duration or $1 \mathrm{~mA}$ for 15 seconds duration gener- 
TABLE 2

SCHEDULES OF CHRONIC DRUG TREATMENTS

Doseage of $\mathrm{mg} / \mathrm{Kg} /$ injection (per day)

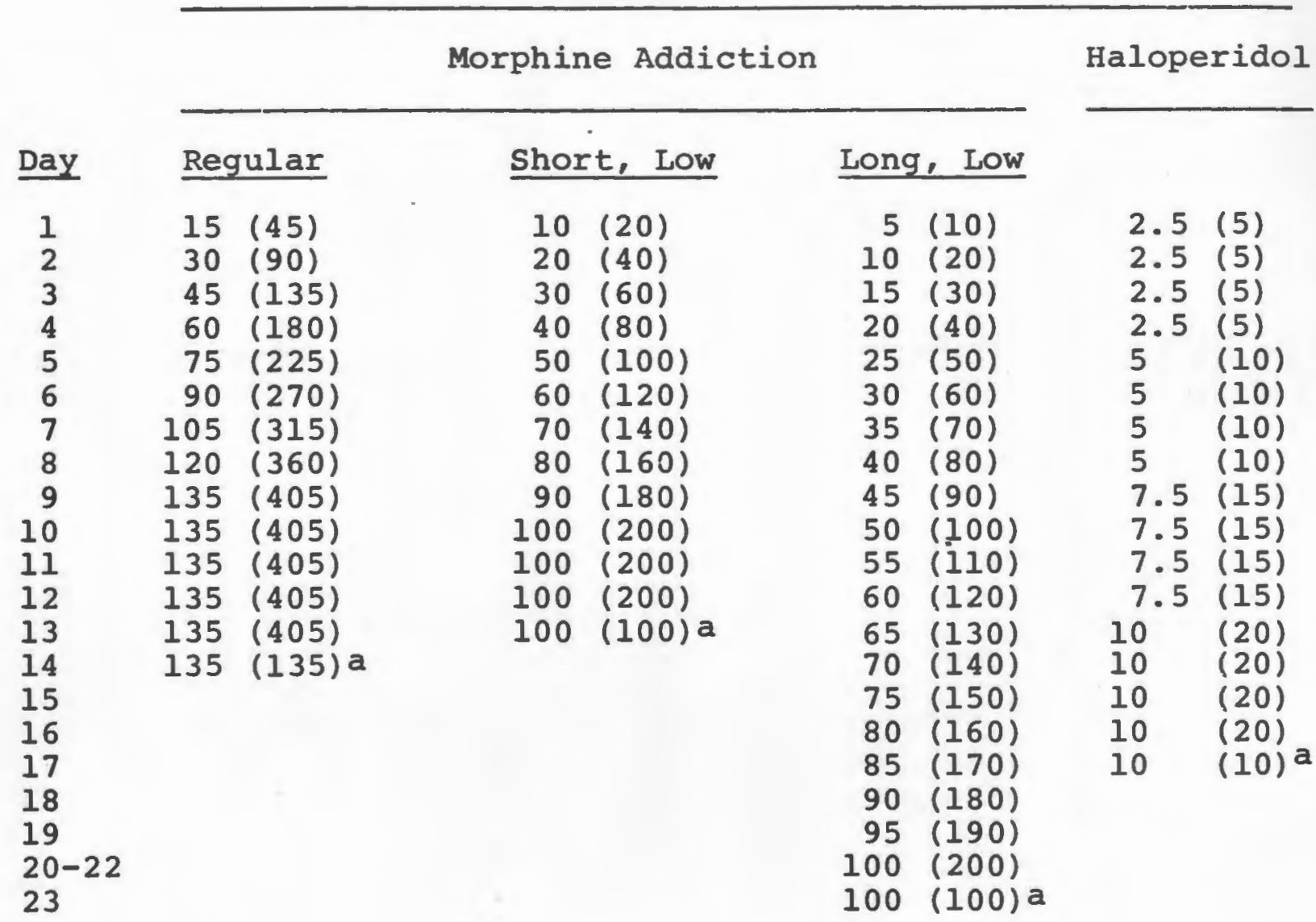

Doses Per Day 3

2

2

2

a Last injection of sequence (one morning injection). 
ated by a Lesion Producing Device (Stoelting Co. Model 58040) was passed through the electrode placed into the brain with a David Kopf Stereotaxic Instrument. With the dorsal cranium horizontal, the coordinates for the nigrostriatal bundle were $1.5 \mathrm{~mm}$ posterior to bregma, $2.0 \mathrm{~mm}$ lateral to the midline suture and $8.5 \mathrm{~mm}$ below the surface of the cranium. Lesions of the medial forebrain bundle were placed $2.0 \mathrm{~mm}$ posterior to bregma, $1.5 \mathrm{~mm} 1$ ateral to the midline suture and $8.0 \mathrm{~mm}$ below the surface of the cran1um.

\section{E. Measurement of W1thdrawa1 S1gns}

At selected times after discontinuation of drug treatment, rats were removed from their home cages and placed individualiy into a novel cage. Signs were measured for 30 minutes. The signs which were noted consisted of "wet shakes," defined as the violent shaking movement of the head or body which resembles movements made by an animal which has been drenched with water; writhing, defined as the dragging of the abdomen along the floor of the cage and drawing in of the abdominal wa11 (Buckett, 1964) unaccompanied by yawning; ptosis, defined as the drooping of the eyelids to form a slit-11ke appearance, unaccompanied by sleep; piloerection; diarrhea and teeth chattering. The frequency of "wet shakes" and writhing was noted during the observation session along with the duration of ptosis. The presence or absence of the other sfgne was noted as present or not present. 
In addition, the rat was weighed and his colonic temperature was measured onehour after receiving the final injection of morphine. The temperature was measured using a digital thermistor thermometer (Digitec Model 581C, UnIted Systems Corp.). The rectal probe was inserted $5 \mathrm{~cm}$ and maintained in place for one minute before recording the temperature. Immediately prior to the observation session, the rats were again weighed and their temperatures taken. These values were compared with the initial measurement in order to establish the magnitude of change in weight and temperature. The descriptions and measurements of these signs may be found in Gianutsos et al. (1975).

\section{F. Aggression}

Aggression was measured by placing similarly treated rats in groups of four into a chamber $(23 \mathrm{~cm} \times 20 \mathrm{~cm} \times 19$ cm) made of Plexiglas with a wire floor. The walls of the chamber were covered with a sound-absorbing rubber material, whth the front left uncovered to allow for observations.

The rats were observed for one hour during which time, three parameters of aggression were measured as described in Lal (1975). These were: attacks (including bites), rearing time and vocalizations. An attack was recorded each time one rat bit, violently shoved or leaped upon another animal. Rearing time consisted of the total elapsed time, In seconds, in which two or more rats assumed an aggressive posture in which they stood on their hind paws facing each 
other in close proximity with their mouths open and vocalizing or when one rat stood over another while vocalizing. These typical postures are 111 ustrated in Figures $1 \mathrm{~A}$ and 1B. Vocalizations were monitored via an audio detection relay (Scientific Prototype Model 761-G) which automatically sent a pulse to a counter when a vocalization was made. The relay was modified to detect sounds in the range of 2400-4800 Hz. A1l three parameters were recorded for six consecutive 10 minute intervals and were sumed to arrive at the figures for responses per hour. Each group of rats was treated statistically as one subject.

\section{G. Locomotor Activity}

At various time intervals after drug treatment (see Table 1), rats were placed individually in clear Plexiglas bins (42 cm X $27 \mathrm{~cm} \times 16 \mathrm{~cm})$ on top of a Selective Activity Meter (Columbus Industries, Model S) for the measurement of locomotor activity. Each meter was enclosed within a separate wooden cabinet equipped with a fan and a house light, both of which were constantly on during the activity measurements.

Bach time the rat crossed one of the six electromagm netic sensors on the meter, a count was recorded. The counts were accumulated in a print-counter (Data Pac, LVE/BRS Model No. 421-09) and printed out at 10 minute intervals. The counts for one hour (six consecutive 10 minute intervals) were summed and activity was expressed as counts 





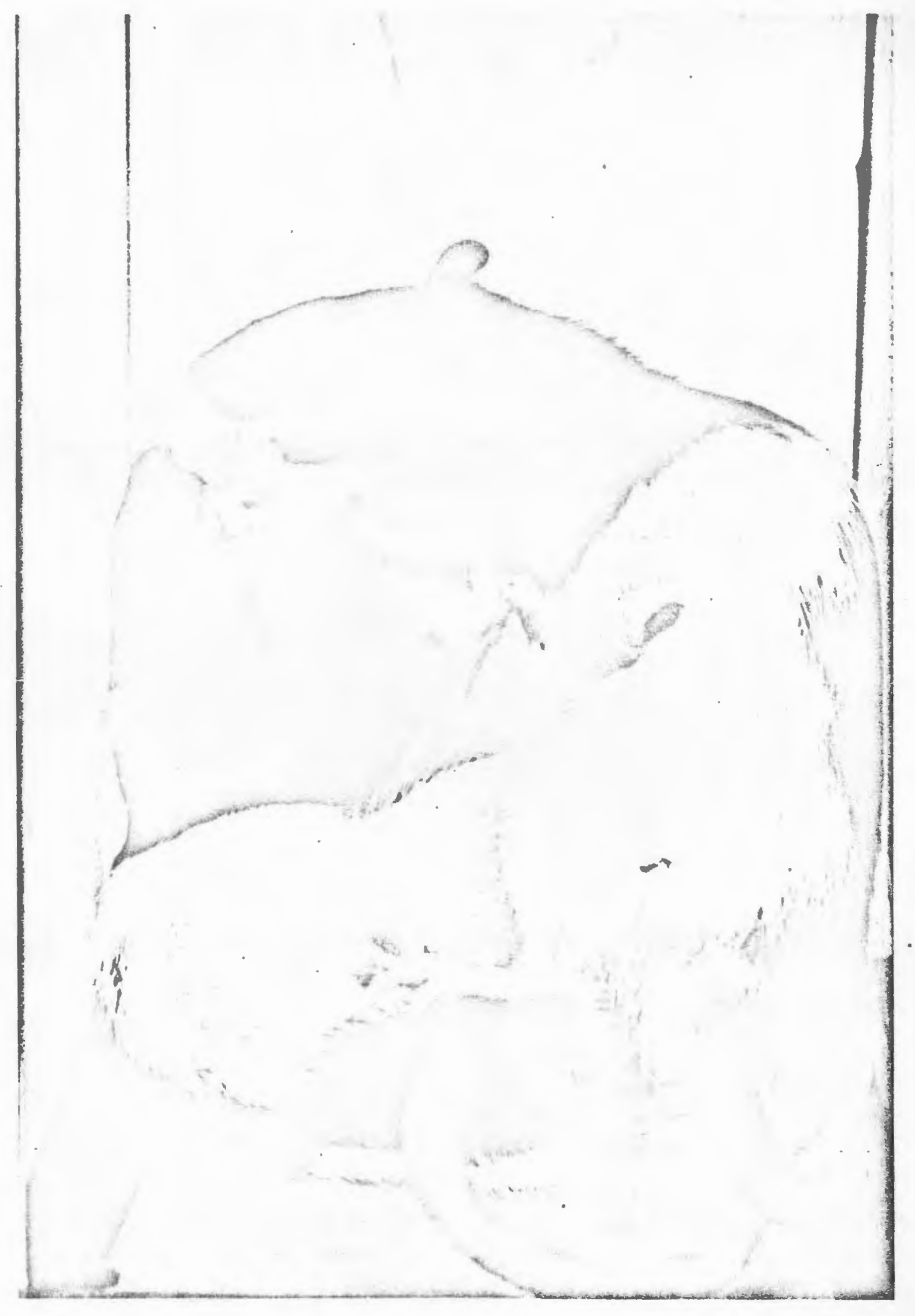


per hour. All activity measurements were made during the morning.

\section{H. Stereotypy}

Stereotypy was measured by placing rats into individual cages (24 cm X $18 \mathrm{~cm} \times 17.5 \mathrm{~cm})$ with a wire grid floor and front. The rats were observed during five consecutive five minute observation periods. Each observation period was separated from the next observation by a five minute recess. The rats were observed at $0,10,20,30$ and $40 \mathrm{~m} 1 \mathrm{n}-$ utes after the session began.

During the observation period, the rats were rated for the intensity of stereotypy according to the five point scale devised by Ernst (1967). The ratings were as follows:

0 - No stereotyped movements.

1 - Rats walking around cage, sniffing over grid, occasionally licking the wires and putting their nose in the grids.

2 - Rats moving around, occasionally biting and gnawing at the wires.

3 - Rats restricting their locomotion to a small area and gnawing intensely at the bottom.

4 - Rats remaining on the same spot for at least 5 minutes while jerkingly gnawing and clinging their teeth around the wires convulsively for longer periods, sometimes interrupted by short intermissions. 


\section{Dopamine Turnover}

The rate of dopamine turnover was evaluated by measuring the rate of disappearance of dopamine from the corpus striatum after the administration of alpha-methyl-p-tyrosine (MPT) methyl ester hydrochloride $(300 \mathrm{mg} / \mathrm{Kg})$, which inhibits the synthesis of the catecholamines (Spector et a1., 1965). The animals were deprived of food for 18-24 hours prior to being sacrificed by decapitation. The brains were rapidiy removed from the cranium and placed on ice. The lateral ventricles were opened to expose the corpus striatum which was removed from each side and pooled. All manipulations were carried out on ice using ice-chilled equipment. The striata were weighed and homogenized in $3 \mathrm{ml}$ of $0.4 \mathrm{~N}$ perchloric acid containing $0.05 \%$ sodium metabisulfite. The homogenate was transferred to a centrifuge tube. The homogenizer was rinsed with 1 ml perchloric acid solution which was added to the homogenate and centrifuged at $12,000 \times \mathrm{g}$ for $10 \mathrm{min-}$ utes In a Serval1 RC 2 B refrigerated centrifuge.

The supernatant from each centrifuge tube was transferred into a large centrifuge tube containing $10 \mathrm{~m} 1$ of $0.5 \mathrm{M}$ tris buffer ( $\mathrm{pH}$ 9.5). The resultant $\mathrm{pH}$ of the sample was $8.5 \pm 0.1$. The samples were allowed to pass through a 9 mm glass column packed with 500 mg of alumina at a rate of 30 drops a minute. The eluate as well as a $5 \mathrm{~m} 1 \mathrm{~d}$ istilled water wash were discarded. The dopamine on the column was then extracted by $4 \mathrm{ml}$ of $0.2 \mathrm{~N}$ acetic acid and collected in a graduated centrifuge tube containing $1 \mathrm{ml}$ of 
EDTA reagent. A two and a half ml sample was transferred to a test tube and assayed spectrofluorometrically (Carlsson and Waldeck, 1958). To the test tube was added $0.2 \mathrm{~m} 1$ of lodine solution and shaken. Exactly three minutes later, $0.2 \mathrm{~m} 1$ alkaline sulfite was added. Tissue blanks were prepared from the residual acetic acid eluate with the addition of alkaline sulfite and lodine reversed. Exactly three minutes after the addition of alkaline sulfite, $0.5 \mathrm{ml}$ of $5 \mathrm{~N}$ acetic acid was added to each test tube and placed into a bath of bolling water for five minutes. Once they had cooled to room temperature, the concentration of dopamine in each sample was estimated by reading the samples at 370 nm whle activating at $320 \mathrm{~nm}$ in an Aminco-Bowman spectrofluorometer. The concentration of dopamine in the experImental samples was determined by comparing the fluorescence with the known concentralion of a standard dopamine solution. The calculated concentration was expressed as micrograms of dopamine per gram of wet tissue. Recovery was found to be $88 \%$. The samples were not corrected for the recovery loss. The turnover of dopamine was calculated from the rate of striatal dopamine depletion observed two hours after the infection of MPT according to the method of Costa and Neff (1970). The quantity of dopamine in the sample obtained after the MPT was compared with the quantity in the striatum immediately after the MPT injection. The calculation of dopamine turnover was carried out using the URI IBM systems 370 computer and consisted of solving the equation: 
$\log \mathrm{DA}_{\mathrm{t}}=\log \mathrm{DA}_{\mathrm{o}}-0.434 \mathrm{kt}$

where $\mathrm{DA}_{0}$ is the initial steady state concentration of dopamine, DAt is the concentration of dopamine at any time, $t$, after the administration of MPT and $k$ is the fractional rate constant. Multiplication of $k$ by the inftial steady state level of dopamine ylelds the. apparent turnover rate.

\section{J. Statistics}

The following statistical procedures were used in this study: When differences were obvious, no statistical procedure was used. Student's "t" test was employed for comparisons Involving two groups. Multiple comparisons were made using the Tukey (b) test except in those cases where all comparisons were made with control, in which case Dunnet's test was used. In one experiment, where the comparison was planned a priori, the Test of Individual Comparisons was utilized. All procedures are described in Winer (1971).

Where data followed a binomial distribution, the ChI Square Test was used. In those instances in which the data was on an ordinal scale, or seriously violated certain assumptions of parametric statistics, the Mann Whitney Test or the Kruskal-Wallis Analysis of Variance was used, depending on the number of groups being tested. These procedures are described in Conover (1971). Multiple comparisons were made in these cases by Dunn's Procedure (Hollander and WoIfe, 1973). 
IV. RESULTS

The results of this investigation are divided into three sections: aggression induced by apomorphine in nalve rats; morphine withdrawal aggression; and behaviors following chronic haloperidol.

\section{A. Apomorphine Induced Aggression in Nalve Rats}

Apomorphine produced aggression in a dose-dependent manner as illustrated in Figure 2. This was determined for use in subsequent experiments. The aggression was charac-. terized by vocalizations, aggressive postures and attacks and biting. At the higher doses, this frequently led to severe infury and bleeding. Doses less than $2.5 \mathrm{mg} / \mathrm{kg}$ falled to produce any aggression, while the $5 \mathrm{mg} / \mathrm{kg}$ dose produced aggression in approximately 20 per cent of the groups tested. The $20 \mathrm{mg} / \mathrm{kg}$ dose rellably produced a substantial aggression and was utilized in further studies. Doses of $5 \mathrm{mg} / \mathrm{kg}$ or less were used in studies where it was predicted that the treatment would increase the aggression.

\section{1) Effect of Ant1-Dopaminergic Drugs}

If the aggression is due to dopaminergic hyperactivity, It would expected that drugs which reduce dopaminergic activity would also reduce the aggression. Drugs from two 
Fig. 2--Dose related elicitation of aggression by apomorphine in naive rats. Apomorphine was injected into groups of four rats, five minutes prior to observations. Points are mean $\pm S$. E. for five different groups. Attacks were counted by the experimenter. Rearing refers to the time, in seconds, spent in aggressive postures (see Figures la, 1b). Vocalizations were counted automatically. The rats were observed for one hour. The dose of the drug was well correlated with the intensity of aggression on al1 three measures ( attacks: $r=0.78$; rearing: $r=0.82$; vocalizations: $r=0.80$ ). 


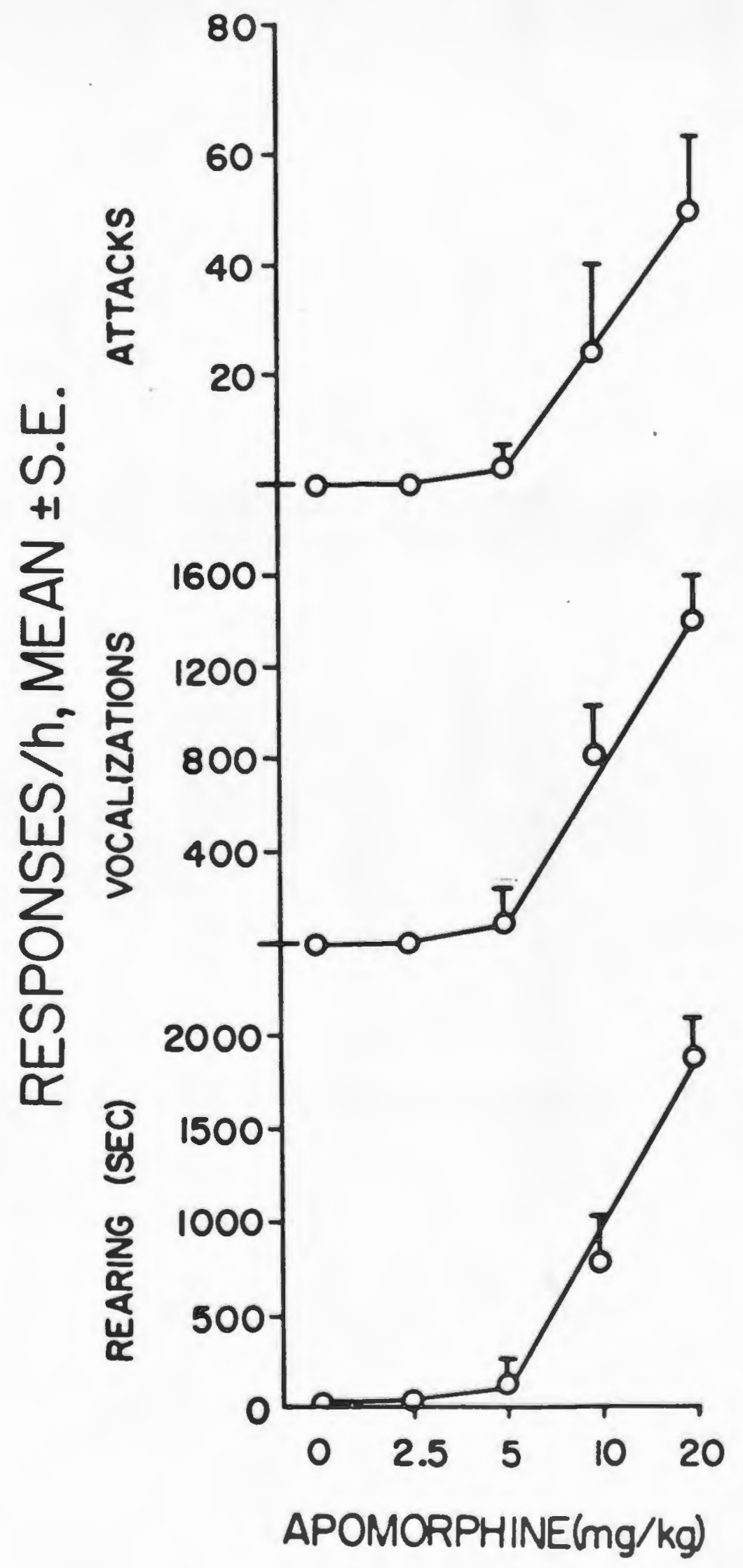


different classes which decrease dopamine activity were used, neuroleptics and narcotics (see Section II.B).

The neuroleptics, haloperidol and oxyperomide, produced a dose-dependent reduction of the aggression induced by the $20 \mathrm{mg} / \mathrm{kg}$ dose of apomorphine (Table 3). This effect was noted on all three parameters of aggression measured. Haloperidol was maxima11y effective at a dose of $2.5 \mathrm{mg} / \mathrm{kg}$, while the $5 \mathrm{mg} / \mathrm{kg}$ dose of oxyperomide abolished the aggression. Simliarly, morphine produced a dose-dependent blockade of the apomorphine-induced aggression, with a dose of $10 \mathrm{mg} / \mathrm{kg}$ being maxima11y effective (Table 4). The morphine-induced blockade of aggression was prevented by the narcotic antagonist, naloxone, which had no effect of 1 ts own. The specificity of this effect is evident from the fact that naloxone had no effect on the reduction in aggression produced by haloperidol (Table 4). These results confirmed the suspected anti-aggression action of anti-dopaminergic drugs. In contrast to the effect of naloxone, an anticholinergic drug, dexetimide, partially reversed the anti-aggression action of haloperidol or oxyperomide as illustrated in Table 5. This effect was produced by doses of dexetimide which apparent1y had 1ittle effect on apomorphine-induced aggression of their own (c.f. Table 9). However, dexetimide was unable to alter the blockade of aggression produced by. morphine (Table 5), suggesting that morphine and the neuroleptics produce their effects by different mechanisms. If 
TABLE 3

EFFECTS OF NEUROLEPTICS ON

APOMORPHINE-INDUCED AGGRESSION

Aggressive Response/Hour

(mean \pm S.E.)

\begin{tabular}{|c|c|c|c|c|c|}
\hline Drug & $\begin{array}{c}\text { Dose } \\
(\mathrm{Mg} / \mathrm{Kg})\end{array}$ & $\mathrm{N}^{3}$ & Attacks & Rearing & Vocalizations \\
\hline Saline & - & 5 & $61 \pm 9$ & $2750 \pm 251$ & $2219 \pm 204$ \\
\hline \multirow[t]{3}{*}{ Haloperidol } & 0.63 & 2 & $59 \pm 5$ & $2358 \pm 756$ & $1351 \pm 97$ \\
\hline & 1.25 & 5 & $28 \pm 8$ & $2358 \pm 544$ & $1190 \pm 487$ \\
\hline & 2.5 & 5 & $2 \pm 2$ & $89 \pm 89$ & $17 \pm 15$ \\
\hline \multirow[t]{3}{*}{ oxyperomide } & 1.25 & 2 & $52 \pm 2$ & $2621 \pm 220$ & $889 \pm 95$ \\
\hline & 2.5 & 5 & $15 \pm 6$ & $1163 \pm 510$ & $386 \pm 148$ \\
\hline & 5.0 & 5 & $2+2$ & $33+33$ & $25 \pm 25$ \\
\hline
\end{tabular}

1 Apomorphine $(20 \mathrm{mg} / \mathrm{Kg})$ was injected into all.groups

2 Haloperidol was injected two hours before testing while oxyperomide was injected 40 minutes before testing.

3 Number of groups (four rats per group) tested.

Values for haloperidol $(2.5 \mathrm{mg} / \mathrm{Kg})$ and oxyperomide $(5 \mathrm{mg} / \mathrm{Kg})$ are significantly different $(\mathrm{P}<0.05)$ from saline control (Dunn's Procedure). 
TABLE 4

EFFECT OF MORPHINE ON APOMORPHINE-INDUCED AGGRESSION1

$$
\begin{aligned}
& \text { Aggressive Response/Hour } \\
& \text { (mean } \pm \text { S.E.) }
\end{aligned}
$$

\begin{tabular}{|c|c|c|c|c|c|}
\hline Drugs 2 & $\begin{array}{l}\begin{array}{l}\text { Dose } \\
\text { (mg/Kg) }\end{array} \\
\end{array}$ & $\mathrm{N}^{3}$ & Attacks & $\begin{array}{l}\text { Rearing } \\
\text { (secs) }\end{array}$ & Vocalizations \\
\hline Saline & - & 5 & $58 \pm 10$ & $1787 \pm 301$ & $1188 \pm 252$ \\
\hline \multirow[t]{2}{*}{ Morphine } & 5 & 5 & $28 \pm 11$ & $1150 \pm 285$ & $702 \pm 221$ \\
\hline & 10 & 5 & $1 \pm 1$ & $30 \pm 30$ & $10 \pm 10$ \\
\hline $\begin{array}{c}\text { Naloxone } \\
+ \\
\text { Morphine }\end{array}$ & $\begin{array}{r}4 \\
10\end{array}$ & 5 & $42 \pm 5$ & $1654 \pm 384$ & $1163 \pm 196$ \\
\hline $\begin{array}{l}\text { Haloperidol } \\
+ \\
\text { Naloxone }\end{array}$ & $\begin{array}{l}2.5 \\
4\end{array}$ & 3 & 0 & $0^{\circ}$ & 0 \\
\hline Naloxone & 4 & 3 & $46 \pm 5$ & $2189 \pm 263$ & $1283+107$ \\
\hline
\end{tabular}

${ }^{I_{\text {Apomorphine }}}(20 \mathrm{mg} / \mathrm{Kg})$ was injected into all groups

2 Morphine was injected 40 minutes before testing, haloperidol was injected 2 hours before testing and naloxone was injected 10 minutes before testing.

${ }^{3}$ Number of groups (4 rats/group) tested. 
TABLE 5

REVERSAL OF NEUROLOPTIC-INDUCED BLOCKADE OF APOMORPHINE-INDUCED AGGRESSION1

BY DEXETIMIDE

\begin{tabular}{|c|c|c|c|c|c|c|c|c|c|}
\hline \multirow[b]{2}{*}{$\begin{array}{l}\text { Pre-Treatment } \\
\text { Drug }\end{array}$} & \multirow[b]{2}{*}{ Dose } & \multirow[b]{2}{*}{$\begin{array}{l}\text { Post-Treatment } \\
\text { Drug }\end{array}$} & \multirow[b]{2}{*}{ Dose } & \multirow[b]{2}{*}{$\underline{\mathbf{N}}$} & \multicolumn{4}{|c|}{$\begin{array}{c}\text { Aggressive Responses/Hour } \\
\text { (mean } \pm \text { S.E.) }\end{array}$} & \multirow[b]{2}{*}{ lizations } \\
\hline & & & & & Attacks & Rear: & ing & Voca & \\
\hline Saline & - & Saline & - & 5 & $47 \pm 10$ & 1633 & \pm 315 & 1119 & \pm 306 \\
\hline \multirow[t]{4}{*}{ Haloperidol } & 2.5 & Saline & - & 3 & $3 \pm 3$ & 71 & \pm 71 & 22 & \pm 23 \\
\hline & & Dexetimide & 1.25 & 2 & $18 \pm 4$ & - 986 & \pm 152 & 583 & \pm 120 \\
\hline & & & 2.5 & 6 & $14 \pm 3$ & 571 & \pm 191 & 403 & \pm 109 \\
\hline & & & 5.0 & 3 & $45 \pm 4$ & 1392 & \pm 209 & 1214 & \pm 342 \\
\hline \multirow[t]{4}{*}{ Oxyperomide } & 5 & Saline & - & 3 & 0 & & 0 & & 0 \\
\hline & & Dexetimide & 1.25 & 4 & $19 \pm 9$ & 615 & \pm 278 & 433 & \pm 207 \\
\hline & & & 2.5 & 4 & $20 \pm 4$ & 562 & \pm 118 & 388 & \pm 110 \\
\hline & & & 5.0 & 3 & $37 \pm 13$ & 1087 & \pm 389 & 998 & \pm 303 \\
\hline \multirow[t]{3}{*}{ Morphine } & 10 & Saline & - & 3 & 0 & & 0 & & 0 \\
\hline & & Dexetimide & 1.25 & 3 & $1 \pm 0$ & & \pm 5 & 12 & \pm 9 \\
\hline & & & $\begin{array}{l}2.5 \\
5.0\end{array}$ & $\begin{array}{l}3 \\
6\end{array}$ & $\begin{array}{c}0 \\
4 \pm 2\end{array}$ & 76 & $\begin{array}{l}0 \\
\pm 52\end{array}$ & 101 & $\begin{array}{l}0 \\
\pm 51\end{array}$ \\
\hline
\end{tabular}

$l_{\mathrm{All}}$ groups were injected with apomorphine $(20 \mathrm{mg} / \mathrm{Kg})$ following treatment with other drugs 
an anticholinergic drug reverses the neuroleptic effect, a cholinergic drug should synergize with the neuroleptic. As can be seen in Table 6, the combination of an approximately $E_{50}$ dose of oxyperomide with an ED 50 dose of the cholinergic drug, pilocarpine, resulted in a reduction of aggression which was greater than elther drug alone. These results suggest a reciprocal interaction between dopamine and acetylcholine. If so, cholinergic stimulation should decrease apomorphine-induced aggression.

\section{2) Effect of Drugs Affecting Acetylcholine}

Data summarized in Table 7 shows that pilocarpine reduced the aggression Induced by the $20 \mathrm{mg} / \mathrm{kg}$ dose of apomorphine in a dose-dependent manner, with the dose of 5 mg/kg of pilocarpine being maximally effective. The experiments summarized in Table 8 were designed to test the effect of various anticholinergics on the pilocarpine-induced blockade of aggression. The data is divided into two consecutive 30 minute segments, rather than a one hour observation period as usually presented. This ts because 1t was noted that the centrally active anticholinergics, dexetimide and atropine, when combined with the high dose of apomorphine used in this experiment, resulted in convulsive-like toxic effects towards the middle of the observation period. These convulsions became apparent after the rats had begun to fight. Therefore, the measurements recorded in the first perlod were analyzed separately from 


\section{TABLE 6}

EFFECT OF PILOCARPINE PLUS OXYPEROMIDE ON APOMORPHINE- 1 INDUCED AGGRESSION

\section{Aggressive Responses/Hour} (mean \pm S.E.)

\begin{tabular}{llcll} 
Drug & $\mathrm{N}^{2}$ & Attacks & $\begin{array}{l}\text { Rearing } \\
\text { (secs) }\end{array}$ & Vocalization \\
\hline Saline & 6 & $53 \pm 4$ & $2702 \pm 122$ & $1693 \pm 221$ \\
Pilocarpine & 6 & $30 \pm 6$ & $1621 \pm 334$ & $451 \pm 88$ \\
Oxyperomide $^{3}$ & 6 & $28 \pm 6$ & $1410 \pm 434$ & $745 \pm 245$
\end{tabular}

Pilocarpine 3

$\underset{\text { Oxyperomide }}{+} \quad 6 \quad 4 \pm 3^{*} \quad 465 \pm 307^{*} \dot{125} \pm 94$

* Significantly different $(p<0.05)$ from pilocarpine or oxyperomide alone by Test of Individual Comparisons (Winer, 1971.)

$120 \mathrm{mg} / \mathrm{Kg}$ of apomorphine injected into all groups.

2 Number of groups (4 rats per group) tested.

$32.5 \mathrm{mg} / \mathrm{Kg} 10 \mathrm{minutes}$ before testing.

$42.5 \mathrm{mg} / \mathrm{Kg} 40$ minutes before testing. 
TABLE 7

BLOCKADE OF APOMORPHINE ${ }^{1}$-INDUCED AGGRESSION BY PILOCARPINE

$$
\text { Aggressive Responses/Hour (Mean } \pm \text { S.E.) }
$$

Dose of

Pilocarpine2

$\underline{(\mathrm{mg} / \mathrm{Kg})}$

$\begin{array}{lrrrr}\underline{N} & \frac{\text { Attacks/Bites }}{7} & & \begin{array}{l}\text { Rearing } \\ \text { (seconds) }\end{array} & \text { Vocalizations } \\ 5 & 51 \pm 9 & 1929 \pm 261 & 1222 \pm 204 \\ 5 & 1 \pm \pm 1^{*} & 1363 \pm 572 & 291 \pm 114 \\ 3 & 0 \pm 0 & 81 \pm 81^{*} & 16 \pm 14^{*} \\ 5 & 12 & 0 \pm 0 & 0 \pm 0\end{array}$

10

0

-

2.5 - 
TABLE 8

EFFECT OF ANTICHOLINERGICS ON PILOCARPINE-INDUCED BLOCKADE OF APOMORPHINE-INDUCED AGGRESSION ${ }^{1}$

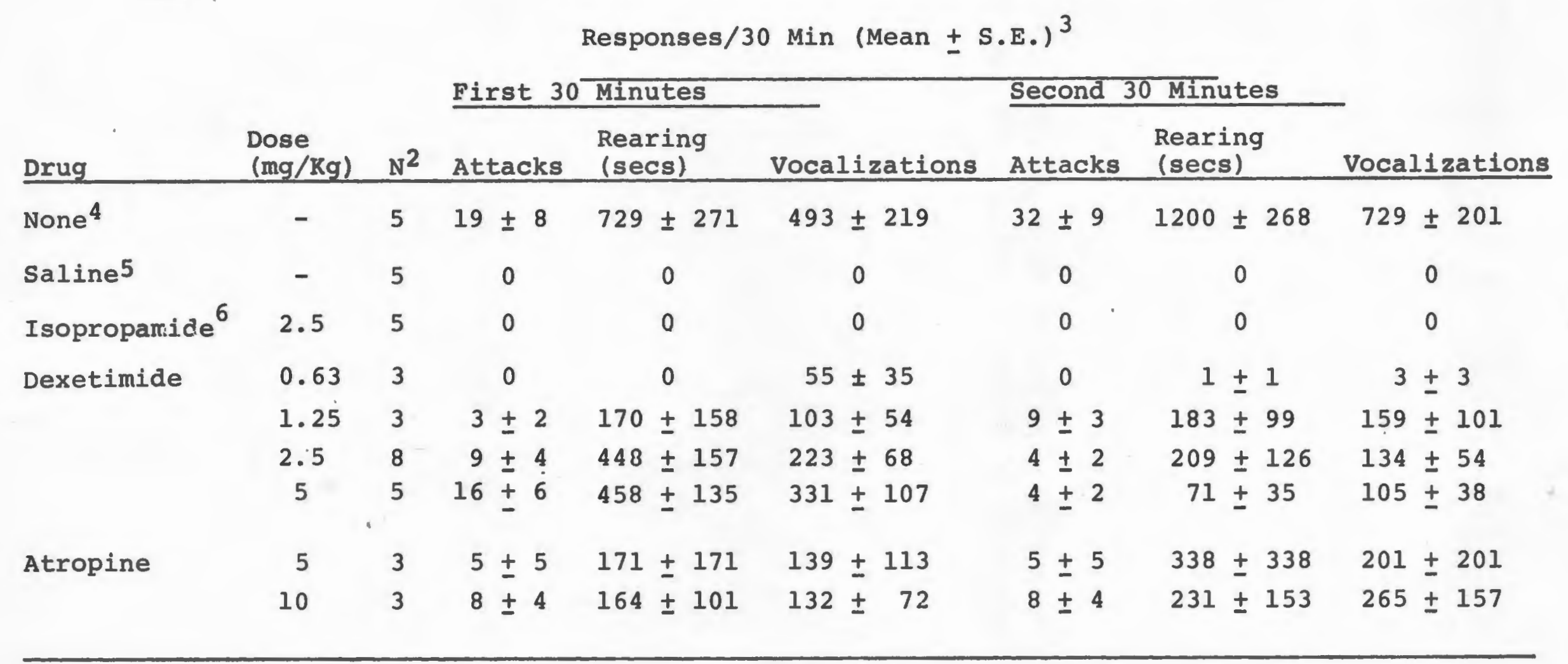

1 Apomorphine $20 \mathrm{mg} / \mathrm{Kg}$ was injected into all groups.

${ }^{2}$ Number of groups tested (4 rats/group) 


\section{Table 8 Continued}

3 Groups were observed for two consecutive 30 minute periods (see text).

4 Apomorphine alone

5 This group and all subsequent groups received apomorphine + pilocarpine (5 mg/Kg) and the appropriate drug.

6 This does of isopropamide blocked pilocarpine-induced ( $5 \mathrm{mg} / \mathrm{Kg}$ ) diarrhea. 
the second segment in order to take the convulsions into account for proper interpretation of the data. Dexetimide and atropine partailly reversed the blockade of aggression by pilocarpine in the first period. During the second half of the observation, these drugs were ineffective in reinstating the aggression, but this effect is probably an artifact attributable to the hyperstimulation and convulsions produced by the drug combinations. The third anticholinergic drug used, isopropamide, does not penetrate into the CNS (Janssen and Niemegeers, 1967). Isopropamide effectively blocked the diarrhea produced by the pilocarpine at the dose used ( $2.5 \mathrm{mg} / \mathrm{kg})$ but had no effect on the aggressionblocking property of pilocarpine, indicating that the effect of cholinergic stimulation in inhibiting aggression is centrally mediated.

Since the cholinergic drug, pilocarpine, blocked the aggression produced by apomorphine,it would be expected that an anticholinergic may increase the aggression. Large doses of dexetimide were combined with a threshold dose ( $5 \mathrm{mg} / \mathrm{kg}$ ) and a sub-threshold dose $(2.5 \mathrm{mg} / \mathrm{kg}$ ) of apomorphine (see Figure 2). Dexetimide alone, in any dose including one as $\mathrm{high}$ as $20 \mathrm{mg} / \mathrm{kg}$, was unable to elicit aggression in the rats (Table 9), although signs resembling amphetamine agitation were present at this dose. However, dexetimide in a dose of $10 \mathrm{mg} / \mathrm{kg}$ elicited aggression when combined with a sub-threshold dose of apomorphine and significantly increased the aggression produced by threshold doses of apomor- 


\section{TABLE 9}

EFFECT OF DEXETIMIDE ON APOMORPHINE INDUCED AGGRESSION

$$
\begin{gathered}
\text { Aggressive Responses/Hour } \\
\text { (Mean } \pm \text { S.E.) }
\end{gathered}
$$

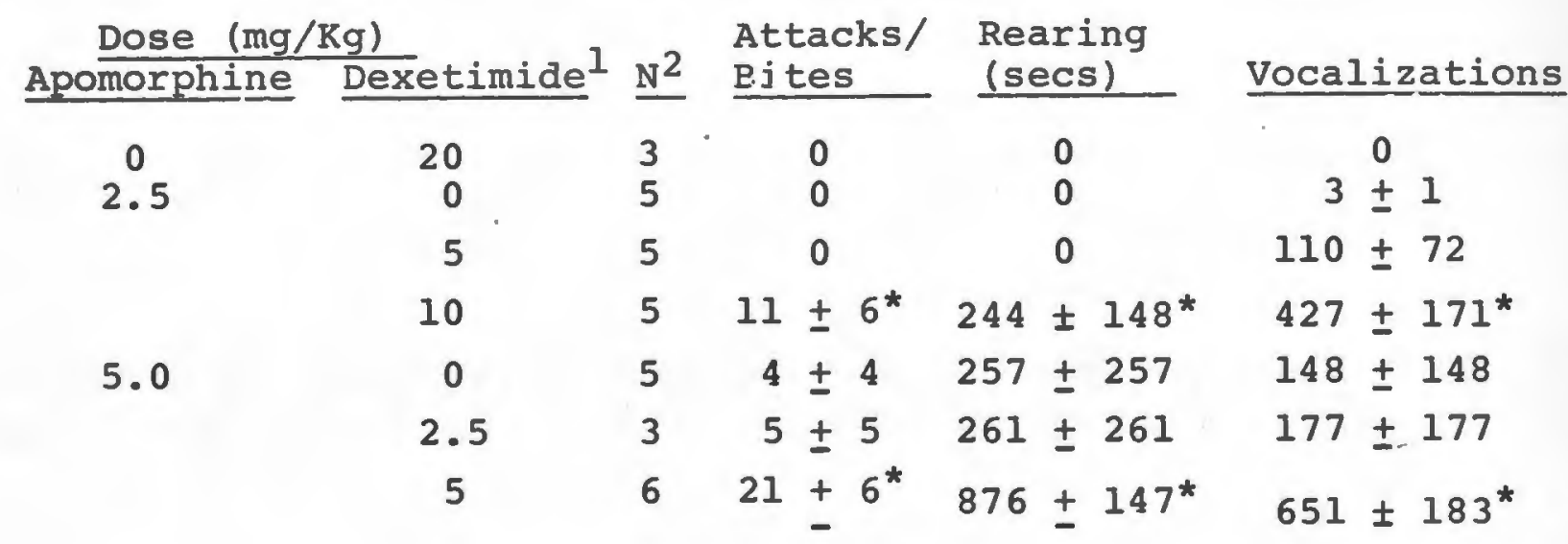

* Significantly different from corresponding no dexetimide group ( $p<.05$ ) by student's test.

${ }^{1}$ Dexetimide was injected 30 minutes before apomorphine. Tests were made 5 minutes later.

${ }^{2}$ Number of groups (4 rats/group) tested. 
phine at a dose of $5 \mathrm{mg} / \mathrm{kg}$ (Table 9).

3) Effect of Amphetamines

It was predicted that amphetamine, which releases dopamine, would intensify the apomorphine-induced aggression. Amphetamine, at a dose of $8 \mathrm{mg} / \mathrm{kg}$, did exacerbate the aggression produced by threshold doses of apomorphine ( $5 \mathrm{mg} / \mathrm{kg})$, but falled to elicit aggression when combined with sub-threshold doses of apomorphine (Table 10). Doses higher than those reported produced severe toxic reactions when the rats were placed in the small confinement used for testing. Since amphetamine releases norepinephrine and serotonin (McLean and McCartney, 1961) as well as dopamine, an investigation into the possible role of these other transmitters as antagonists of an amphetamine effect on aggression was undertaken.

clonidine, which stimulates alpha noradrenergic receptors (Anden et a1., 1970b) was used to explore the role of norepinephrine. As is illustrated in Table 11, combinations of clonidine and sub-threshold doses of apomorphine resulted in a marked and dose-dependent increase in the aggression. Doses of clonidine as smal1 as $0.13 \mathrm{mg} / \mathrm{kg}$ produced a violent behavior characterized by an excessively large proportion of biting when combined with normally ineffective doses of apomorphine.

The serotonergic influence was measured in two ways. Some preliminary data is presented in Table 12 in which 
TABLE 10

EFFECT OF AMPHETAMINE ON APOMORPHINE-INDUCED AGGRESSION

Aggressive Responses/Hour

(mean \pm S.E.)

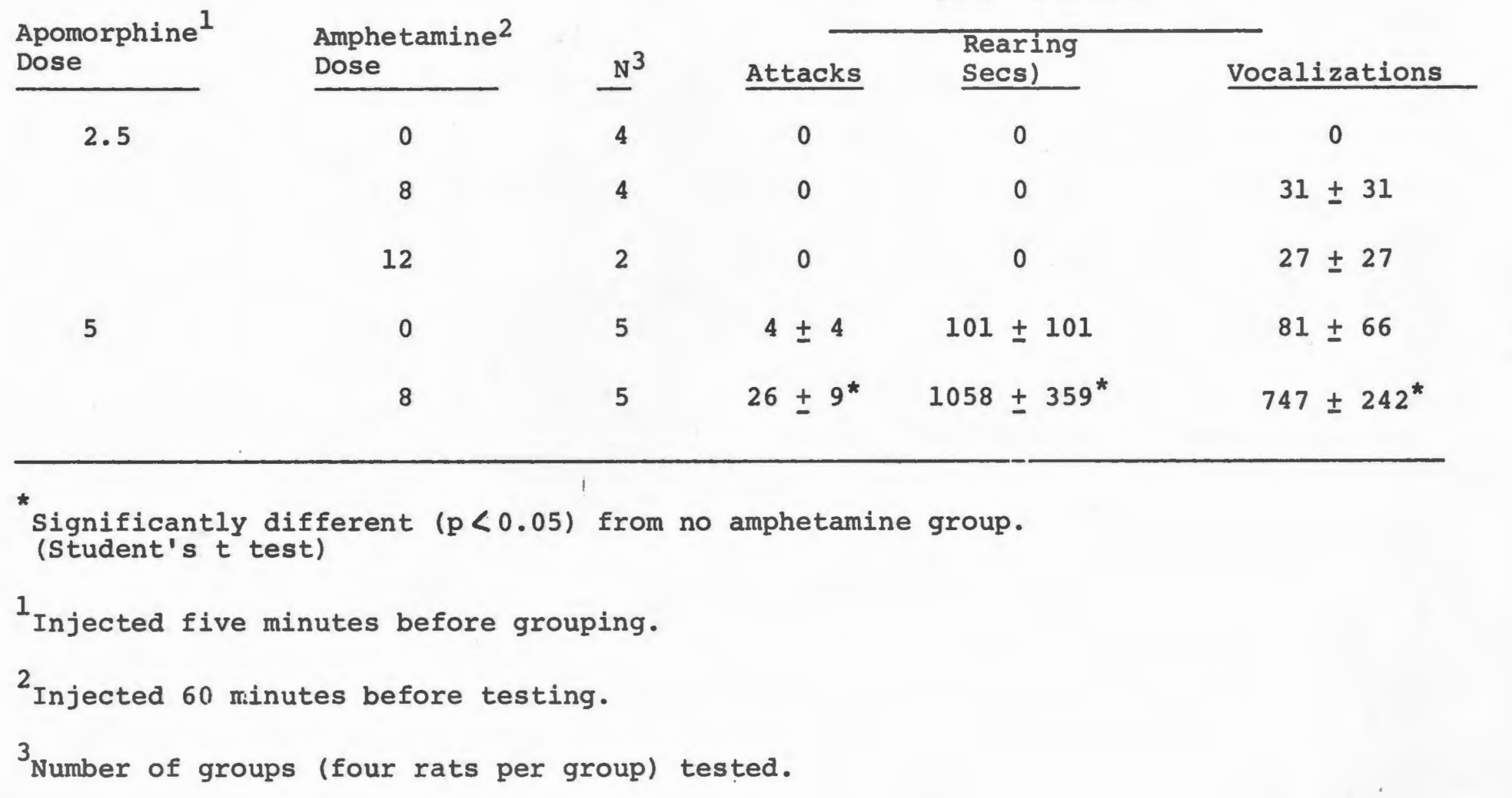


TABLE 11

EFFECT OF CLONIDINE ON APOMORPHINE-INDUCED AGGRESSION

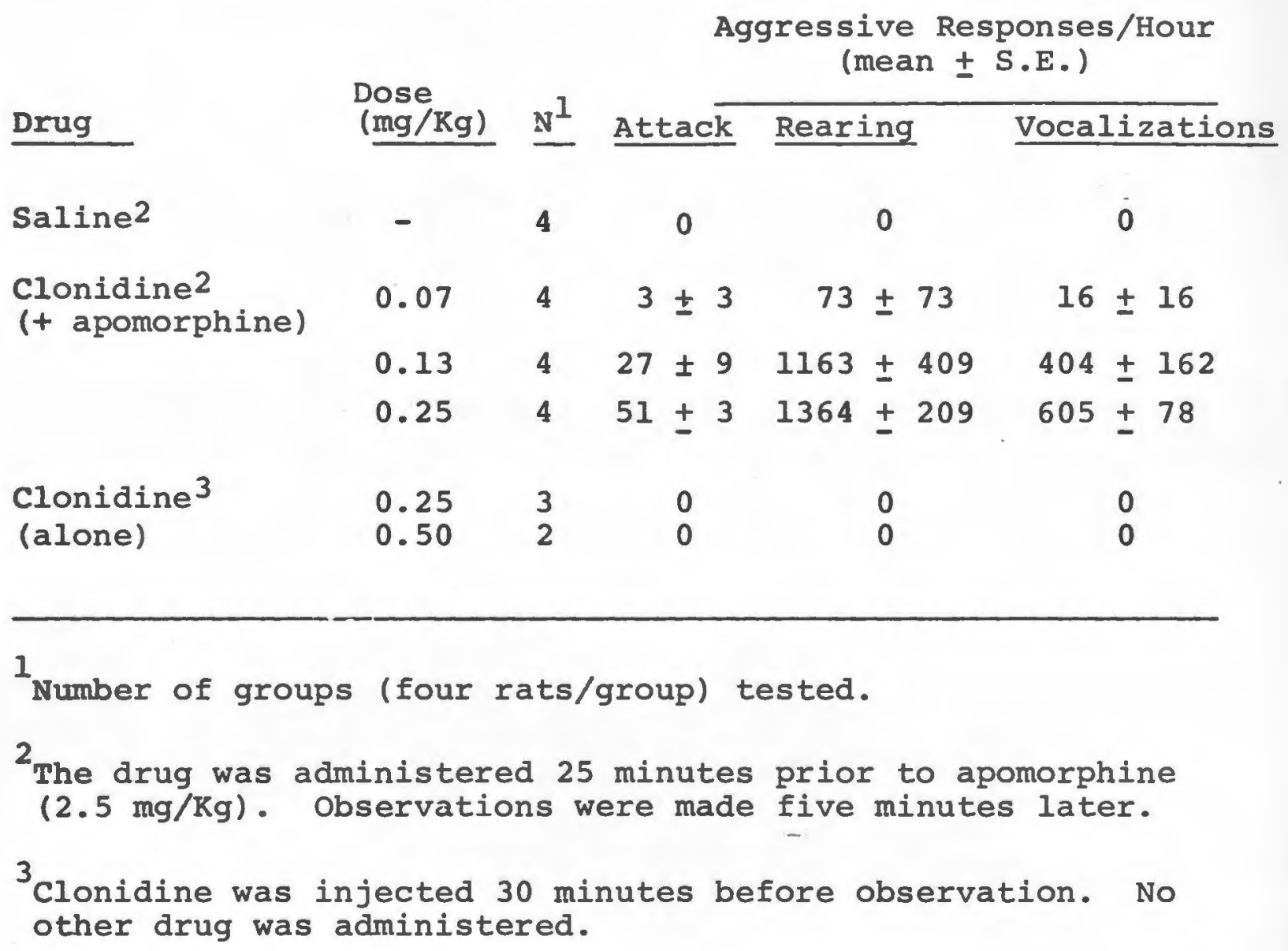


TABLE 12

EFFECT OF AMPHETAMINE PLUS CYPROHEPTADINE ON APOMORPHINE

INDUCED AGGRESSION

\begin{tabular}{|c|c|c|c|c|c|c|}
\hline \multirow[b]{2}{*}{ Drugl } & \multirow[b]{2}{*}{$\begin{array}{l}\text { Apomorphine } \\
\text { Dose } \\
\text { (mg/Kg) } \\
\end{array}$} & \multirow[b]{2}{*}{$\underline{N^{2}}$} & \multicolumn{3}{|c|}{$\begin{array}{l}\text { Aggressive Responses/Hour } \\
\text { (mean } \pm \text { S.E.) }\end{array}$} & \multirow[b]{2}{*}{ Lizations } \\
\hline & & & Attacks & $\begin{array}{l}\text { Rearing } \\
\text { (secs) }\end{array}$ & Vocali & \\
\hline Saline & 1.25 & 3 & 0 & 0 & & 0 \\
\hline Amphetamine ${ }^{3}$ & 1.25 & 3 & 0 & 0 & 18 & \pm 18 \\
\hline $\begin{array}{l}\text { Amphetamine } \\
\quad+ \\
\text { Cyproheptadine }\end{array}$ & 1.25 & 3 & $6 \pm 6$ & $186 \pm 186$ & 103 & \pm 87 \\
\hline Saline & 2.5 & 4 & 0 & 0 & & 0 \\
\hline Amphetamine $e^{5}$ & 2.5 & 4 & 0 & 0 & 30 & \pm 30 \\
\hline Cyproheptadine6 & 2.5 & 2 & 0 & 0 & & 0 \\
\hline $\begin{array}{l}\text { Amphetamine } \\
\quad+ \\
\text { Cyproheptadine }^{6}\end{array}$ & 2.5 & 4 & $20+11^{\star}$ & $966+583^{*}$ & 495 & $+167^{\star}$ \\
\hline
\end{tabular}

* Significantly different $(\mathrm{p}<0.05)$ from saline control (Mann Whitney Test)

1 Drugs were injected followed by apomorphine at the indicated doses. 


\section{TABLE 12 continued}

${ }^{2}$ Number of groups tested (4 rats per group).

${ }^{3} 8 \mathrm{mg} / \mathrm{Kg}$. 60 minutes before testing.

${ }^{4} 8 \mathrm{mg} / \mathrm{Kg} .45$ minutes before testing.

${ }^{5} 4 \mathrm{mg} / \mathrm{Kg} .60$ minutes before testing.

${ }_{4}^{6} \mathrm{mg} / \mathrm{Kg} .45$ minutes before testing. 
cyproheptadine, a blocker of serotonin receptors (Stone et a1., 1961), was used. When combined with amphetamine, cyproheptadine appeared to produce a weak elicitation of aggression by sub-threshold doses of apomorphine. Cyproheptadine alone, at the doses used, did not influence the apomorphine-1nduced aggression. Secondly, parachloroamphetamine (PCA), a related phenethylamine which produces a longlasting depletion of brain serotonin (Sanders-Bush et al., 1972) markedly lowered the effective dose of apomorphine. When PCA was given In a dose of $12 \mathrm{mg} / \mathrm{kg}$, three days before testing, there was no spontaneous aggression in the rats, but there was considerable aggression after small $(0.63-2.5 \mathrm{mg} / \mathrm{kg})$, normally Ineffective doses of apomorphine (Figure 3 ). These results would suggest that serotonin opposes dopamine-induced aggression.

\section{B. Morphine Withdrawal Aggression}

1) 72 Hour Withdrawal Aggression

Morphine withdrawal aggression was studied because it also may have a dopaminergic basis (Puri and Lal, 1973a). Any similarities between morphine withdrawal aggression and apomorphine-induced aggression would provide further support for the mechanisms proposed.

a) Effect of Dopamine

Rats were made dependent on morphine by the three methods described in section III.c.l. As expected, the 
Fig. 3--Dose related elicitation of aggression by apomorphine in p-chloroamphetamine (PCA) treated rats. Apomorphine was injected into groups of four rats, three days after PCA (12 mg/kg in a single injection). Points are mean $\pm S$. E. for four groups, except for the $2.5 \mathrm{mg} / \mathrm{kg}$ dose of apomorphine which represents data for one group. Apomorphine or saline was injected five minutes before observations. 


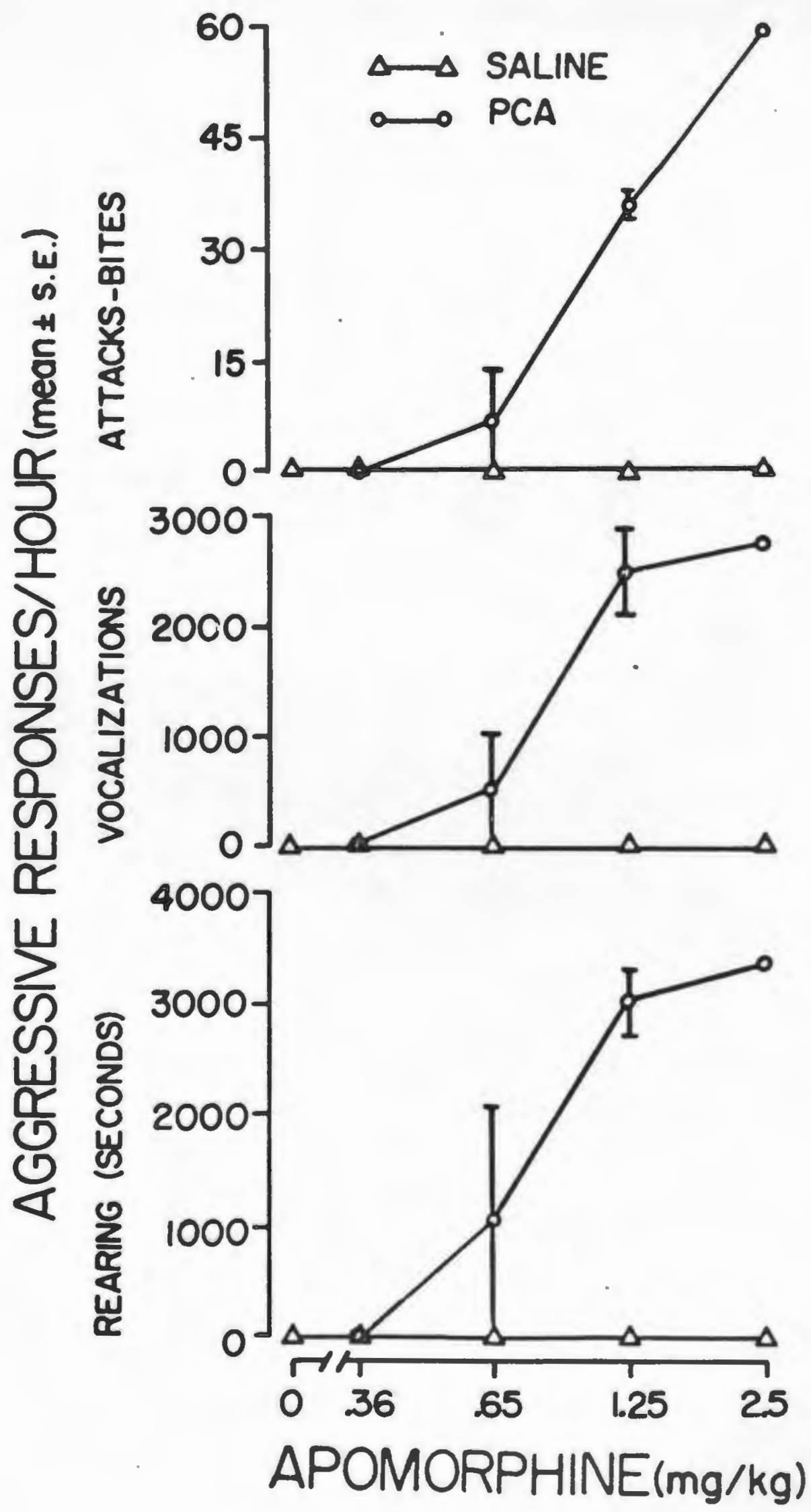


rats addicted to a terminal dose of $405 \mathrm{mg} / \mathrm{kg} / \mathrm{day}$ demonstrated considerable aggression 72 hours after their last morphine infection (Table 13). Decreasing the amount of morphIne infected during addiction to a terminal dose of $200 \mathrm{mg} / \mathrm{kg}$ resulted in significantly less aggression during withdrawal on all three parameters tested, whlle increasing the length of time that the rats received morphine injections from 15 to 25 days, while maintaining the terminal dose at $200 \mathrm{mg} / \mathrm{kg}$, produced aggression which was indistinguishable from the usual high dose schedule (Table 13). This indicates that the degree of aggression is dependent on the amount of morphine administered and the duration of addiction. The high dose schedule was utilized for all further experiments.

It is interesting to note that the aggression peaks at 72 hours of withdrawal, while other signs of withdrawal (e. g. "wet shakes", ptosis, hypothermia), peak at 24-48 hours of withdrawal (Martin et a1., 1963; Gianutsos et al., 1975). Spontaneous locomotor activity was also measured during withdrawal to determine if any pattern was evident. It can be seen from the data summarized in Table 14 that locomotor activity was significantly lower than in normal rats at 48 hours of withdrawal, when most signs of withdrawal are at their most intense. The activity was significantly higher than control at 72 hours of withdrawal, when aggression was at its maximum. The activity was normal at 24 hours of withdrawa1. 
TABLE 13

EFFECT OF DIFFERENT SCHEDULES OF ADDICTION ON 72 HOUR MORPHINE WITHDRAWAL AGGRESSION

\begin{tabular}{|c|c|c|c|c|c|c|}
\hline \multirow{2}{*}{$\begin{array}{l}\text { Terminal } \\
\text { Dose } 1 \\
\text { (mg/Kg) }\end{array}$} & \multirow{2}{*}{$\begin{array}{l}\text { Length of }{ }^{2} \\
\text { Addiction } \\
\text { (days) }\end{array}$} & \multirow[b]{2}{*}{$\mathbf{N}^{3}$} & \multicolumn{4}{|c|}{$\begin{array}{c}\text { Aggressive Responses/Hour } \\
\text { (mean } \pm \text { S.E.) }\end{array}$} \\
\hline & & & Attacks & $\begin{array}{l}\text { Rearing } \\
\text { (secs) }\end{array}$ & & Vocalizations \\
\hline 405 & 14 & 13 & $32 \pm 2$ & $3216 \pm$ & 118 & $1864 \pm 150$ \\
\hline 200 & 15 & 6 & $13 \pm 4^{*}$ & $1877 \pm$ & $532^{*}$ & $904 \pm 323$ \\
\hline 200 & 25 & 3 & $29 \pm 5$ & $3399 \pm$ & 161 & $2524 \pm 103$ \\
\hline
\end{tabular}

*

Significantly different $(p<0.05$ ) from 405 group (Student's $t$ test).

1

Final daily dose of morphine at which rats were maintained (see methods).

2 Total number of days during which morphine injections were given.

3 Number of groups (4 rats per group). 
LOCOMOTOR ACTIVITY OF RATS DURING MORPHINE WHTHDRAWAL

Period of

withdrawal 1

Control ${ }^{2}$

24 hours

48 hours

72 hours

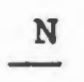

10

10

10

10
Locomotor Activity Counts (mean \pm S.E.)

$1138 \pm 106$

$1101 \pm 131$

$810 \pm 84^{*}$

$1429 \pm 101^{*}$

* Significantly different $(p<0.05)$ from control (Dunnet's Test)

1 Hours since last morphine injection (135 mg/Kg)

2 Naive, non-addicted rats 
As expected from the data of Puri and Lal (1973a), a small dose of apomorphine $(1.25 \mathrm{mg} / \mathrm{kg})$ increased, while haloperidol $(0.64 \mathrm{mg} / \mathrm{kg})$ decreased the 72 hour morphine withdrawal aggression (Table 15). Lesions of the dopaminergic nIgro-striatal bundle (NSB) reduced the intensity of the aggression (Table 16). Small lestons ( $1 \mathrm{~mA}, 15 \mathrm{sec)}$ of the bundle decreased aggression by about 50 per cent, wh1le more extensive lesions ( $2 \mathrm{~mA}, 30 \mathrm{sec}$ ) produced a virtually complete blockade of the aggression. These lesions have been shown to produce the characteristic rise in dopamine levels in the striatum 24 hours after the lesion, followed by a gradual depletion of striatal dopamine, with the larger lesion producing a more complete depletion (Hynes et a1.; 1975). These results provide further evidence for the dopaminergic basis of morphine withdrawal aggression.

In contrast to the effects in normal rats (c.f. Table 5), dexetimide did not affect the blockade of aggression by haloperidol in morphine withdrawn rats (Table 17). It was determined in pilot experiments that the $0.64 \mathrm{mg} / \mathrm{kg}$ dose of haloperidol which was used in this study was the minimum effective dose in blocking withdrawal aggression. Dexetimide by itself did not reduce the aggression, while the combination of haloperidol and dexetimide produced the usual blociade of aggression (Table 17). These results suggest an alteration of the normal dopaminergic/cholinergic balance during morphine withdrawal and point up the first difference between morphine withdrawal aggression and apomorphine-tnduced 
TABLE 15

EFFECT OF APOMORPHINE OR HALOPERIDOL ON 72 HOUR MORPHINE WITHDRAWAL AGGRESSION

\begin{tabular}{|c|c|c|c|c|c|}
\hline \multirow[b]{2}{*}{ Drug } & \multirow[b]{2}{*}{$\begin{array}{l}\text { Dose } \\
\text { (mg/Kg) }\end{array}$} & \multirow[b]{2}{*}{$\mathrm{N}^{1}$} & \multicolumn{3}{|c|}{$\begin{array}{l}\text { Aggressive Resporses/Hour } \\
\text { (mean } \pm \text { S.E.) }\end{array}$} \\
\hline & & & Attacks & $\begin{array}{l}\text { Rearing } \\
\text { (secs) }\end{array}$ & Vocalizations \\
\hline Saline & - & 5 & $30 \pm 3$ & $3060 \pm 315$ & $1771 \pm 181$ \\
\hline Apomorphine ${ }^{2}$ & 1.25 & 7 & $82 \pm 5$ & $3324 \pm 210$ & $1995 \pm 377$ \\
\hline Haloperidol ${ }^{3}$ & 0.64 & 4 & $0 \pm 0$ & $3 \pm 3$ & $15 \pm 11$ \\
\hline
\end{tabular}

1

Number of groups (4 rats/group) tested.

2 Apomorphine or saline was injected 5 minutes before testing.

3 Haloperidol was injected 2 hours before testing. 
TABLE 16

EFFECT OF BRAIN LESTONS ON 72 HOUR MORPHINE WITHDRAWAL AGGRESSION

\begin{tabular}{|c|c|c|c|c|c|c|}
\hline \multirow[b]{2}{*}{ Lesion } & \multirow[b]{2}{*}{$\mathrm{N}^{1}$} & \multicolumn{4}{|c|}{$\begin{array}{c}\text { Aggressive Response/Hour } \\
\text { (mean } \begin{array}{c}\text { S.E.2 }\end{array}\end{array}$} & \multirow[b]{2}{*}{ ations } \\
\hline & & Attacks & $\begin{array}{l}\text { Rearin } \\
\text { (secs) }\end{array}$ & & Vocal1za & \\
\hline None & 5 & $29 \pm 3$ & $3013 \pm$ & 241 & $2091 \pm$ & 128 \\
\hline NSB Sma11 & 5 & $24 \pm 8$ & $771 \stackrel{+}{-}$ & $201 *$ & $477 \pm$ & $116 *$ \\
\hline NSB Large & 5 & $1 \pm 0 *$ & $18 \pm$ & $6 *$ & 26. \pm & $8 *$ \\
\hline MFB Sma11 & 5 & $22 \pm 12$ & $1524 \pm$ & 621 & $588 \pm$ & $229 *$ \\
\hline $\begin{array}{l}\text { NSB Large } \\
+ \\
\text { Apomorphine }\end{array}$ & 2 & $47 \pm 5 *$ & $1209 \pm$ & 200 & $702 \pm$ & 29 \\
\hline
\end{tabular}

All lesions were made at 48 hours of withdrawal. Tests were performed 24 hours later. NSB designates nigro-striatal bundle, MFB designates medial forebrain bundle. Small means 1 mA of current was passed through electrode for 15 seconds, large means $2 \mathrm{~mA}$ for 30 seconds.

* Significantly different ( $p(0.05)$ from normal rats (Tukey Test). Number of groups tested ( 4 rats per group). 
TABLE 17

EFFECT OF DEXETIMIDE ON HALOPERIDOL INDUCED BLOCKADE

OF MORPHINE WITHDRAWAL AGGRESSION

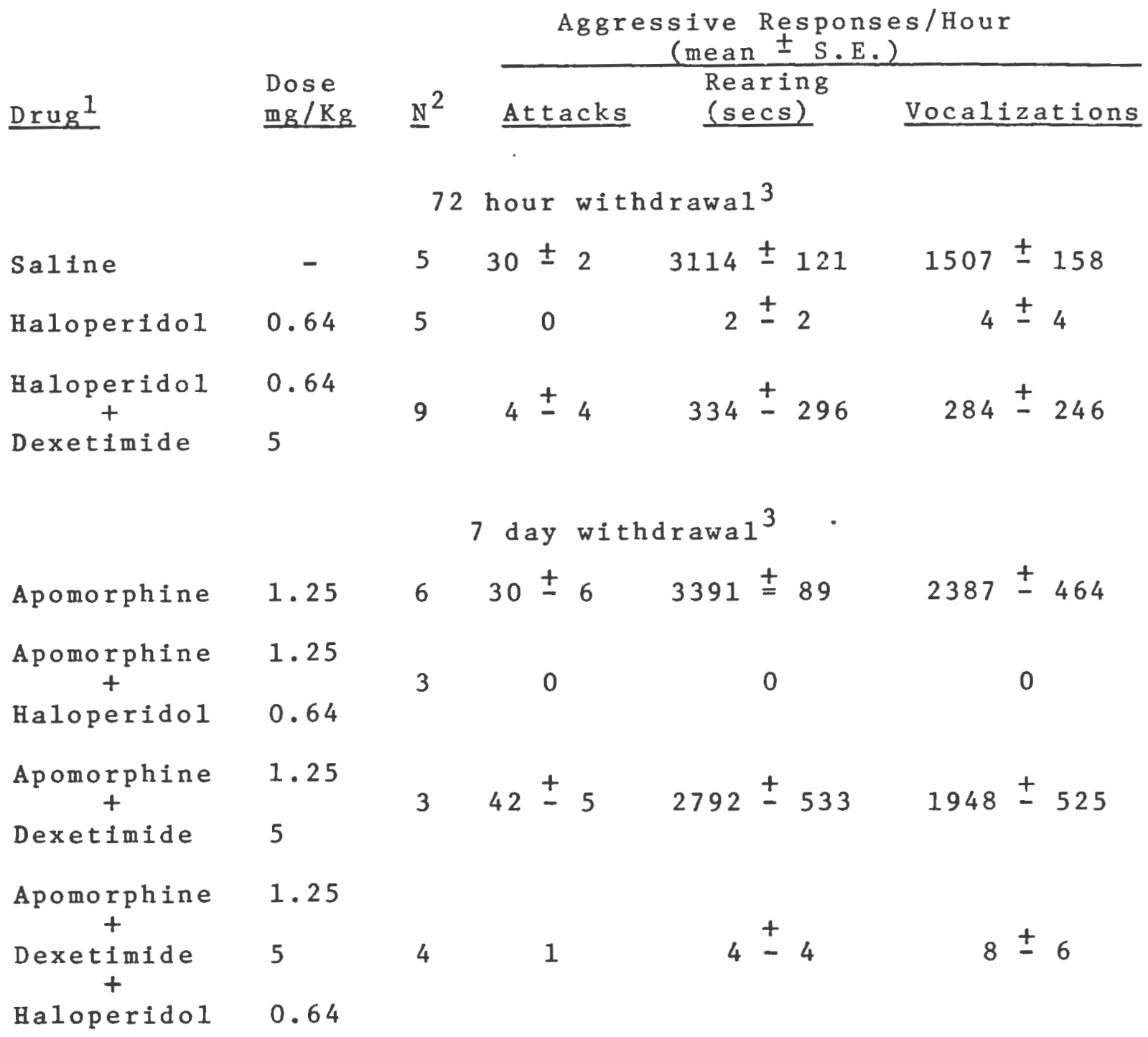

1 Haloperidol was injected two hours before testing while dexetimide and apomorphine were injected 40 minutes and 10 minutes, respectively, before testing.

2 Number of groups (four rats per group) tested.

3 Time since last morphine injection. 
aggression.

b) Effect of Acetylcholine

In order to further test the similarities between morphine withdrawal aggression and apomorphine-induced aggression, the effect of cholinergic stimulation and blockade was tested. The cholinergic agonist, pilocarpine, reduced the 72 hour morphine withdrawal aggression in a dose-dependent manner (Figure 4), with the $10 \mathrm{mg} / \mathrm{kg}$ dose being maximally effective in reducing all three measures of aggression. The anticholinergic, dexetimide, produced a dose-dependent increase in the aggression (Table 18) with the $10 \mathrm{mg} / \mathrm{kg}$ dose being effective. Similar results were noted in apomorphineInduced aggression.

c) Effect of Clonidine

Clonidine, at a dose of $0.25 \mathrm{mg} / \mathrm{kg}$, intensified the aggression normally seen at 72 hours of withdrawal (Table 19). Clonidine produced a similar enhancement of apomorphIne-induced aggression, suggesting that noradrenergic activity may be important in the aggression.

\section{2) ELICITED WITHDRAWAL AGGRESSION}

Naloxone, a narcotic-antagonist, is capable of precipitating a withdrawal syndrome if administered to dependent rats within a few hours of a narcotic(Wei et a1., 1973), but certain characteristics of the withdrawal differ from spontaneous withdrawal (see Gianutsos et al., 1975). It 
Fig. 4--Dose related reduction of 72 hour morphine withdrawal aggression by pilocarpine. Pllocarpine or saline was injected into groups of four morphine withdrawn rats 10 minutes prior to observations. 


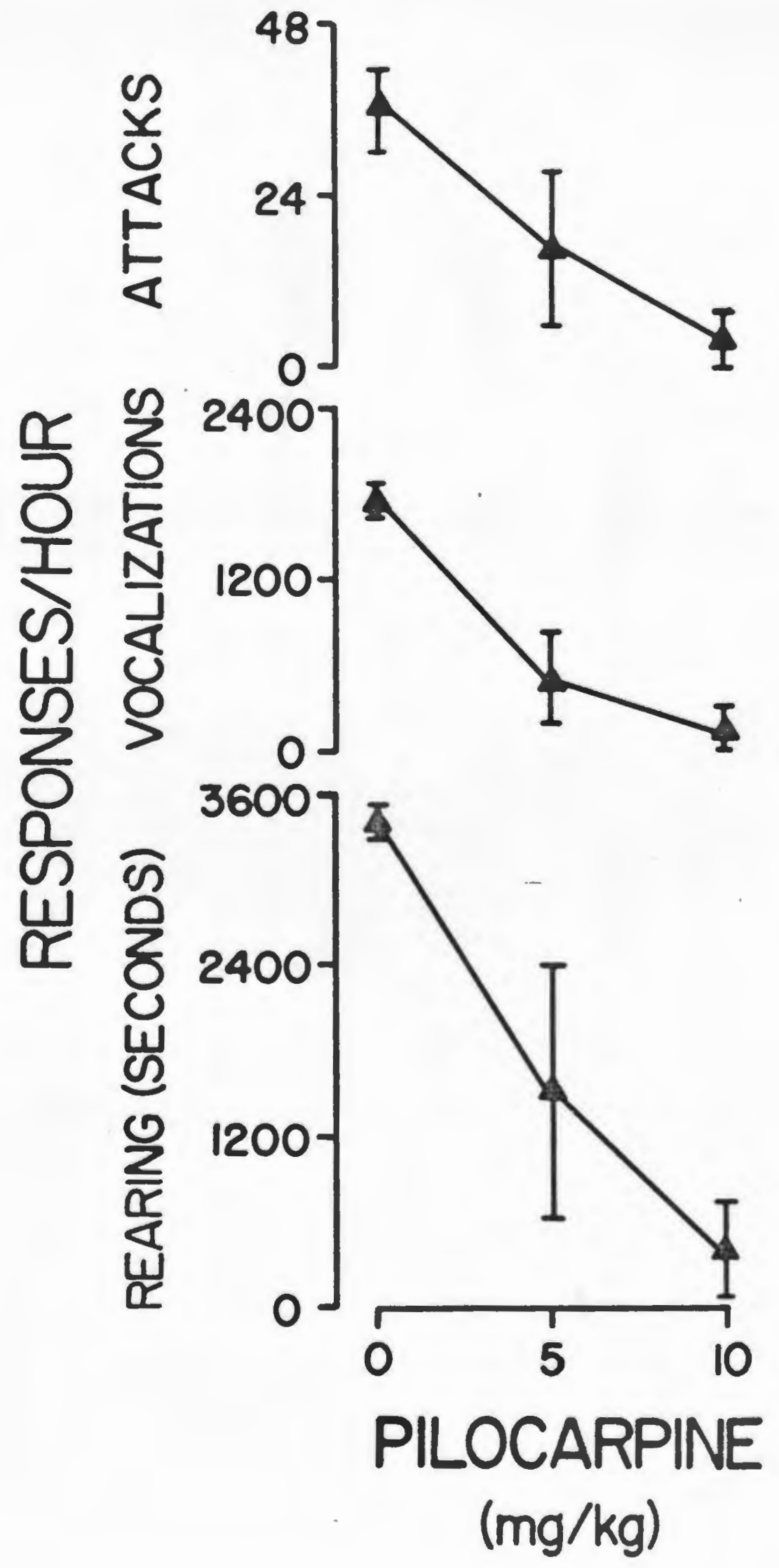


TABLE 18

\section{EFFECT OF DEXETIMIDE ON 72 HOUR MORPHINE WITHDRAWAL AGGRESSION}

Dose of

Dexetimide 1 (mg/Kg)

$\begin{array}{rr}0 & 5 \\ 5 & 3 \\ 10 & 4\end{array}$

Aggressive Responses/Hour (mean \pm S.E.)

Rearing (secs)

Vocalizations

Attacks

$22 \pm 7$

$1515 \stackrel{ \pm}{-} 875$

$1117 \pm 406$

$22 \pm 9$

$1870 \pm 1009$

$1221 \pm 570$

$57 \pm 8^{*}$

$2891 \pm 641$ $2098 \pm 308^{*}$.

* Significantly different ( $p<.05)$ from saline control (Omg/Kg) by (Tukey (b) Test).

1

Dexetimide was injected 35 minutes before grouping.

3 Number of groups ( 4 rats/group) tested. 
TABLE 19

EFFECT OF CLONIDINE ON MORPHINE-WITHDRAWAL AGGRESSION ${ }^{1}$

\begin{tabular}{|c|c|c|c|c|c|c|c|c|}
\hline \multirow[b]{2}{*}{ Drug } & \multirow[b]{2}{*}{$\underline{\mathrm{N}}^{2}$} & & & \multicolumn{4}{|c|}{$\begin{array}{c}\text { Aggressive Responses/Hour } \\
\text { (mean } \pm \text { S.E.) }\end{array}$} & \\
\hline & & & Attac & cks & & $\begin{array}{l}\text { aring } \\
\text { ecs) }\end{array}$ & Vocal1: & zations \\
\hline Saline & 4 & ${ }^{\circ}$ & $13 \pm$ & 4 & 861 & \pm 311 & $352=$ & \pm 205 \\
\hline clonidine 3 & 6 & & $37 \pm$ & $4^{*}$ & 1808 & $\pm 253^{*}$ & $723:$ & \pm 67 \\
\hline
\end{tabular}

* Significantly different (p<0.05) from saline (student's $t$ test).

172 hours after last morphine injection.

2 Number of groups (four rats/group) tested.

3 clonidine was injected at a dose of $0.25 \mathrm{mg} / \mathrm{Kg} 30$ minutes before observations. 
was decided to investigate whether naloxone could likewise precipitate aggression in dependent rats. When administered to morphine-dependent rats four hours after their terminal dose of morphine, $4 \mathrm{mg} / \mathrm{kg}$ of naloxone abruptly precipitated signs of withdrawal as described in Table 20. Most notable were diarrhea, a loss in body weight and a profound hypothermia. Dependent rats given saline or apomorphine at this time showed no signs of withdrawal except for a mild hypothermia following apomorphine (Tab1e 20). When rats treated with naloxone were grouped, they failed to consistently show aggression even when a higher dose of naloxone ( 8 mg/kg) was used as illustrated in Table 21 . In contrast, when these rats were injected with a small dose of apomorphine (1.25 mg/kg) elther alone or in combination with naloxone four hours after their last morphine infection, they exhibited considerable aggression (Table 21). Amphetamine likewise produced some aggression, elther alone or when combined with naloxone (Table 21). In order to control for a possible direct anti-aggression action of naloxone, the drug was administered to 72 hour morphine-withdrawn rats. As can be seen from the data in Table 22 , naloxone falled to affect either the spontaneous 72 hour withdrawal aggression or the potentiation of aggression produced by apomorphIne. These data provide further evidence for a latent supersensitivity of dopamine receptors as a result of narcotic dependence. 
PRECIPITATED NARCOTIC WITHDRAWAL FOUR HOURS

AFTER TERMINAL MORPHINE INJECTION

\begin{tabular}{|c|c|c|c|c|c|c|c|}
\hline \multirow[b]{2}{*}{ Symptom } & \multicolumn{4}{|c|}{ Occurence ${ }^{1}$} & \multirow{2}{*}{\multicolumn{3}{|c|}{ Apomorphine $e^{2}(7)$}} \\
\hline & No $D$ & $\operatorname{Drug}^{2}(12)$ & $\mathrm{Na} 1 \mathrm{c}$ & oxone $e^{2}(16)$ & & & \\
\hline Diarrhea & \multicolumn{2}{|r|}{$1 / 12$} & \multicolumn{2}{|c|}{$15 / 16 * *$} & \multicolumn{3}{|c|}{$0 / 7$} \\
\hline Teeth Chattering & \multicolumn{2}{|r|}{$0 / 12$} & \multicolumn{2}{|c|}{$11 / 16 * *$} & \multicolumn{3}{|c|}{$0 / 7$} \\
\hline Weight Change $(g)^{3}$ & +8.0 & \pm 1.6 & $-4 \cdot 9$ & 1.6 & +7.4 & \pm & 1.2 \\
\hline $\begin{array}{l}\text { Temperature } \\
\text { Reduction }(\text { deg })^{4}\end{array}$ & 1.26 & $6 \pm 0.11$ & 4.95 & $0.49 *$ & 2.41 & \pm & $0.23 *$ \\
\hline Wet Shakes & 0.2 & \pm 0.1 & 3.0 & $0.6 *$ & 0.3 & \pm & 0.2 \\
\hline Ptosis & 5.0 & \pm 5.05 & 550.0 & $\pm 138.0 *$ & 45.0 & \pm 3 & 36.0 \\
\hline Writhes & 0.1 & \pm 0.1 & 0.3 & 0.2 & 0 & \pm & 0 \\
\hline
\end{tabular}

* Significantly different from no drug (student's t Test).

** Significantly different from no drugs (Chi Square)

1 Mean \pm S.E. or frequency of occurence out of total number observed.

2 Saline, naloxone ( $4 \mathrm{mg} / \mathrm{Kg}$ ) or apomorphine $(1.25 \mathrm{mg} / \mathrm{Kg}$ ) injected 4 hours after terminal dose of morphine $(135 \mathrm{mg} / \mathrm{Kg})$. Observations made for $30 \mathrm{~min}$., 10 minutes after injection. Number in ( ) denotes number of animals observed.

3 Change in body weight from weight immediately prior to last morphine injection.

4 Fall in body temperature from hyperthermia seen one hour after last morphine injection. 
TABLE 21

ELICITATION OF WITHDRAWAL AGGRESSION IN MORPHINE DEPENDENT RATS FOUR HOURS AFTER MORPHINE INJECTION

\begin{tabular}{|c|c|c|c|c|c|c|c|c|c|}
\hline \multirow[b]{2}{*}{ Drug $^{1}$} & \multirow[b]{2}{*}{$\begin{array}{l}\text { Dose } \\
(\mathrm{mg} / \mathrm{Kg})\end{array}$} & \multicolumn{6}{|c|}{$\begin{array}{c}\text { Responsęs/Hour } \\
\text { (mean }- \text { S.E.) }\end{array}$} & \multirow{2}{*}{\multicolumn{2}{|c|}{ Vocalizations }} \\
\hline & & $\underline{\mathrm{N}}^{2}$ & $\underline{\Delta t}$ & tacks & $\begin{array}{l}\text { Rear } \\
\text { (sed }\end{array}$ & $\begin{array}{l}\text { rin } \\
\text { (s) }\end{array}$ & & & \\
\hline None & - & 3 & 0 & & 2 & \pm & 2 & 0 & \\
\hline \multirow[t]{2}{*}{ Naloxone } & 4 & 8 & 0 & & 3 & \pm & 2 & $130 \pm$ & 48 \\
\hline & 8 & 9 & 4 & \pm 3 & 77 & \pm & 50 & $237 \pm$ & 69 \\
\hline Apomorphine & 1.25 & 4 & 46 & \pm 12 & 2472 & \pm & 558 & $1233 \pm$ & 189 \\
\hline \multirow[t]{2}{*}{ Amphetamine } & 2 & 8 & 7 & \pm 3 & 1347 & \pm & 496 & $423 \pm$ & 187 \\
\hline & 4 & 4 & 0 & & 3 & \pm & 3 & $42 \pm$ & 29 \\
\hline $\begin{array}{l}\text { Naloxone } \\
+ \\
\text { Apomorphine }\end{array}$ & $\begin{array}{l}4 \\
1.25\end{array}$ & 4 & 60 & \pm 14 & 2896 & \pm & 167 & $2162 \pm$ & 109 \\
\hline $\begin{array}{l}\text { Naloxone } \\
+ \\
\text { Apomorphine }\end{array}$ & $\begin{array}{l}8 \\
1.25\end{array}$ & 4 & 40 & \pm 9 & 2326 & \pm & 365 & $1793 \pm$ & 236 \\
\hline $\begin{array}{l}\text { Naloxone } \\
+ \\
\text { Amphetamine }\end{array}$ & $\begin{array}{l}4 \\
2\end{array}$ & 4 & 16 & \pm 4 & 978 & \pm & 306 & $1359 \pm$ & 460 \\
\hline
\end{tabular}

1

Drugs injected 4 hours after last morphine injection ( $135 \mathrm{mg}$ / $\mathrm{Kg}$ ). Apomorphine was injected 5 minutes, while naloxone was injected 10 minutes before observation. Amphetamine was injected 60 minutes prior to testing.

2

Number of groups tested ( 4 rats/group). 
TABLE 22

EFFECT OF APOMORPHINE OR NALOXONE ON 72 HOUR MORPHINE WITHDRAWAL AGGRESSION

\begin{tabular}{|c|c|c|c|c|c|}
\hline \multirow[b]{2}{*}{$\operatorname{Drug}^{2}$} & \multirow[b]{2}{*}{$\begin{array}{l}\text { Dose } \\
\left(\mathrm{mg} / \mathrm{Kg}_{\mathrm{g}}\right)\end{array}$} & \multirow[b]{2}{*}{$\mathrm{N}^{1}$} & \multicolumn{3}{|c|}{ 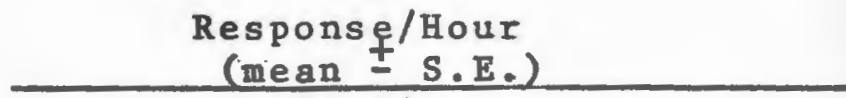 } \\
\hline & & & Attacks & $\begin{array}{l}\text { Rearing } \\
\text { (secs) }\end{array}$ & VocaIizations \\
\hline None & - & 6 & $30 \pm 4$ & $3296 \pm 185$ & I\&69 \pm 19.5 \\
\hline Apomorphine & 1.25 & 7 & $87 \pm 5$ & $3324 \pm 210$ & $1995 \pm 377$ \\
\hline \multirow[t]{2}{*}{ Naloxone } & 4 & 5 & $42 \pm 5$ & $3474 \pm 94$ & $2145 \pm 115$ \\
\hline & 8 & 6 & $28 \pm 3$ & $2294 \pm 248$ & $1562 \pm 222$ \\
\hline $\begin{array}{l}\text { Apomorphine } \\
+ \\
\text { Naloxone }\end{array}$ & $\begin{array}{l}1.25 \\
4\end{array}$ & 2 & $75 \pm 2$ & $3409 \pm 90$ & $1838 \pm 355$ \\
\hline & & & & & .. \\
\hline
\end{tabular}

1 Number of group tested (4 rats/group):

2 Apomorphine was injected 5 minutes before testing while naloxone was injected 10 minutes before testing. Injections were made 72 hours after last morphine Injection. 


\section{3) Protracted Aggression}

It is known that some of the signs of narcotic abstinence can be detected even weeks or months after withdrawal. in rats (Martin and sloan, 1971) and humans (Himmelsbach, 1941), a phenomenon known as protracted abstinence. Therefore, it was of interest to determine if aggression would 11kewise be present during protracted abstinence. Rats were made dependent on morphine and allowed to undergo continuous withdrawal for 30 days. When grouped, these rats exhibited aggression as shown in Table 23. The aggression was markedly enhanced by apomorphine ( $1.25 \mathrm{mg} / \mathrm{kg}$ ), a normally ineffective dose, and blocked by a small dose of morphine (10 mg/kg) (Table 23). A large (2 mA, $30 \mathrm{sec})$ lesion of the nigro-striatal bundle produced 24 hours before testing completely blocked the aggression. When the effect of the lesion was bypassed by stimulating the postsynaptic receptors with apomorphine, the aggression was reinstated (Table 23). Lestons of the adjacent medial forebrain bundle, which carries noradrenerglc and serotonergic fibers, did not significantly affect the aggression. These results suggest that the dopaminergic supersensitivity which develops during morphine dependence is a long lasting phenomenon. 
TABLE 23

EFTECT OF APOMORPHINE AND BRAIN LESIONS ON MORPHINE-WITHDRAWAL AGGRESSION.

\begin{tabular}{|c|c|c|c|c|}
\hline \multirow[b]{2}{*}{ Treatment } & \multirow[b]{2}{*}{$\mathrm{N}^{1}$} & \multicolumn{3}{|c|}{$\begin{array}{c}\text { Aggressive Responses/Hour } \\
\text { (mean } \underline{\text { S.E.) }}\end{array}$} \\
\hline & & Attacks/Bites & $\begin{array}{l}\text { Rearing } \\
(\operatorname{secs})\end{array}$ & Vocalizations \\
\hline & & ISOLATED CON? & ROLS ${ }^{2}$ & \\
\hline No Drug & 6 & $1 \pm 0.3$ & $52 \pm 48$ & $4 \stackrel{t}{-} 2$ \\
\hline Apomorphine 3 & 4 & 0 & $9 \pm 9$ & $14 \pm 3$ \\
\hline
\end{tabular}

72 HOUR MORPHINE WITHDRAWAL

No Drug $\quad 3 \quad 26 \pm 6 \quad 3599 \pm 12191 \pm 271$

30 DAY MORPHINE WITHDRAWAL

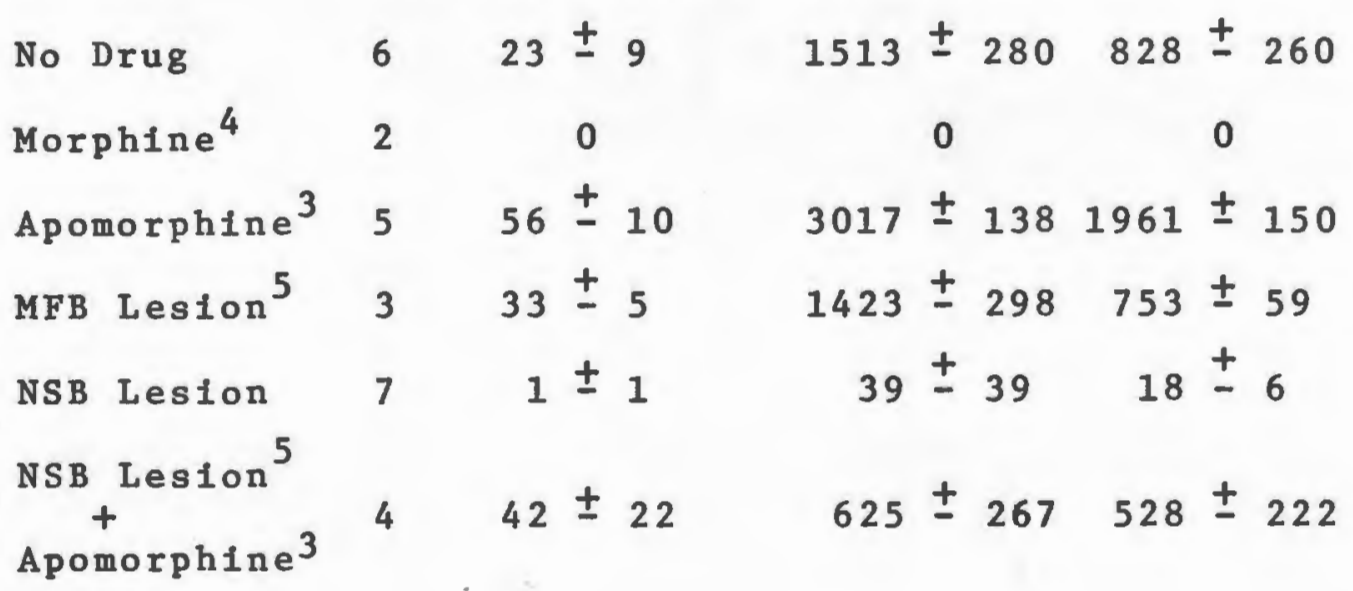

1 Number of groups ( 4 rats/group) tested.

2

Rats housed one per cage for 30 days.

$31.25 \mathrm{mg} / \mathrm{Kg}$

$410 \mathrm{mg} / \mathrm{Kg}, 30 \mathrm{minutes}$ prior to testing.

5 .Lesions were produced 24 hours before testing. MFB denotes medial forebrain bundle and NSB denotes nigrostriatal bundle. 


\section{Chronic Haloperidol}

If it is assumed that morphine-withdrawal aggression reflects a dopaminergic supersensitivity produced as a result of dopamine receptor blockade by morphine, then certain similarities should be noted between chronic morphine and chronic haloperidol, since haloperidol is generally regarded to block dopamine receptors (Carlsson and Lindquist, 1963; Anden et a1., 1970a). Tor this reason, haloperidol was administered to rats chronically and observations were made after the drug was discontinued.

Following the cessation of chronic treatment with haloperidol, rats exhibited an apparent supersensitivity to the stereotypy-producing actions of apomorphine (Table 24) or amphetamine (Table 25). It is widely believed that stereotypy produced by these drugs is dependent upon dopaminergic stimulation (Ernst, 1967; Snyder et a1., 1970). Doses of apomorphine $(1.25 \mathrm{mg} / \mathrm{kg})$ and amphetamine $(7.5 \mathrm{mg} / \mathrm{kg})$ were selected which produced a low to moderate degree of stereotypy in normal rats on the basis of pilot experiments. When these drugs were administered to rats three days after stopping chronic treatment with haloperidol, the stereotypy was significantly increased. When the rats treated chronIcally with haloperidol were grouped after discontinuation of the drug, no spontaneous aggression was observed (Table 26). However, when these rats receIved small doses of apomorphine $(0.63-2.5 \mathrm{mg} / \mathrm{kg})$, considerable aggression was 
TABLE 24

APOMORPHINE ${ }^{1}$ INDUCED STEREOTYPY IN RATS AFTER CHRONIC TREATMENT WITH HALOPERIDOL

\begin{tabular}{lcc} 
Group & N & $\begin{array}{c}\text { Stereotypy Score } \\
(\text { Median } \pm \text { S. E. })\end{array}$ \\
\hline $\begin{array}{l}\text { Contro1 } \\
2\end{array}$ & 16 & $7 \pm 1.3$ \\
$\begin{array}{c}\text { Chronic } \\
\text { Haloperido1 }\end{array}$ & 18 & $12 \pm 1.3 *$ \\
\hline
\end{tabular}

* Significantly different $(p<0.025)$ from control (Mann-Whitney U-Test).

$11.25 \mathrm{mg} / \mathrm{kg}, 10 \mathrm{minutes}$ before testing.

2 Nalve rats.

372 hours after last haloperidol injection. 
TABLE 25 AMPHETAMINE $^{1}$ INDUCED STEREOTYPY IN RATS AFTER CHRONIC
TREATMENT WITH HALOPERIDOL

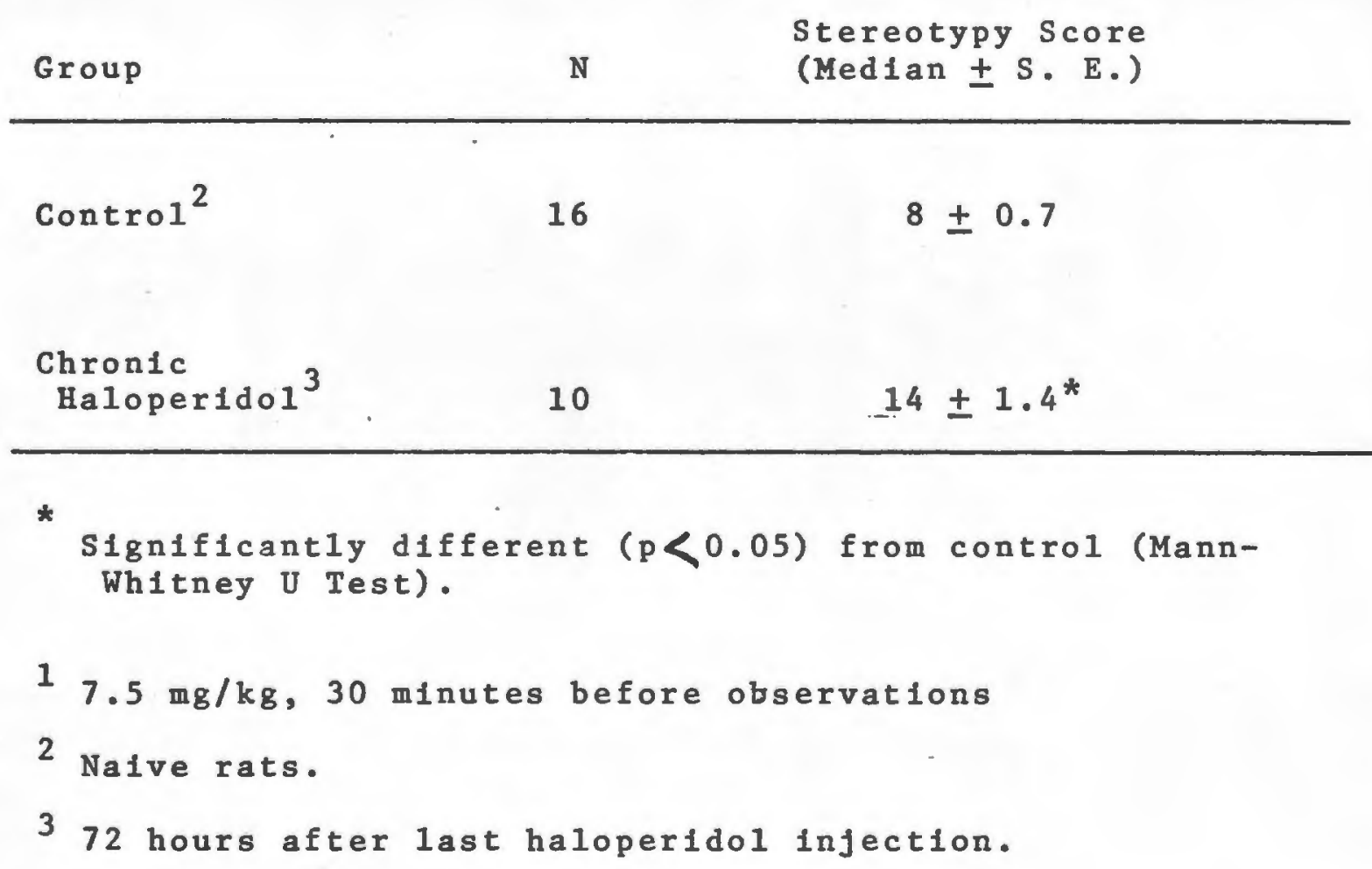


TABLE 26

APOMORPHINE INDUCED AGGRESSION FOLLOWING CHRONIC HALOPERIDOL ADMINISTRATION

\begin{tabular}{|c|c|c|c|c|c|c|}
\hline \multirow[b]{2}{*}{ Drug } & \multirow{2}{*}{$\begin{array}{l}\text { Dose } \\
\text { (mg/kg) }\end{array}$} & \multirow{2}{*}{$\begin{array}{l}\text { Days of } \\
\text { W1th- } \\
\text { drawa1 } 1\end{array}$} & \multirow[b]{2}{*}{$\mathrm{N}^{2}$} & \multicolumn{3}{|c|}{$\begin{array}{c}\text { Aggressive Responses/Hour } \\
(\text { mean }+ \text { S. E.) }\end{array}$} \\
\hline & & & & Attacks & Rearing & Vocalizations \\
\hline \multicolumn{7}{|c|}{ Isolated Controls ${ }^{3}$} \\
\hline Saline & - & - & 4 & 0 & 0 & 0 \\
\hline Apomorphine & 2.5 & - & 4 & $1 \pm 1$ & $22 \pm 22$ & $19 \pm 3$ \\
\hline \multicolumn{7}{|c|}{ Chronic Haloperido $1^{4}$} \\
\hline Saline & - & 3 & 5 & 0 & $7 \pm 7$ & $4 \pm 4$ \\
\hline \multirow[t]{8}{*}{ Apomorphine } & 1.25 & 2 & 3 & 0 & 0 & 0 \\
\hline & 2.5 & 2 & 2 & $13 \pm 10$ & $1606 \pm 1475$ & $895 \pm 830$ \\
\hline & 1.25 & 3 & 3 & $1 \pm 1$ & $17 \pm 17$ & $6 \pm 6$ \\
\hline & 2.5 & 3 & 8 & $59 \pm 13$ & $1734 \pm 303$ & $1359 \pm 310$ \\
\hline & 0.64 & 7 & 3 & $6 \pm 3$ & $678 \pm 340$ & $440 \pm 259$ \\
\hline & 1.25 & 7 & 3 & $22 \pm 6$ & $2668 \pm 349$ & $1730 \pm 666$ \\
\hline & 2.5 & 7 & 4 & $78 \pm 17$ & $2747 \pm 154$ & $1951 \pm 313$ \\
\hline & 2.5 & 18 & 4 & $8 \pm 8$ & $528 \pm 512$ & $312 \pm 310$ \\
\hline
\end{tabular}


TABLE 26 continued

1 Refers to number of days after terminal injection of haloperidol.

2 Number of groups tested ( 3 rats per group).

3 Housed one per cage for three weeks.

4 Animals infected chronically with haloperidol as described in Methods. 
observed (Table 26). This indicated that rats who exhibit dopaminergic supersensitivity, exhibit a supersensitivity to the aggression eliciting effects of apomorphine as well, which would be consistent with the explanation proposed in morphine withdrawal. However, in contrast to morphine-withdrawal aggression, there was no spontaneous aggression after chronic haloperidol. The aggression produced by apomorphine was particularly intense seven days after "withdrawal" but had subsided by 18 days (Table 26). If amphetamine was $1 \mathrm{n}$ jected instead of apomorphine, aggression was observed infrequently and inconsistently (Table 27), in contrast to the effect seen during morphine withdrawal. There was virtually no aggression even with a dose of amphetamine as high as $16 \mathrm{mg} / \mathrm{kg}$.

Despite the fact that aggression was not elicited by amphetamine in rats after chronic haloperidol, the locomotor stimulation produced by amphetamine was increased. It can be seen in Figure 5 that a normally ineffective dose of amphetamine $(0.2 \mathrm{mg} / \mathrm{kg})$ produced a significant stimulation of locomotor activity after chronic treatment with haloper1do1. This effect of amphetamine was further analyzed in Figure 6. It should be noted, first of all, that rats which had been treated with haloperidol chronically exhibited an Increased spontaneous activity after drug administration was discontinued when compared with drug-free rats. (This was also noted when chronically haloperidol treated rats were compared with rats treated chronically with $0.3 \%$ tartaric 
TABLE 27

FAILURE OF AMPHETAMINE TO INDUCE AGGRESSION IN RATS CHRONICALLY TREATED WITH HALOPERIDOL

\begin{tabular}{|c|c|c|c|c|c|c|c|c|}
\hline \multirow[b]{2}{*}{ Drug } & \multirow{2}{*}{$\begin{array}{l}\text { Dose } \\
(\mathrm{mg} / \mathrm{kg})\end{array}$} & \multirow{2}{*}{$\begin{array}{l}\text { Days of } \\
\text { W1th- } \\
\text { drawa } 1\end{array}$} & \multirow{2}{*}{$\mathrm{N}^{2}$} & \multicolumn{5}{|c|}{$\begin{array}{c}\text { Aggressive Responses/Hour } \\
(\operatorname{mean}+\text { S.E.) }\end{array}$} \\
\hline & & & & Attacks & \multicolumn{2}{|c|}{ Rearing } & \multicolumn{2}{|c|}{ Vocallzations } \\
\hline Saline & - & 3 & 4 & 0 & & 0 & & 0 \\
\hline \multirow[t]{3}{*}{ d-amphetamine } & 4 & 3 & 3 & 0 & & 0 & & 0 \\
\hline & 8 & & 5 & $2 \pm 2$ & 72 & \pm 72 & 69 & \pm 44 \\
\hline & 16 & & 1 & 0 & & 0 & & 5 \\
\hline \multirow[t]{2}{*}{ 1-amphetamine } & 8 & 3 & 3 & $5 \pm 5$ & 772 & \pm 772 & 96 & \pm 90 \\
\hline & 16 & & 2 & $2 \pm 1$ & 84 & \pm 62 & 65 & \pm 18 \\
\hline \multirow[t]{2}{*}{ d-amphetamine } & 8 & 7 & 2 & 0 & & 0 & & 0 \\
\hline & 16 & & 2 & 0 & & 0 & & 0 \\
\hline \multirow[t]{2}{*}{ 1-amphetamine } & 8 & 7 & 2 & 0 & & 0 & & \pm 6 \\
\hline & 16 & & 2 & 0 & & 0 & & \pm 6 \\
\hline apomorphine & 2.5 & 7 & 3 & $72 \pm 19$ & 3016 & \pm 341 & 1801 & \pm 295 \\
\hline
\end{tabular}


TABLE 27 continued

1 Refers to days since last haloperidol infection.

2 Number of groups tested ( 3 rats per group).

3 Amphetamines were injected 30 minutes prior to observations. Apomorphine was infected 5 minutes before testing. 
Fig. 5--Effect of amphetamine on locomotor activity in normal and chronic haloperidol treated rats. Amphetamine was injected, at the indicated doses, to normal rats and to rats who had recelved their last of a series of haloperidol injections three to six days prior to testing. Activity was measured for one hour, 60 minutes after the amphetamine injection. Each point is the mean $\pm S$. E. for 10 rats. Asterisks (*) indicate that the dose significantly increased locomotor activity $(\mathrm{p}<0.05)$ compared with the corresponding saline ( $0 \mathrm{mg} / \mathrm{kg}$ ) control (Dunnet's Test, Winer, 1971). 


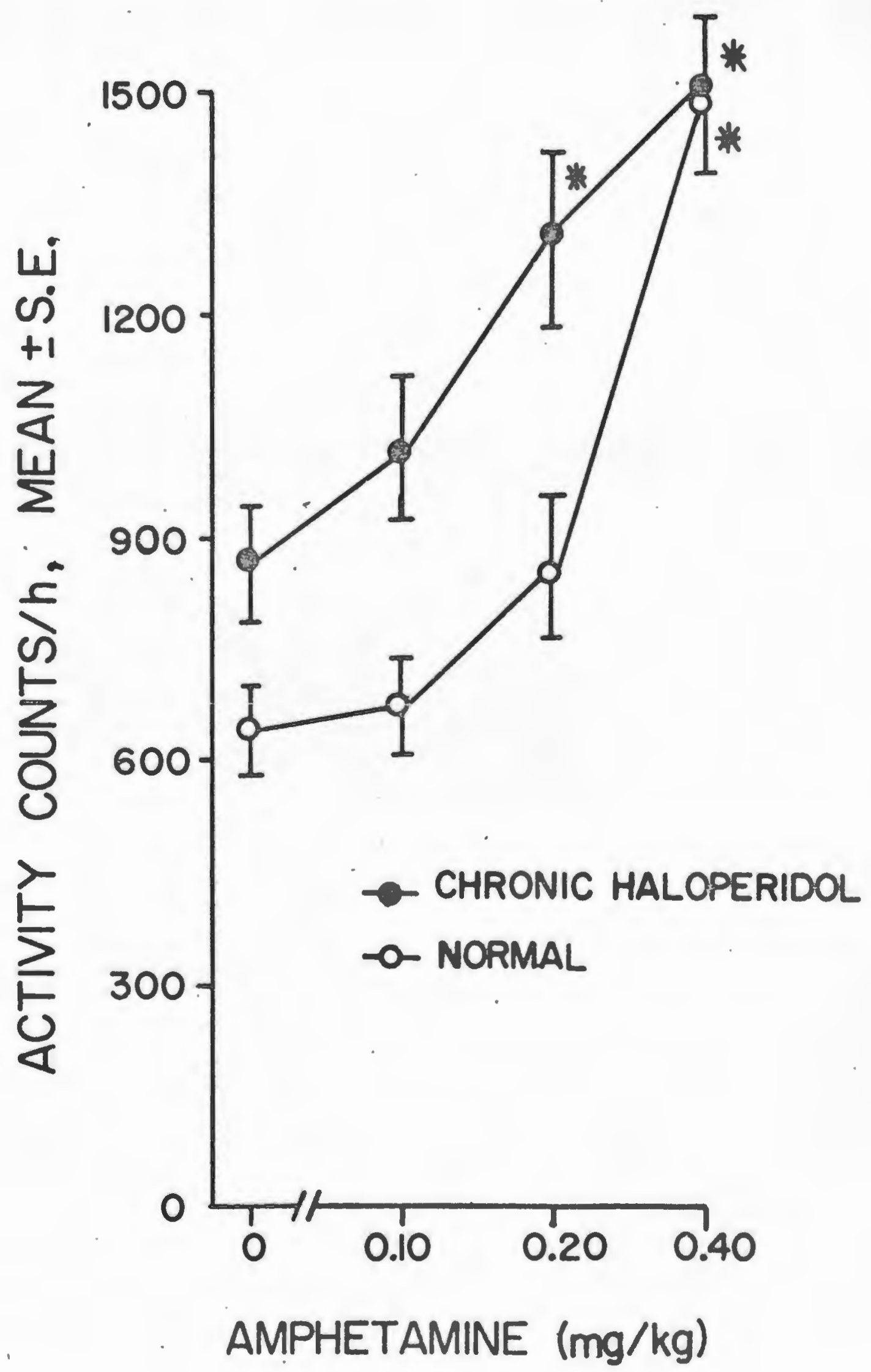


Fig. 6--Effect of amphetamine, apomorphine or alpha-methy1-p-tyrosine (MPT) on locomotor activity in normal and chronically haloperidol treated rats. The rats were chronically treated with haloperidol, then withdrawn for three to five days before locomotor activity testing. Amphetamine ( $1.6 \mathrm{mg} / \mathrm{kg}$ ) was injected 60 minutes before testing, while apomorphine $(0.5 \mathrm{mg} / \mathrm{kg})$ was injected 10 minutes before testing. MPT was injected either 4 hours or 4 and 16 hours before testing. Locomotor activity in haloperidol treated rats was significantly higher than control rats in each comparison $(p<0.01)$. MPT significantly reduced locomotor activity in all groups (MPT vs. no MPT, p<0.01). After MPT treatment, amphetamine induced locomotor stimulation was not higher than the control activity of normal rats, but was significantly higher ( $p<0.01$ ) in haloperidol treated rats, except when these rats were given two doses of MPT (stripped bars). Apomorphine failed to increase locomotor activity in normal rats $(p>0.05)$, but did produce stimulation in the chronic haloperidol group $(\mathrm{p}<0.05)$. 


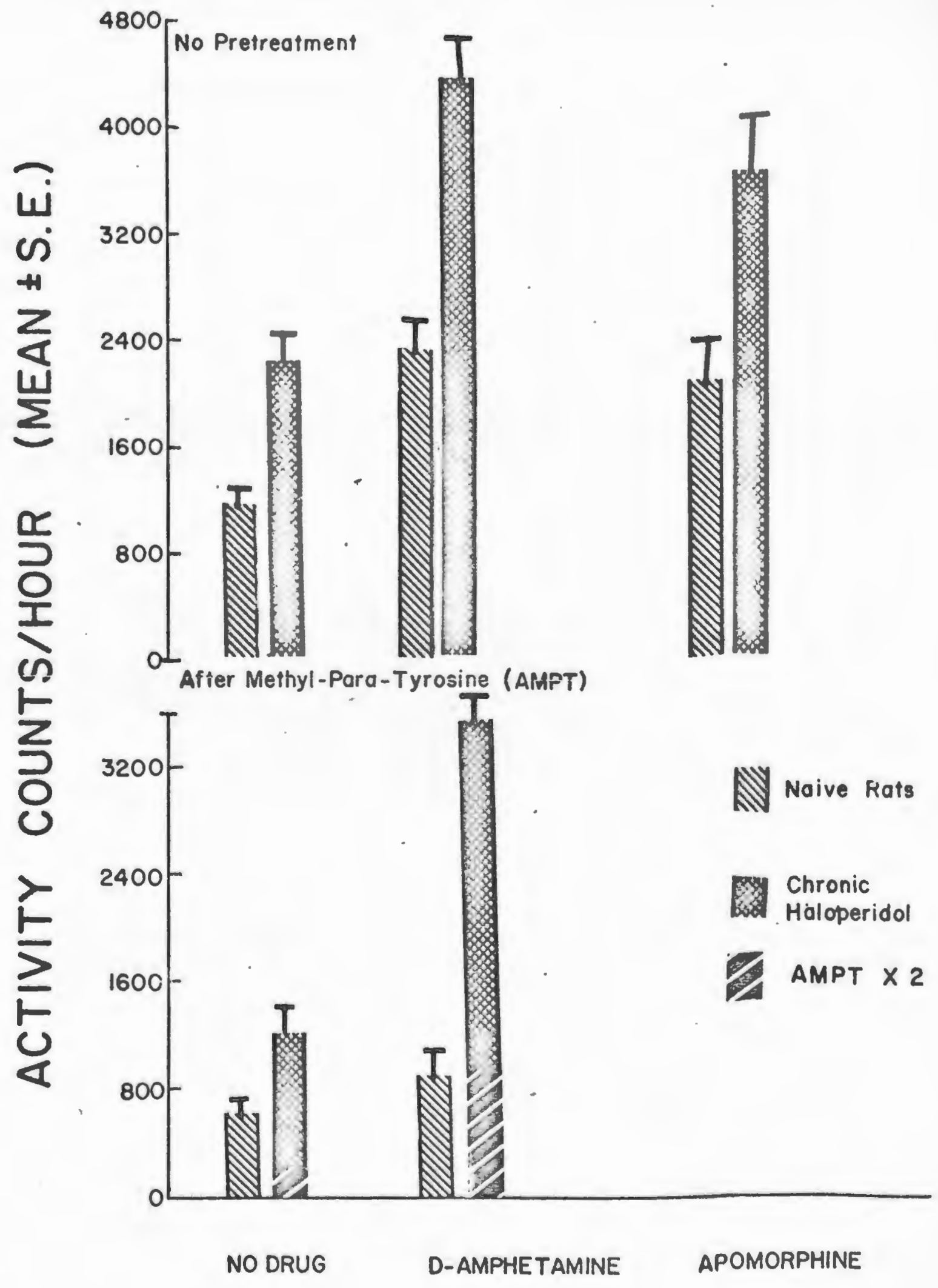


acid, the vehicle for haloperidol, in pilot experiments.) In addition, they exhibited an enhanced response to the stimulation produced by apomorphine and to the maximally effective dose of amphetamine $(1.6 \mathrm{mg} / \mathrm{kg})$. When alpha-methyl-ptyrosine (MPT) was administered (200 mg/kg, four hours before testing), it reduced the spontaneous locomotor activity and blocked the stimulation produced by amphetamine in normal rats (Figure 6). However, amphetamine was still capable of producing a marked stimulation after MPT in the chronic haloperidol group, and only a very large dose of MPT (two doses of $200 \mathrm{mg} / \mathrm{kg}$ each, 12 hours apart) was capable of blocking the amphetamine in these rats. These results further support the idea of a dopaminergic supersensitivity after chronic haloperidol.

The influence of drugs having an effect on acetylcholine was also studied. Dexetimide was more effective in producing locomotor stimulation following chronic haloperidol. As shown in Figure 7, normally ineffective doses of dexetimide produced a significant increase in locomotor activity when tested four to six days after termination of repeated haloperidol treatment. In contrast, pilocarpine was less effective in reducing locomotor activity after chronic haloperidol as illustrated in Figure 8. Pilocarpine normally depresses activity at a dose of $4 \mathrm{mg} / \mathrm{kg}$, but this dose did not reduce activity in the chronic haloperidol group. These results are suggestive of a cholinergic hyposensitivity after chronic haloperidol. Pentobarbital was equally 
Fig. 7--Effect of dexetimide on locomotor activity in normal and chronic haloperidol treated rats. Dexetimide was injected at the indicated doses into normal rats and to rats who had recelved their last of a series of haloperidol injections three to six days before testing. Activity was measured for one hour, 30 minutes after injection. Asterisks (*) Indicate that the dose significantly increased ( $p<0.05$ ) locomotor activity compared with the corresponding saline (0 mg/kg) control group (Dunnet's Test, Winer, 1971). 


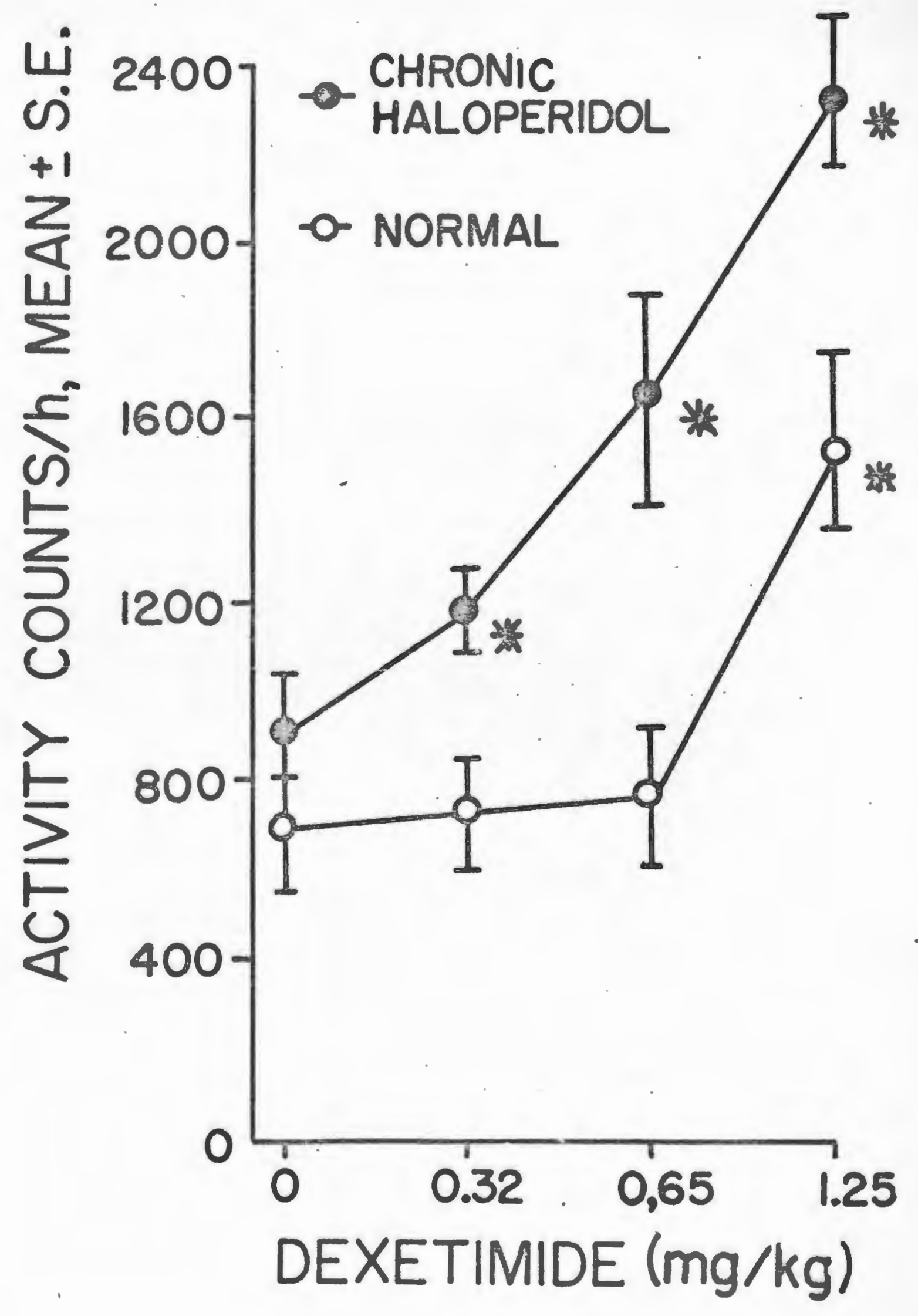


Fig. 8--Effect of pilocarpine on locomotor activity in normal and chronic haloperidol treated rats. Pilocarpine was injected at the indicated doses to normal rats and to rats who had recelved their last of a series of haloperidol injections three to six days before testing. Activity was measured for one hour, ten minutes after the injection. Asterisks (*) Indicate that the dose significantly (p 0.05) decreased locomotor activity compared with the corresponding saline ( $0 \mathrm{mg} / \mathrm{kg}$ ) contro1 group (Dunnet's Test, Winer, 1971). 


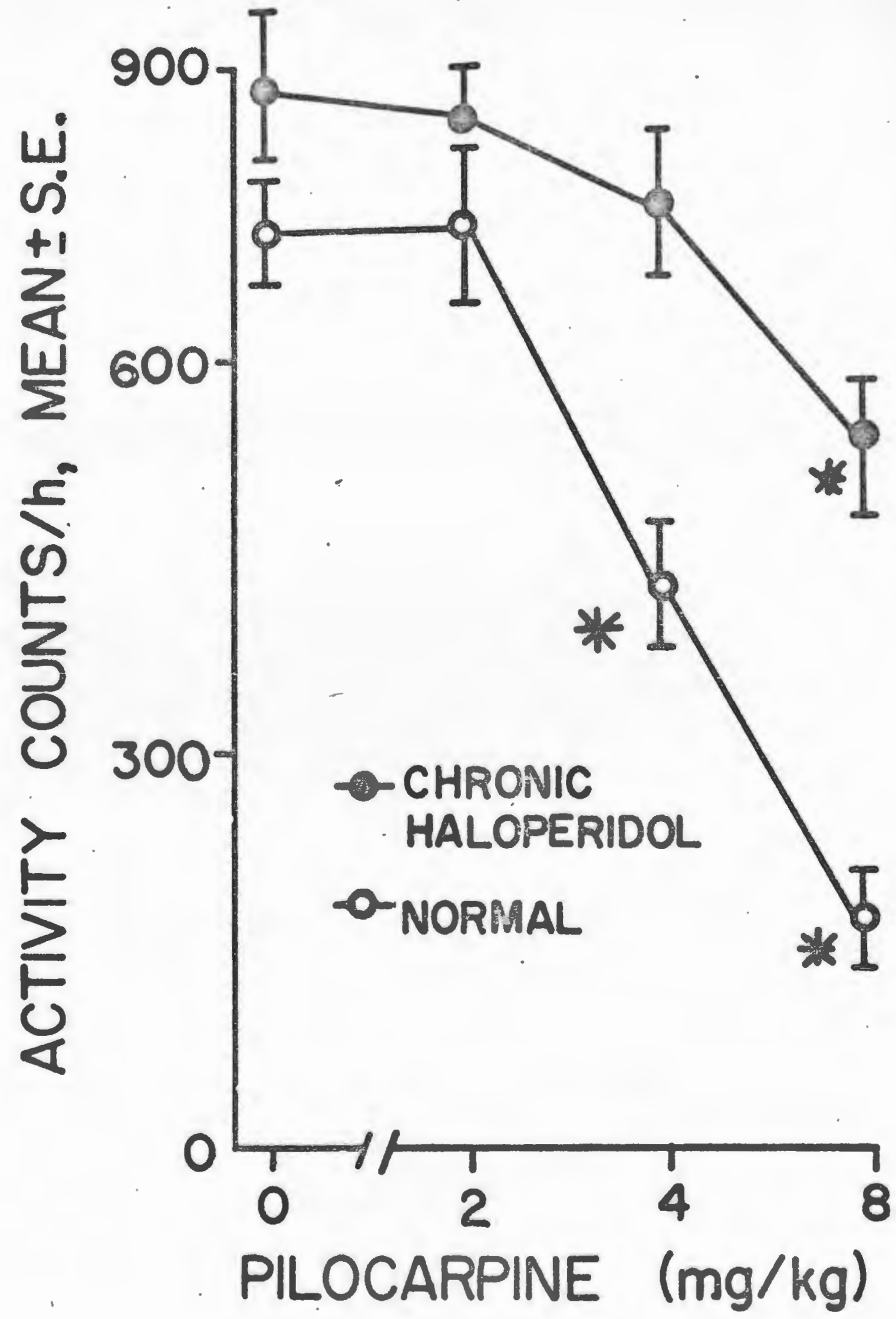


effective in both normal and haloperidol "withdrawn" rats (Tab1e 28).

Lastly, the dynamics of striatal dopamine were directly measured following termination of chronic treatment with haloperidol, in order to determine if neurochemical substantiation for the dopaminergic supersensitivity could be obtained. It can be seen from Table 29 that neither the steady state level nor the turnover of striatal dopamine differed in the chronic haloperidol group when compared with naive rats. However, doses of apomorphine which produced no change in dopamine turnover in normal rats, significantly reduced striatal dopamine turnover when given seven days after the terminal dose of haloperidol (Figure 9), supporting a concept of dopaminergic supersensitivity. 
TABLE 28

EFFECT OF PENTOBARBITAL ON LOCOMOTOR ACTIVITY IN RATS AFTER CHRONIC TREATMENT WITH HALOPERIDOL

\begin{tabular}{|c|c|c|c|}
\hline \multirow[b]{2}{*}{ Group } & \multirow[b]{2}{*}{$\mathbf{N}$} & \multicolumn{2}{|c|}{$\begin{array}{l}\text { LOCOMOTOR ACTIVITY COUNTS/HOUR } \\
(\text { Mean }+ \text { S. E.) }\end{array}$} \\
\hline & & Saline & Pentobarb1ta1 \\
\hline Control ${ }^{2}$ & 5 & $690 \pm 68$ & . $432 \pm 48 *$ \\
\hline Chronic Haloperido ${ }^{3}$ & 5 & $891 \pm 66$ & $656 \pm 82 *$ \\
\hline
\end{tabular}

* Significantly different ( $<<0.05)$ from corresponding saline control (Student's $t$ test).

1 Pentobarbital ( $10 \mathrm{mg} / \mathrm{kg}$ ) was inkected 10 minutes before testing.

2 Naive rats.

3 Three to six days after last haloperidol injection. 
TABLE 29

EFFECT OF CHRONIC HALOPERIDOL TREATMENT ON STRIATAL DOPAMINE

$$
\begin{array}{cc}
\text { CHRONIC } \\
\text { CONTROLS }^{1} \text { HALOPERIDOL }
\end{array}
$$

$\begin{array}{lcr}\begin{array}{l}\text { Striatal Dopamine Level } \\ (\text { nmol/gram) }\end{array} & 43.7 \pm 2.7 & 39.9 \pm 4.8 \\ \begin{array}{l}\text { Dopamine Turnover } \\ (\text { nmol/g/hour) }\end{array} & 11.7 \pm 1.3 & 12.3 \pm 1.7\end{array}$

Values are mean and standard error based upon four animals used in each group. There was no difference (p 0.05) between controls and chronic haloperidol groups on either measure (student's $t$ test).

1 Naive rats.

2 Rats treated chronically with haloperidol and then left drug free for seven days before testing. 
Fig. 9--Effect of apomorphine on striata1 dopamine turnover in normal rats and after chronic haloperidol. Rats were sacrificed 30 minutes after apomorphine or saline. The drugs were injected into either normal rats or rats who had received haloperidol for 17 days. Tests were made seven days after the last haloperidol injection. The dose of 0.63 $\mathrm{mg} / \mathrm{kg}$ significantly reduced the striatal dopamine turnover in the chronic haloperidol group ( $<<0.05)$ while the dose of $2.5 \mathrm{mg} / \mathrm{kg}$ was the minimum effective dose in normal rats. Points are mean + S. E. for four rats. Dunnet's Test was used for statistical evaluations. 


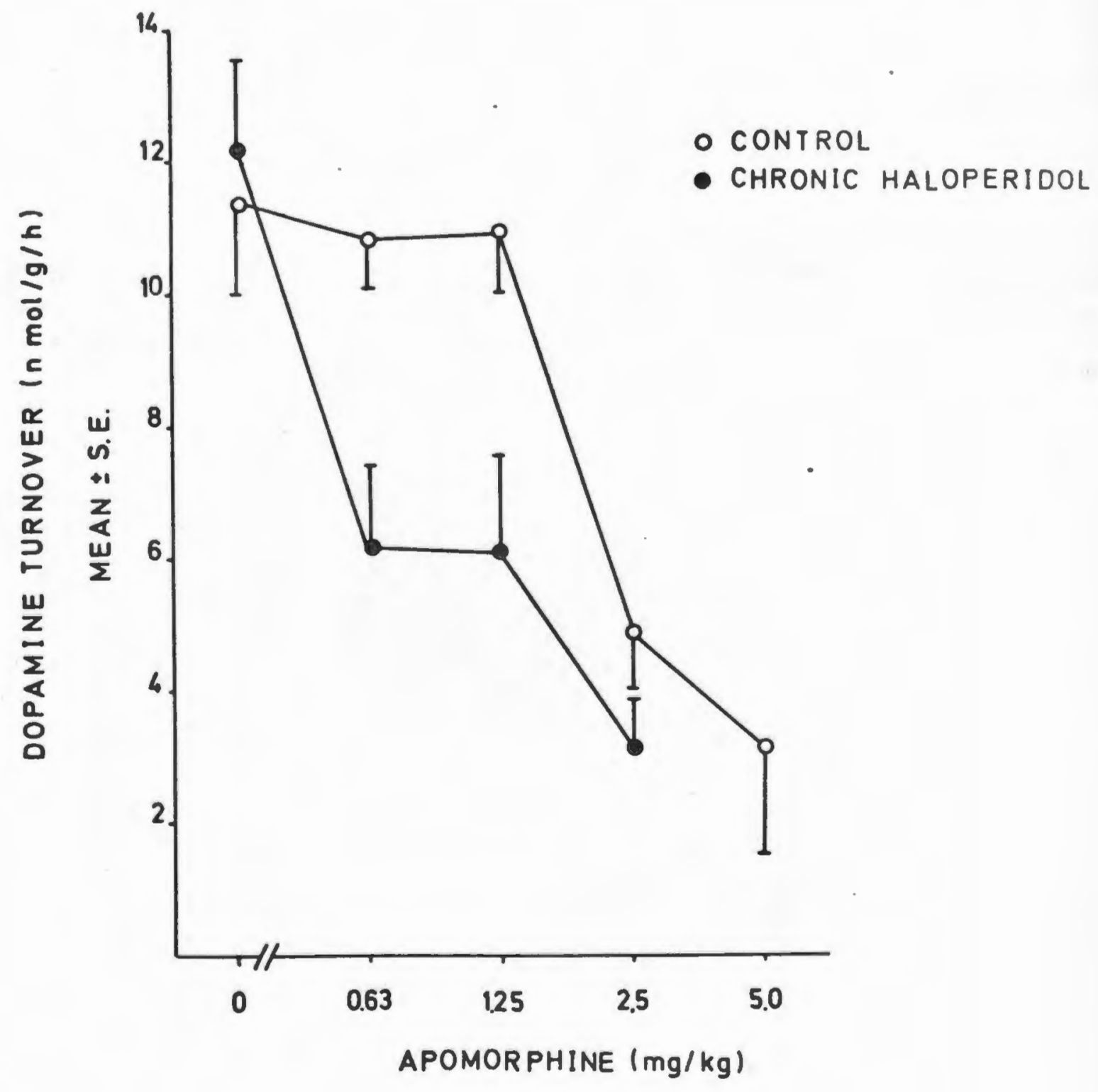




\section{DISCUSSION}

The discussion of the results will be divided into the same three sections used in the results (1.e., apomorphineinduced aggression, morphine withdrawal aggression, chronic haloperidol) examining the role of the various neurotransmitters in the behavior. In addition, there will be a section which will specifically compare haloperidol with morphine.

In brief, the postulated mechanisms behind drug-induced aggression may be summarized as shown in Table 30. Dopamine plays a major role in the initiation and maintenance of the behavior, with acetylcholine and serotonin having an antagonistic effect. Stimulation by norepinephrine appears to facilitate the aggression, but further experimentation is necessary to clearly establish this effect. In general, apomorphine-induced aggression and morphine-withdrawal aggression appear to operate under the same mechanisms.

During morphine withdrawal, there is spontaneous and amphetamine stimulated aggression in contrast to the behaviors noted after chronic haloperidol, despite the fact that after either treatment there is evidence of dopaminergic supersensitivity. Several possibilities for this apparent contradiction will be discussed. In brief, these 
TABLE 30

EFFECT OF BRAIN NEUROTRANSMITTERS IN DRUG INDUCED AGGRESSION

Transmitter

TYPE OF AGGRESSION

$\begin{array}{cc}\text { Apomorphine } & \text { Morphine } \\ \text { Induced } & \text { Withdrawal }\end{array}$

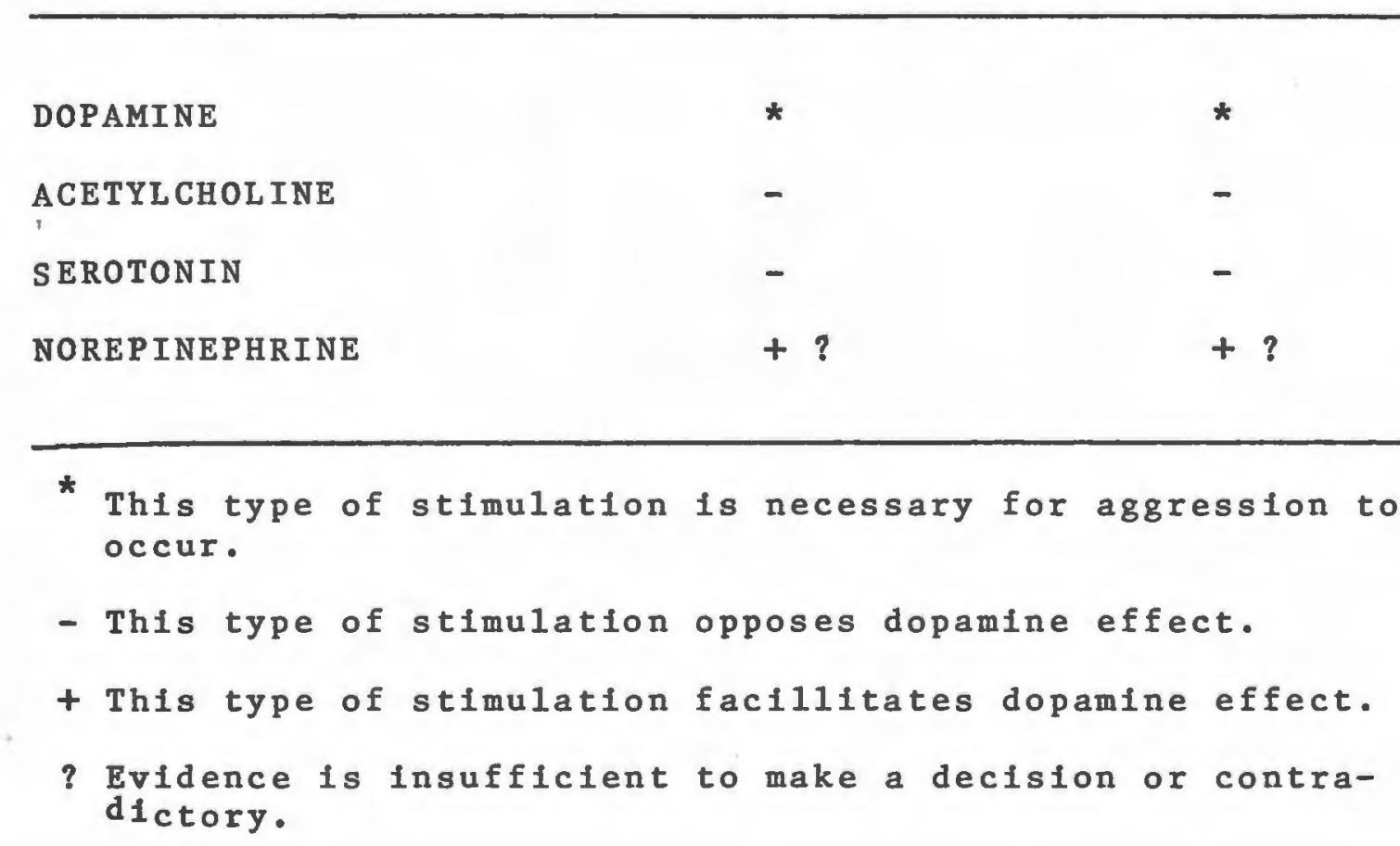


explanations are that chronic haloperidol may lead to an Inhibition of neurotransmitter release in selected brain areas; the supersensitivity after each drug may be qualitatively or quantitatively different; morphine may direct1y interfere with compensatory mechanisms to alter the normal balance in brain function; or any combination of these effects.

\section{A. Apomorphine-Induced Aggression}

1) Role of Dopamine

Apomorphine induced aggression in a dose-dependent manner. This was rellably established using three different parameters of aggression. It is generally accepted that apomorphine stimulates dopamine (DA) receptors on the basis of blochemical (Anden et a1., 1967), histochemical (Anden et a1., 1967), behavioral (Ernst, 1967) and neuroanatomical (Price and Fibiger, 1974) studies. In addition, large doses of apomorphine have pre-synaptic actions on dopamine neurons, causing both an inhibition of DA uptake and a dose-dependent release (Ferris et $\underline{\text { al1. }}$, 1974).

These mechanisms may be considered to be responsible for the aggression produced by apomorphine, since it was found that the aggression was blocked by neuroleptics, drugs which are believed to block DA receptors with little if any direct effect on norepinephrine (Nyback et al., 1968; Anden et a1., 1970a). In addition the aggression was shown to be intensifled by amphetamine. Previous reports have also shown that 
the aggression produced by apomorphine plus reserpine is increased by Intraventricular dopamine (Patni and Dandiya, 1974).

Evidence for a dopaminergic basis for drug-induced aggression is also supported by several reports in the 11terature. For example, the aggression in mice elicited by amphetamine is blocked by neuroleptics while drugs which inhibit the synthesis of norepinephrine (NE), such as FLA-63, or block NE receptors, such as phenoxybenzamine do not have a clear-cut blocking action (Hasselager et a1., 1972). S1m11arly, fighting was observed in rats after treatment with DOPA plus reserpine and a peripheral decarboxylase inhibitor, which produced a substantial elevation of brain DA (Benkert et a1., 1973a). Elevation of brain NE levels with pargyline plus dihydroxyphenylserine falled to produce fighting (Benkert et a1., 1973a). In addition, the aggression produced by ET-495 was increased by L-DOPA (Butterworth et a1., 1975). A detailed search of the literature revealed that drug-induced aggression not associated with elevated DA receptor activity is rarely, if ever, observed. Therefore, it may be concluded that DA plays a primary role in drug-induced aggression.

2) Cholinergic - Dopaminergic Interaction

Cholinergic activity in the CNS produces a variety of effects on aggression, depending on the model studied. For example, local injection of cholinergic compounds into the 
hypothalamus (Myers, 1964) or amydgala (A111kmets et a1., 1969) of cats produces a rage response which includes attacks on the experimenter. Similarly, anticholinergic drugs are potent inhibitors of isolation-induced aggression in mice (Janssen et a1., 1960). On the other hand, cholinergic drugs suppress the hyperirritability resulting from septal lestons (Stark and Henderson, 1972), while the anticholinergic, scopolamine, when combined with an inhibitor of mono amine oxidase, results in aggression-1ike responses in rats (Randrup and Munkvard, 1969). In the present experiment, pllocarpine blocked both the aggression which occurs during morphine withdrawal and the aggression Induced by injections of apomorphine, while dexetimide, an anticholinergic compound (Janssen et $\underline{a 1} ., 1971$ ) devold of serotonergic or noradrenergic blocking properties (Janssen, 1971) enhanced both forms of aggression. Furthermore, moderately effective doses of oxyperomide and pilocarpine were synergistic. These results would argue that the effect of cholinergic stimulation in drug-induced aggression is antagonistic to dopaminergic stimulation. The blockade of aggression by pilocarpine appeared to be centrally mediated since it was partially reversed by anticholinergic drugs having a central action but was unaffected by the peripherally acting anticholinergic 1sopropamide (Janssen and Niemegeers, 1967) at a dose which blocked the pilocarpine-induced diarrhea.

The extensive evidence for a balance between acetylcho- 
IIne and dopamine in the CNS (see Section II.C.1) suggests an explanation for the apparent paradoxical effects of cholinergic stimulation on aggression. Acetylcholine (ACh) has a widespread distribution in the CNS and 1 t may be possible that activity in certain brain areas enhances, while activity in other brain areas reduces aggression. It is interesting in this regard that cholinergic drugs injected into the central nucleus of the amygdala suppress the rage response produced by cholinergic stimulation of the hypothalamus (Decsi et a1., 1969). It is possible that the proposed cholinergic inhibitory system directly interacts with a dopaminergic system which initiates the aggressive responding. Therefore, aggression elicited by DA hyperactivity - as a result of apomorphine injection or morphine withdrawal - is modulated by the activation of a cholinergic inhibitory system in a manner analogous to the control of motor movements proposed by Klawans (1968). Pilocarpine would synergize with this cholinergic system, while dexetimide would antagonize it. It should be remembered from Section II.C.1 that many other behaviors produced as a result of DA stimulation are antagonized by $\mathrm{ACh}$, such as stereotypy and locomotor stimulation (Mennear, 1965; Arnfred and Randrup, 1968; Klawans et a1., 1970) while the locomotor stimulation produced by anticholInergics is dependent on DA (Thornburg and Moore, 1973b). However, neurochemical support for this hypothesis is lacking. Dopaminergic drugs reduce the release of ACh in the striatum (Sethy and Van Woert, 1974) while anticholinergics 
reduce the utilization of DA (O'Keefe et a1., 1970; Haubrich and Goldberg, 1975). It would be expected from the above hypothesis that DA stimulation should facilitate the release of ACh. It should be pointed out that the neurochemical ananyses were made only in the striatum, which may not be the area responsible for aggression. Interestingly, amphetamine causes an increase in ACh output from the cortex, which is prevented by alpha-methy1-p-tyrosine (Nistri et a1., 1972). Alternatively, it may be hypothesized that the reduced $\mathrm{ACh}$ as a result of DA stimulation is the mechanism which triggers the aggression, or that still other interactions are necessary.

In addition to the effects enumerated above, low doses of anticholinergic drugs were also able to partially reverse the blockade of aggression produced by the neuroleptics but not the blockade produced by morphine. Anticholinergics also reverse the increase in dopamine turnover produced by the neuroleptics (Anden, 1972) as well as some of the anti-psychotic activity of these drugs (SIngh and Smith, 1973).

\section{3) Dopaminergic-Serotonergic Interaction}

Evidence in favor of a serotonergic system which antagonizes aggression was also provided by this study. It was predicted that amphetamine, which releases dopamine (Besson et a1., 1971; Chiueh and Moore, 1973), would Intensify apomorphine induced aggression. Although amphetamine did in- 
crease the aggression occuring after threshold doses of apomorphine, no aggression was elicited by the combination of amphetamine and sub-threshold doses of apomorphine. It should be remembered that release of serotonin by amphetamine reduced the locomotor stimulation produced by the drug (Breese et a1., 1974). It was demonstrated that the combination of amphetamine plus cyproheptadine, a serotonin receptor blocker, and a sub-threshold dose of apomorphine did result in significant aggression, while cyproheptadine at the dose used had no effect of 1ts own. This suggests that serotonin release antagonizes aggression. However, cyproheptadine is non-specific in its effect, since it is anticholinergic and antihistaminic in addition to being anti-serotonergic and these other effects would have to be ruled out before making a definite conclusion.

An additional test of this hypothesis utilized p-chloroamphetamine (PCA) which produces a long-lasting depletion of brain serotonin (Sanders-Bush et a1., 1972). This drug produced a marked reduction in the threshold dose of apomorphine necessary for eliciting aggression. Recent evidence (Yunger et a1., 1974) suggests that large doses of PCA cause a degeneration of substantia nigra cells, so that it may be interpreted that the apomorphine effect is due to a dopaminergic denervation supersensitivity after PCA. Alternatively, it may be hypothesized that PCA causes reduced activity in a serotonin-containing inhibitory system and therefore removes an inhibition of dopaminergic activity. Consistent 
with the latter interpretation are studies which show that parachlorophenylalanine (PCPA), an inhibitor of serotonin biosynthesis (Koe and Weissman, 1966), elicits aggression after treatment with DOPA in mice (Lycke et a1., 1969) and rats (Benkert et $\underline{a 1}, 1973 \mathrm{~b}$ ). Furthermore, three days after an injection of $20 \mathrm{mg} / \mathrm{kg}$ of $\mathrm{PCA}$, there is spontaneous aggression in mice (Gianutsos and Lal, 1975).

Apomorphine causes a transient elevation in serotonin turnover which is antagonized by neuroleptics (Grabowska et a1., 1973). Furthermore, activity in the dopaminergic caput nuclei caudati rostromedialis of the caudate nucleus is abolished by activation of serotonergic nuclei in the caudate (Cools, 1974). These results suggest that dopaminergic activity activates a serotonergic system which attenuates the effects of the dopaminergic stimulation that initiated the cycle.

In addition, the disruption of behavior produced by scopolamine is antagonized by elevating brain serotonin with 5-hydroxytryptamine (Swonger and Rech, 1972), while pilocarpine increases brain serotonin turnover (Haubrich and Reid, 1972). These findings suggest a co-operation between $\mathrm{ACh}$ and serotonin in the CNS. Since both neurotransmitters appear to reduce drug-induced aggression, such a co-operative relationship would be consistent with the data presented. 
4) Effect of Clonidine

clonidine dose-dependently and reliably elicited aggression when combined with a sub-threshold dose of apomorphine. It was previously reported that a very high dose of clonfdine ( $1 \mathrm{mg} / \mathrm{kg}$ ) could induce some aggression in rats after apomorphine or ET-495 (Senau1t, 1974), while a smaller dose $(0.2 \mathrm{mg} / \mathrm{kg})$ increased the "ferocity" and motor activity of rats produced by ET-495 while inhibiting the stereotypy (Butterworth et al., 1975). The present results confirmed and extended the subjective impressions gained by these fixed dose experiments. Clonidine, by itse1f, did not produce aggression in rats.

clonidine is considered to be a centrally acting noradrenergic stimulant since it decreases the rate of depletion of norepinephrine in the brain after alpha-methyl-ptyrosine (Anden et al., 1970b). This effect was measured both biochemically and histochemically. However, clonidine In vitro is also reported to inhibit the stimulation induced release of norepinephrine from brain slices (Starke and Montel, 1973) and block the increase in cyclic AMP formation by norepinephrine (Vetulani et al., 1975), which suggests that clonidine may have an anti-adrenergic effect. Similarly, clonidine in low doses decreased the self-stimulation of the medial forebrain bundle, which is usually enhanced by norepinephrine (Vetulani et a1., 1975). Clonidine does not affect the turnover of dopamine in the striatum (Anden et a1., 1970b; Rochette and Bradet, 1975). 
If it is assumed that clonidine is a noradrenergic agonist, it may be argued that dopaminergic activity initiates noradrenergic activity (or vice versa) and that this combination leads to the expression of aggression. Some evidence which would support this notion is as follows: Apomorphine-induced aggression is blocked by large doses of the alpha-adrenergic receptor blocker, phenoxybenzamine (Senault, 1974) or the beta noradrenergic receptor blocker, L-propranolol (Butterworth et a1., 1975). In mice, a very large dose of clonidine induces aggression by itself, but this aggression is blocked by haloperidol and not by phenoxybenzamine. Neurochemically, apomorphine increases the turnover of norepinephrine, apparently by an indirect action through stimulation of dopamine receptors (Persson and Waldeck, 1970). On the other hand, Geyer and Segal (1974) reported that intracerebral injections of dopamine enhance shock induced aggression, while intracerebral norepinephrine reduces theaggression. Similarly, it was shown in REM-sleep deprived rats that aggression could be elicited by apomorphine, L-DOPA or phenoxybenzamine (Carlini and Lindsey, 1974). These latter results suggest that norepinephrine reduces aggression.

An alternative explanation may be that the clonidine effect is mediated by serotonin. Clonidine, at a dose which does not affect serotonin metabolism on 1 ts own ( $1 \mathrm{mg} / \mathrm{kg}$ ), antagonized the increase in the accumulation of the serotonin 
metabolite, 5-hydroxyindoleacetic acid produced by apomorphine (Maj et al., 1973). Thus, it may be argued that, as above, stimulation of dopamine receptors produces a compensatory antagonistic activation of serotonin neurons. clonidine, therefore, would exacerbate the aggression induced by apomorphine by preventing the release of serotonin which would normally antagonize the aggression in a manner analogous to the arguement for PCA (above).

\section{B. Morphine Withdrawa1 Aggression}

Aggression during morphine withdrawal has been considered to reflect a dopaminergic supersensitivity in the CNS since it is enhanced by apomorphine (Puri and La1, 1973a), amphetamine (Thor, 1969; Lal et a1., 1971) and L-DOPA (Puri and Lal, 1973a) and reduced by haloperidol (Puri and Lal, 1973a). The degree of aggression was shown to be dependent on the amount of morphine administered during the addiction process, since increasing the terminal dose or the duration of addiction increased the amount of aggression seen during withdrawa1. The aggression reaches its maximum intensity at 72 hours of withdrawal, in contrast to other signs of withdrawal which peak earlier. However, the onset of withdrawal hyperactivity was found to be well correlated with the appearance of the aggression.

The aggression was reduced by morphine, haloperidol or lesions of the dopaminergic nigro-striatal bundle, which pro- 
vides further support for the role of dopamine in the withdrawal aggression. The withdrawal aggression was affected In qualitatively the same way as apomorphine-induced aggression. It was found to be blocked by morphine, haloperidol or pilocarpine and increased by dexetimide, apomorphine, amphetamine and clonidine, Implying that the same mechanisms responstble for apomorphine-induced aggression also govern morphine-withdrawal aggression. However, in contrast to these effects in nalve rats, anticholinergics falled to antagonize the blockade of aggression produced by neuroleptics in addicted rats. Th1s will be discussed further below.

\section{1) Elicited Aggression}

Naloxone precipitated withdrawal in addicted rats when administered within a few hours of the last morphine infection, but the symptamatology had some differences from the withdrawal produced by witholding of morphine injections. In the naloxone precipitated withdrawal, there was evidence of teeth chattering and lacrimation which are not seen during spontaneous withdrawal and the naloxone treated rats showed more diarrhea and fewer "wet shakes" than spontaneously withdrawn rats (see Glanutsos et a1., 1975). In addition, the naloxone-treated rats falled to consistently show aggression during the time in which they exhibited other signs of withdrawal. It should be pointed out that rats undergoing etther naloxone-precipitated or spontaneous withdrawal are hyperirritable and will vocalize and struggle violently 
and bite the experimenter when handled. However, when grouped, the naloxone treated rats did not consistently fight with each other. Since the onset of withdrawal aggression in spontaneously withdrawn rats occurs later than other signs, it perhaps may be expected that aggression during naloxone-precipitated withdrawal may occur at a later time as well. Furthermore, the possibility remains, as yet untested, that naloxone may compress the withdrawal period such that aggression may emerge earlier than normal after naloxone treatment (that is to say before 48-72 hours of withdrawal) but not during the time of peak drug effect. Naloxone's action could not be attributed to a direct antiaggression action since it falled to affect either the 72 hour withdrawal aggression or the weak elicitation of aggression produced by amphetamine at four hours of withdrawal. However, it is interesting that naloxone causes an increase In brain dopamine levels in morphine dependent rats (Iwamoto et a1., 1973), which is suggestive of decreased transmitter release. Clearly, such an effect would prevent the expression of withdrawal aggression.

In contrast to the effect of naloxone, apomorphine administered as 11 ttle as four hours after the last morphine injection was capable of eliciting intense aggression in addicted rats without producing other signs of withdrawal. The aggression was produced either in the presence or absence of naloxone. These results strongly suggest that the 
addicted rats have a latent dopaminergic supersensitivity which remains masked during the addiction process while morphine infections are continued. Despite the fact that there are supersensitive DA receptors at the time of withdrawal, the aggression st111 does not emerge unt11 48-72 hours 1ater. It is possible, although untested, that the supersensitivity functionally increases in intensity over the course of withdrawal as a compensation for other withdrawal signs. It is interesting that directly and indirectly acting dopaminergic agonists reduce the severity of withdrawal, except for aggression which is intensified (Gianutsos, Hynes and Lal, in preperation). Exactly how this may take placẹ is highly speculative, but Marshall and Smith (1974) showed that, in mice, caudate tyrosine hydroxylase activity is depressed at 36 hours of withdrawal, but returns to normal by 72 hours. Thus, one could predict that aggression emerges as the biphasic changes in tyrosine hydroxylase activity return towards normal.

\section{2) Protracted Aggression}

Following the chronic administration of morphine, spontaneous aggression as well as the supersensitivity to apomorphine was evident at 30 days of withdrawal. This suggests that the neuronal changes associated with narcotic dependence and withdrawal are long-lasting phenomena. Lesioning of the nigro-striatal bundle (NSB), which is the mafor dopaminergic fiber tract, reduced the aggression, while lesioning the ad- 
jacent medial forebrain bundle was ineffective. When a normally Ineffective dose of apomorphine was administered to dependent rats with the NSB lesion, the aggression was reinstated which demonstrated that the normal pre-synaptic nerve stimulation of receptors could be successfully substituted by a direct chemical stimulation in the lesioned rats and further demonstrated the presence of supersensitive dopamine receptors. The supersensitivity was also demonstrated neurochemically since rats which were withdrawn for 30 days required a significantly smaller dose of apomorphine to produce a decrease in striatal dopamine turnover (reported in Gianutsos et $\underline{\text { al }}$., 1974).

\section{Chronic Haloperidol}

Following prolonged treatment with haloperidol, rats exhibited an enhanced sensitivity to the actions of apomorphine and amphetamine in stereotypy and locomotor activity. Since these effects are believed to be dependent on DA stimulation (Ernst, 1967; Snyder et al., 1970; Costa et a1., 1972; Thornburg and Moore, 1973a), it may be proposed that a dopaminergic supersensitivity develops during chronic haloperidol treatment. Since haloperidol. is believed to block dopamine receptors (Nyback et al., 1968; Anden et a1., 1970a; Koe, 1974), this supersensitivity may reflect a compensatory adaptation to the prolonged receptor blockade. This supersensitivity was also demonstrated neurochemically by a shift to the left in the apomorphine dose-response curve for re- 
ducing dopamine turnover in the striatum. Normally ineffective doses of apomorphine were capable of reducing striatal dopamine turnover after chronic haloperidol treatment.

In addition, there was a marked shift to the left of the apomorphine-induced aggression dose-response curve after repeated injections with haloperidol. However, in constast to the effect of chronic morphine, there was no spontaneous or amphetamine-induced aggression after chronic haloperidol, despite the presence of supersensitive dopamine receptors. It is interesting that amphetamine induces aggression after chronic morphine (Thor, 1969; Lal et all, 1971) or chronic ethanol (Mann and La1, 1975) both of which are abused drugs, but falled to induce aggression after prolonged treatment with haloperidol, a non-abused drug. The reason for these effects is not clear, but several explanations may be offered. For example, it may be proposed that haloperidol stabilizes the pre-synaptic dopamine neuronal membrane (Janssen, 1967). Such a stabilization may prevent the release of dopamine by stimulation of the nerve or by amphetamine so that the amount of dopamine reaching the receptor is insufficient to produce aggression. Such an effect, if it in fact occurs, would have to be long-1asting and specific for brain areas which are responsible for aggression, since other actions of amphetamine (stereotypy, locomotor stimulation) are enhanced after chronic haloperidol. A long-lasting alteration of presynaptic dopamine mechanisms may be an important aspect of the haloperidol action, working in concert with receptor 
blockade for the alleyiation of schizophrenia. Clearly, it would not be beneficial to treat schizophrenics with haloperIdol only to produce supersensitive receptors, requiring ever increasing doses of an antagonist and which, in the absence of receptor blockade, would result in an exacerbation of symptoms when the drug was discontinued.

Evidence to support this hypothesis is lacking. However, Seeman and Lee (1975) demonstrated that neuroleptics block the coupling between nerve Impulse and dopamine release, which was correlated with anti-psychotic potency. Alternatively, the interaction between DA and other neurotransmitters (e.g. serotonin, $A(h)$ may be different after chronic haloperidol or morphine (see below). Lastly, the supersensitivity occuring after chronic haloperidol may be qualitatively or quantitatively different from the supersensitivity occuring after chronic morphine (see below).

Long-term neuroleptic therapy reportedly results in tardive dyskinesias in humans which is associated with dopaminergic supersensitivity and a cholinergic subsensitivity (Klawans, k973; Gerlach et a1., 1974). A similar relationship was demonstrated with drug effects on locomotor activity in rats following chronic haloperidol in the present experiment. The stimulation produced by dopaminergic agonists (amphetamine, apomorphine) was enhanced in these rats. A similar effect was reported in mice (Thornburg and Moore, 1974; Von Volghtlander et a1:, 1975). In addition, the 
stimulation of locomotor activity produced by the anticholinergic, dexetimide, was likewise enhanced. Conversely, the decrease in locomotor activity produced by cholinergic stimulation (pilocarpine) was antagonized after chronic treatment with haloperidol. A gneralized increase in CNS excitability could be proposed as the mechanism responsible for these effects, except that the effect of pentobarbital in reducing locomotor activity was identical in normal and in chronically haloperidol treated rats. This would also rule out an explanation based on interference with drug metabolism.

The locomotor stimulation produced by both amphetamine (Costa et al., 1972; Thornburg and Moore, 1973̣a; Hollister et al., 1974) and anticholinergics (Thornburg and Moore, 1973b) is dependent on dopaminergic stimulation. However, this is not a general phenomenon, since the improvement of shuttle-box avoldance by amphetamine requires catecholamines, while the similar effect of the anticholinergic, scopolamine, is not dependent on catecholamines (Rech and Moore, 1968). Several anticholinergics are known to block the reuptake of dopamine (Coyle and Snyder, 1969) and, although this has not been studied with dexetimide, it could provide an explanation for the enhanced stimulatory effects since the dopamine which would be prevented from returning to the pre-synaptic neuron for Inactivation would react with supersensitive receptors. However, it has been demonstrated that anticholinergics produce their effects on locomotor stimulation by an anticholinergic rather than an uptake-blocking mechanism (Thornburg 
and Moore, 1973c). Purthermore, the decreased effectiveness of pilocarpine could not be accounted for by a mechanism which is based on blockade of catecholamine uptake. Since cholinergic drugs antagonize the stimulation produced by dopaminergic drugs (Mennear, 1965), while anticholinergics apparently facilitate the expression of DA activity held in check by cholinergic stimulation, it may be concluded that the results can be explained by a reduced sensitivity of the cholinergic receptor as a result of chronic neuroleptic treatment (also see below).

\section{Comparison of Haloperidol and Morphine}

Haloperidol and morphine share a number of similar behavioral and biochemical actions related to dopamine. For example, both drugs produce a state of immobility (Costall and Naylor, 1974); block the stereotypy produced by dopaminergic agonists (Janssen et a1., 1965; Puri et al., 1973); block jumping produced by a combination of DOPA + amphetamine (Colpaert et al., 1975); Inhibit conditioned avoldance responding (Niemegeers et a1., 1964); Inhibit brain self stimulation (Wauquier et a1., 1974; 1975); and Inhibit the aggression produced by DOPA + amphetamine (Lal et a1., 1972) by shock (La1 et a1., 1975a) and, as shown here, the aggression produced by apomorphine or morphine withdrawal. In addition, both morphine and haloperidol increase the turnover of brain dopamine (see II.B.3); increase the activity of dopamine stimulated adenylate cyclase 
(Iwatsubo and Clouet, 1975); and increase plasma prolactin levels while decreasing plasma luetinizing hormone levels (C1emens et a1., 1974; Dobrin and Mares, 1974). After chronic treatment with either drug, behavioral and neurochemical evidence of dopaminergic supersensitivity is noted (this thesis and Puri and Lal, 1973a; 1974b; Tarsy and Baldessarini, 1973). In addition, repeated treatment with either drug results in locomotor stimulation during withdrawal (this thesis) and facilitates recovery from lesions of the lateral hypothalamus (Hynes et a1., 1975). Moreover, morphine withdrawn rats are tolerant to the increase in striatal dopamine turnover produced by either drug (Puri and Lal, 1974a).

However, equally striking are the differences between the two drugs. Most notable, of course, is the well recognized ability of morphine to produce physical dependence and reinforcing properties. Recently, G11ck and Cox (1975) demonstrated that very small doses of haloperidol would be self administered by the rat, but it is generally recognized that haloperidol is not abused and does not produce physical dependence. In addition, the behavioral effects of morphine and haloperidol are differentially antagonized by different compounds. Anticholinergics reverse the blockade of aggression produced by neuroleptics, but not that produced by morphine. On the other hand, morphine's actions were antagon-. ized by naloxone, but haloperidol's were not. Similar results have been demonstrated for the catalepsy produced by narcotics and neuroleptics (Kuschinsky and Hornykiewicz, 
1972; Costal1 and Naylor, 1974) and for the blockade of mouse jumping induced by DOPA + amphetamine (Colpaert et al., 1975) and the blockade of brain self-stimulation (Wauquier et al., 1974; 1975) produced by efther drug. This points up an important difference in the dopaminergic/cholinergic balance between these two compounds and suggests that the reduction of dopaminergic activity by morphine may be indirect. Furthermore, the ability of anticholinergics to reverse the neuroleptic-induced blockade of aggression was lost after chronic treatment.

It was pointed out previously that chronic treatment with elther haloperidol or morphine produces measurable dopaminergic supersensitivity, but only treatment with the latter results in spontaneous aggression. One possible explanation has already been offered (see previous section). Alternatively, there may be differences in the supersensitivity produced by the two drugs. Kuschinsky (1975) observed that morphine dependent rats falled to show an enhanced sensitivity to apomorphine-induced stereotypy, while a dopaminergic supersensitivity was demonstrated neurochemically. some unpublished, preliminary observations in our laboratory would be consistent with these results. However, following chronic haloperidol, enhanced apomorphine-induced stereotypy is readily observed (this thesis and Schelkunov, 1967;

Tarsy and Baldessarini, 1973). Furthermore, the supersensitivity produced by morphine appears to be longer lasting 
than the comparable supersensitivity produced by haloperidol (N.B. apomorphine-induced aggression appeared to fade 18 days after stopping haloperidol, while the morphine effect lasted for at least 30 days of withdrawal). This suggests that morphine and haloperidol may produce a qualitatively different supersensitivity, perhaps by interacting with different types or groups of receptors.

It should be remembered that after chronic haloperidol, a subsensitivity to cholinergic stimulation was noted. Since neuroleptics, as a result of DA receptor blockade, increase the release of $\mathrm{ACh}$ (Stadler et al., 1973; Guyenet et al., 1975; McGeer et a1., 1974) one may hypothesize a three stage process of adaptation to CNS DA receptor blockade. In the first stage, since blockade of DA receptors by neuroleptics reduces the stimulation of those receptors (and increases the release of $\mathrm{ACh}$ ), the post-synaptic neuron would attempt to compensate by sending messages to the dopamine neuron to increase the synthesis and release of DA in order to override the effect of the neuroleptic or other drug. There is ample evidence that this occurs after neuroleptics (Anden et a1., 1971; Carlsson and Lindquist, 1963). Since this method is inefficient over the long-term, the post-synaptic neuron could also compensate by becoming supersensitive to stimulation by DA. In the meantime, the cholinergic sensitive receptors could also compensate for the unusally large number of messages reaching them by becoming less sensitive to cholinergic stimulation. By these adaptations, a new 
homeostatic balance is developed. ' (Incidentally, if one was to speculate that an enhanced release of ACh from DA sensitive sites was responsible for the anti-aggression action of the neuroleptics, it would explain the antagonism by anticholinergics of the neuroleptic effect.) Although this hypothesis was presented in terms of DA and ACh, it would work equally we11 for DA and serotonin (1.e., DA receptor blockade would reduce the need for serotonin to antagonize DA and so the serotonin neuron would decrease its activity. In the long run, one would predfct that the serotonin receptors per se would become supersensitive due to a lack of stimulation and this would contribute to the lack. of aggression during "withdrawal" of haloperidol).

Morphine, on the other hand, may be thought of as interfering with and modifying the normal compensatory proceses, so that a more drastic or entirely different mechanism for adaptation would be called into play. There are some differences in the effects of morphine and haloperidol on ACh. It is believed, for example, that morphine blocks the release of ACh (Beleslin and Polak, 1965), although this effect has been questioned (Mullin and Phi111s, 1974). A resulting cholinergic supersensitivity has been proposed as being responsible for narcotic withdrawal (Paton, 1969). A1though it is known that ACh utilization is increased during withdrawal of narcotics (Domino and Wilson. 1973), this effect does not appear to follow the temporal pattern of the 
abstinence syndrome (Mullin and Phillis, 1974). It has been noted that neuroleptics accelerate the turnover of $\mathrm{ACh}$ in the striatum, but do not affect cortical ACh turnover (Trabucchi et al., 1974), while morphine decreases the turnover of ACh in the cortex, with no effect on the striatum (Cheney et $\underline{\text { I }}$., 1974). This has been attributed to a combined direct effect on morphine on $\mathrm{ACh}$ neurons and an indirect effect mediated by DA (Cheney et a1., 1974). Furthermore, Yarbrough (1974) was unable to demonstrate an increased sensitivity of cortical neurons to $\mathrm{ACh}$ when measured six hours after a terminal injection of morphine, but the efficacy of atropine in blocking the effects of $\mathrm{ACh}$ was reduced (another apparent distinction between morphine and haloperidol, since the behavioral effects of anticholinergics were increased after chronic haloperidol).

In spite of the seeming cholinergic supersensitivity, there are some inconsistencies. The ratio of the effective anti-aggression dose of pilocarpine to haloperidol in blocking apomorphine-induced aggression in naive rats was $2: 1$ ( $5 \mathrm{mg} / \mathrm{kg}: 2.5 \mathrm{mg} / \mathrm{kg}$ ). The ratio of these drugs in blocking morphine withdrawal aggression was $16: 1$ (10 $\mathrm{mg} / \mathrm{kg}: 0.64 \mathrm{mg} / \mathrm{kg})$. Thus, despite the fact that there is supposed to be a dopaminergic supersensitivity and a cholinergic supersensitivity during narcotic withdrawal, pilocarpine (cholinergic stimulation) was relatively much less effective than dopaminergic receptor blockade in decreasing morphine withdrawal aggression 
than in decreasing apomorphine-induced aggression in naive rats. Thus it may be proposed that the normal compensatory balance between $\mathrm{ACh}$ and $\mathrm{DA}$ is interferred with during morphine addiction and the central cholinergic stimulation may not be relied upon following chronic morphine. In other words, while cholinergic receptors in the simpler circuitry of the peripheral nervous system may adapt by becoming more sensitive to cholinergic stimulation, central cholinergic neurons, which are under a more complex regulation, may be bypassed and become functionally inoperative. If so, withdrawal aggression may be evident because of the functional lack of a cholinergic inhibitory system.

In addition, morphine is known to increase the turnover of serotonin in the brain (Way et a1., 1968; Yarbrough et al., 1971; Haubrich and Blake, 1973). There is apparently no tolerance to this effect when rats are made dependent by morphine injections (Bowers and Kleber, 1971). Administration of PCPA prevents the development of morphine tolerance and physical dependence (Way et a1., 1968). If one proposes that the increased turnover of serotonin is a consequence of increased release of serotonin directly produced by morphine, this may contribute to the anti-aggression action of the drug and provide an explanation for the aggression during withdrawa1. It may be further assumed that this continual re1-. ease produces a decrease in sensitivy of serotonin receptors, analogous to the arguement made for subsensitive cholinergic receptors after chronic haloperidol (above), and/or an addi- 
tional further compensatory increase in sensitivity of dopamine receptors. Under this assumption, very sensitive DA receptors would be associated with subsensitive serotonergic receptors during morphine withdrawal, in contrast to the assumption made for chronic haloperidol in which both sets of receptors were assumed to be supersensitive.

Lastly, the recent discovery of endogenous morphine11ke peptides in the brain (Hughes, 1975) introduces another posstble mechanism for the direct or indirect actions of narcotics. Although the exact significance of these endogenous compounds is unclear at this time, their importance cannot be ruled out. 
VI SUMMARY AND CONCLUSIONS

1. Apomorphine induced aggression in a dose-dependent manner in naive rats. The aggression was blocked, dose-dependently, by haloperidol, oxyperomide and morphine and increased by amphetamine. These results suggest that the aggression is the result of hyperactivity of dopaminergic systems in the brain.

2. The blockade of aggression by haloperidol or oxyperomide was reversed by anticholinergics, but not by naloxone. Morphine's anti-aggression action was reversed by naloxone but not by anticholinergics. This suggests that the neuroleptics and morphine produce a blockade of aggression by different mechanisms, perhaps involving a cholinergic component in the case of neuroleptics.

3. Apomorphine-induced aggression was blocked dose-dependent1y by pilocarpine and increased by dexetimide. In addition, It was enhanced by pretreatment with p-chloroamphetamine or clonidine, while the amphetamine effect was enhanced by cyproheptadine. These results suggest that the aggression is modulated by activity in cholinergic, serotonergic and. possibly, noradrenergic areas. Cholinergic and serotonergic stimulation appears to inhibit aggression while noradrenergic stimulation may facilitate the aggression. 
4. Morphine withdrawal aggression was noted when withdrawal was inftiated by witholding of morphine injections. The aggression was blocked by morphine, haloperidol or by lesions of the dopaminergic nigro-striatal bundle and was enhanced by apomorphine. When withdrawal was precipitated by naloxone, aggression was not observed when other signs of withdrawal stress were noted. However, a small dose of apomorphine was able to elicit aggression when given as little as four hours after the last morphine injection. These results further provide evidence that chronic morphine administration results in dopaminergic supersensitivity and that this is reflected in the withdrawal aggression, but suggests that mere removal of morphine from its "receptors" by naloxone is insufficient to elicit the aggression.

5. Morphine withdrawal aggression was noted even 30 days after withdrawal was inftiated and was enhanced by small doses apomorphine and blocked by nigro-striatal lesions, suggesting that the supersensitivity produced during narcotic dependence is a long-lasting phenomenon.

6. Morphine withdrawal aggression pharmacologically resembled apomorphine-induced aggression since both were enhanced by dexetimide, amphetamine and clonidine and both were reduced by haloperidol, morphine and pilocarpine. However, the blockade of aggression produced by haloperidol was reversed by anticholinergics in naive rats, but not in morphine-withdrawnrats, suggesting that an alteration in a cholinergic 
inhibitory system or in the balance between dopaminergic and cholinergic activity develops during the course of narcotic addiction.

7. Following discontinuation of long-term treatment with haloperidol, enhanced apomorphine or amphetamine induced stereotypy or locomotor stimulation was observed, leading to the conclusion that this treatment induces supersensitivity of dopamine receptors. This was further supported by neurochemical evidence which showed that the dose response curve for apomorphine-induced reduction in striatal dopamine turnover was shifted to the left after chronic treatment with haloperidol was discontinued.

8. The dose of apomorphine required to elicit aggression was also markedly reduced after cessation of chronic haloperidol injections, supporting the hypothesis of dopaminergic supersensitivity as the mechanism for morphine withdrawal aggression. In contrast to the effect of chronic morphine, there was no spontaneous or amphetamine-induced aggression after chronic haloperidol. These results suggest either that other mechanisms besides dopaminergic súpersensitivity are necessary for morphine withdrawal aggression; or that the supersensitivity produced after these two treatments are dissimilar; or that after chronic haloperidol treatment there Is interference with the process of transmitter release; or. that there are differences in the balance between dopamine and other trangmitters after treatment with the two drugs; or any combination of these factors. 
9. Following chronic haloperidol, the stimulation of locomotor activity produced by dexetimide was increased and the locomotor depression produced by pilocarpine was decreased, while pentobarbital wasequi-effective in naive and chronica11y haloperidol treated rats. These results suggested that a cholinergic subsensitivity develops during chronic haloperidol treatment, perhaps as a compensatory mechanism. 


\section{BIBLIOGRAPHY}

Agid, Y., Javoy, F. and Glowinsk1, J.: Hyperactivity of remaining dopaminergic neurons after partial destruction of the nigro-striatal dopaminergic system in the rat. Nature 245: 150-151, 1973 .

Ahtee, L. and Kaariainen, I.: The role of dopamine in pilocarpine-induced catalepsy. N. S. Arch. Pharmacol. 284: $25-38,1974$.

Allikmets, L. H., Vahing, V. A. and Lapin, I. P.: Dissimilar influences of imipramine, benactyzine and promazine on effects of micro-injections of noradrenaline, acety 1 choline and serotonin into the amygdala in the cat. Psychopharmacologia 15: 392-403, 1969.

Anden, N. E.: Dopamine turnover in the corpus striatum and the limbic system after treatment with neuroleptic and anti-acetylcholine drugs. J. Pharm. Pharmaco1. 24: 905-906, 1972 .

Anden, N. E. and Bedard, P.: Influences of cholinergic mechanisms on the function and turnover of brain dopamine. J. Pharm. Pharmacol. 23: 460-462, 1971 .

Anden, N. E., Butcher, S. G., Corrod1, H., Fuxe, K. and Ungerstedt, U.: Receptor activity and turnover ofdopamine and noradrenaline after neuroleptics. Eur. J. Pharmacol. 11: 303-314, 1970a.

Anden, N. E., Carlsson, A., Dahlstrom, A., Fuxe, K., Hillarp, N. A. and Larsson, K.: Demonstration and mapping out of nigro-neo-striatal dopamine neurons. Life Sci. 3: $523-530,1964$.

Anden, N, E., Corrodi, H., Fuxe, K., Hokfelt, B., Hokfelt, T., Rydin, C. and Svensson, T.: Evidence for a central noradrenaline receptor stimulation by clonidine. Life Sci. $\underline{9}$ : 513-523, 1970b.

Anden, N. E., Corrodi, H., Fuxe, K. and Ungerstedt, U.: Importance of nervous impulse flow for the neuroleptic induced increase in amine turnover in central dopamine neurons. Eur. J. Pharmacol. 15: 193-199, 1971. 
Anden, N. E., Dahlstrom, A., Fuxe, K. and Hokfelt, T.: The effect of haloperidol or chlorpromazine on the amine levels of central monoamine neurons. Acta Physiol. Scand. 68: 419-420, 1966a.

Anden, N. E., Dahlstrom, A., Fuxe, K. and Larsson, K.: Functional role of the nigro-neostriatal dopamine neurons. Acta Pharmacol. Toxicol. 24: 263-274, $1966 \mathrm{~b}$.

Anden, N. E., Dahlstrom, A., Fuxe, K. and Larsson, K.: Further evidence forthe presence of nigro-neostriatal dopamine neurons in the rat. Amer. J. Anat. 116: $329-333,1965$.

Anden, N. E., Dah1strom, A., Fuxe, K., Larsson, K., O1son, L. and Ungerstedt, U.: Ascending monoamine neurons to the telencephalon and diencephalon. Acta Physiol. Scand. 67: $313-326,1966 \mathrm{c}$.

Anden, N. E., Fuxe, K., Hamberger, B. and Hokfelt, T.: A quantitative study on the nigro-neostriatal dopamine neuron system in the rat. Acta Physiol. Scand. 67: $306-312,1966 \mathrm{~d}$.

Anden, N. E., Fuxe, K. and Larsson, K.: Effect of 1 arge mesencephalic-diencephalic lesions on the noradrenalin, dopamine and 5-hydroxytryptamine neurons in the central nervous system. Experientia 22: 842-843, 1966e.

Anden, N. E., Robenson, A., Fuxe, K. and Hokfelt, T.: Evidence for dopamine receptor stimulation by apomorphine. J. Pharm. Pharmacol. 19: 627-629, 1967.

Arbuthnott, G. W., Crow, T. J., Fuxe, K., 01son, C. and Ungerstedt, U.: Depletion of catecholamines induced by electrical stimulation of central monoamine pathways. Brain Res. 24: 471-483, 1970.

Arnfred, T. and Randrup, A.: Cholinergic mechanisms in brain inhibiting amphetamine-induced stereotyped behaviour. Acta Pharmacol. Toxicol. 26: $384-394,1968$.

Asper, H., Baggiolini, M., Burki, H. R., Lauener, H., Ruch, W. and Stille, G.: Tolerance phenomena with neuroleptics. Catalepsy, apomorphine stereotypies and striatal dopamine metabolism in the rat after single and repeated administration of loxapine and haloperidol. Eur. J. Pharmacol. 22 : 287-294, 1973 .

Azrin, N. H., Hutchinson, R. R. and Hake, D. F.: Extinctioninduced aggression. J. Exp. Anal. Behav. 9: 191-204, 1966. 
Azzaro, A. J. and Rutledge, C. O.: Selectivity of release of norepinephrine, dopamine and 5-hydroxytryptamine by amphetamine in various reglons of rat brain. Biochem. Pharmaco1. 22: 2801-2813, 1973 .

Bartholini, G. and Pletscher, A.: Atropine-induced changes of cerebral dopamine turnover. Experientia 27: 13021303,1972 .

Baxter, B. L., Gluckman, M. I., Ste1n, L. and Scern1, R. A.: Self-injection of apomorphine in the rat: possible reinforcement by a dopamine receptor stimulant. Pharmacol. Blochem. Behav. 2: 387-391, 1974 .

Beleslin, D. and Polak, R. L.: Depression by morphine and chloralose of acetylcholine release from the cat's brain. J. Physiol. 177: 411-419, 1965.

Benkert, 0., Gluba, H. and Matussek, N.: Dopamine, noradrenaline and 5-hydroxytryptamine in relation to motor activity, fighting and mounting behaviour. I. LDOPA and DL-threo-dihydroxyphenylserine in combination with R04-4602, pargyline and reserpine. Neuropharmacology 12: 177-186, 1973a.

Benkert, 0. and Kohler, B.: Intrahypothalamic and intrastriatal dopamine and norepinephrine injections in relation to motor hyperactivity in rats. Psychopharmacologia 24: $318-325,1972$.

Benkert, 0., Renz, A. and Matussek, N.: Dopamine, noradrenaline and 5-hydroxytryptamine in relation to motor activity, ighting and mounting behaviour. II. L-DOPA and DL-threo-dihydroxyphenylserine in combination with RO 4-4602 and parachlorophenylalanine. Neuropharmacology 12: $187-193,1973 \mathrm{~b}$.

Bernstein, H. and Moyer, K. E.: Aggressive behavior in the rat: effects of isolation and olfactory bulb lesions. Brain Res. 20: 75-84, 1970 .

Bertler, A. and Rosengren, E.: Occurence and distribution of catecholamines in brain. Acta Physiol. Scand. 47: 350-361, 1959 .

Besson, M. J., Cheramy, A., Feltz, P. and Glowinski, J.: Dopamine: spontaneous and drug-induced release from the caudate nucleus in the cat. Brain Res. 32: 407424,1971 . 
Bloom, F. E., Costa, E. and Salmoiraghi, G. C.: Anesthesia and the responsiveness of individual neurons of the caudate nucleus of the cat to acetylcholine, norepinephrine and dopamine administered by microelectrophoresis. J. Pharmacol. Exp. Ther. 150: 244-252, 1965.

Boshka, S. E., Weissman, M.C. and Thor, D. H.: A technique for inducing aggression in rats utilizing morphine withdrawal. Psycho1. Rec. 16: 541-543, 1966.

Bowers, M. B. and Kleber, H.D.: Methadone increases mouse brain 5-hydroxyindoleacetic acid. Nature 229: 134-135, 1971 .

Bowers, M. B. and Roth, R. H. : Interaction of atropine-like drugs with dopamine-containing neurones in rat brain. Br. J. Pharmacol. 44: 301-306, 1972 .

Boyd, E. M.: Chlorpromazine tolerance and physical dependerce. J. Pharmacol. Exp. Ther. 128: 75-78, 1960.

Brady, J. V. and Nauta, W. J. H.: Subcortical mechanisms in emotional behavior: affective changes following septal lesions in the albino rat. J. Comp. Physiol. Psychol. 46: $339-346,1953$.

Branchey, L., Bodner, S. and Friedhoff, A. J.: Effect of chronic morphine implantation on tyrosine hydroxylase activity in the rat caudate. Res. Comm. Chem. Path. Pharmacol. $\underline{8}$ : 707-710, 1974 .

Breese, G. R., Cooper, B. R. and Mueller, R. A.: Evidence for involvement of 5-hydroxytryptamine in the actions of amphetamine. Br. J. Pharmaco1. 52: 307-314, 1974 .

Breese, G. R. and Traylor, T. D.: Effect of 6-hydroxydopamine on brain norepinephrine and dopamine: evidence for selective degeneration of catecholamine neurons. J. Pharmacol. Exp. Ther. 174: 413-420, 1970 .

Buckett, W. R.: A new test for morphine-like physical dependence (addiction liability) in rats. Psychopharmacologia 6: $410-416,1964$.

Bunney, B. S., Aghajanian, G. K. and Roth, R. H.: Amphetamine L-DOPA and apomorphine: effects on activity of rat dopaminergic neurons. Federation Proc. 32: 247, 1973a.

Bunney, B. S., Walters, J. R., Roth, R. H. and Aghajanian, G. K.: Dopaminergic neurons: effect of antipsychotic drugs and amphetamine on single cell activity. J. Pharmacol. Exp. Ther. 185: 560-571, $1973 \mathrm{~b}$. 
Butcher, L. L., Engel, J. and Fuxe, K.: Behavioral, blochemical and histochemical analyses of the central effects of monoamine precursors after peripheral decarboxylase Inhibition. Brain Res. 41: 387-411, 1972 .

Butcher, S.G. and Butcher, L. L.: Origin and modulation of acetylcholine activity in the neostriatum. Brain Res. 71: $168-171,1974$.

Butterworth, R. F., Polgnant, J. C. and Barbeau, A.: Apomorphine and piribedil in rats: biochemical and pharmacologic studies. In Advances in Neurology, vol. 9, Dopaminergic Mechanisms, ed. by D. Calne, T. N. Chase and A. Barbeau, pp. 307-326, Raven Press, New York, 1975.

Cannon, W. B. and Rosenblueth, A.: The Supersensitivity of Denervated Structures, Macmi11an, New York, 1949.

Carlini, E. A. and Gonzalez, C.: Aggressive behaviour induced by marihuana compounds and amphetamine in rats previously made dependent on morphine. Experientia 28:542-544, 1972.

Carlin1, E. A. and Lindsey, C. J.: Pharmacological manipulations of brain catecholamines and the aggressive behavior induced by marihuana in REM-sleep-deprived rats. Aggressive Behavior 1: 81-99, 1975 .

Carlsson, A., Fuxe, K., Hamberger, B. and Lindquist, M.: Biochemical and histochemical studies on the effects of Imipramine-11ke and (+)-amphetamine on central and per1pheral catecholamine neurons. Acta Phystol. Scand. 67: 481-497, 1966 .

Carlsson, A. and Lindquist, M.: Effect of chlorpromazine or haloperidol on formation of 3-methoxytyramine and normetanephrine in mouse brain. Acta Pharmacol. Toxicol. 20: $140-144,1963$.

Carlsson, A. and Waldeck, A.: A fluorometric method for the determination of dopamine. Acta Physiol. Scand. 44: 293-298, 1958 .

Carr, L. A. and Moore, K. E.: Norepinephrine: release from brain by d-amphetamine in vivo. Science 164: 322-323, 1969.

Cegrell, L., Nordgren, L. and Rosengren, A. M.: Effect of decarboxylase inhibition and neuroleptic drugs on the dopa level in rat brain. Res. Comm. Chem. Path. Pharmacol. 1: $479-484,1970$. 
Chance, M.: A peculiar form of social behaviour induced in mice by amphetamine. Behaviour 1: 64-69, 1948.

Cheney, D. L., Trabucch1, M., Racagn1, G., Wang, C. and Costa, E.: Effects of acute and chronic morphine on regional rat brain acetylcholine turnover rate. Life Sci. 15: 1977-1990, 1974 .

Chiueh, C. C. and Moore, K. E.: Release of endogenously synthesized catechols from the caudate nucleus by stimulation of the nigrostriatal pathway and by the administration of d-amphetamine. Brain Res. 50: 221-225, 1973.

Cicero, T. J., Wilcox, C. E., Smithloff, B. R., Meyer, E. R. and Lawrence, C. S.: Effects of morphine in vitro and in vivo on tyrosine hydroxylase activity in rat brain. B1ochem. Pharmaco1. 22: 3237-3246, 1973 .

Clemens, J. A., Smelstig, E. B. and Sawyer, B. D.: Anti-psychotic drugs stimulate prolactin release. Psychopharmacologia 40: 123-127, 1974 .

Clement-Cormier, Y. C., Kebabian, J. W., Petzold, G. I. and Greengard, P.: Dopamine-sensitive adenylate cyclase in mammalian brain: a possible site of action of anti-psychotic drugs. Proc. Nat. Acad, Sc1. 71: 1113-1117, 1974.

Clouet, D. H., Johnson, J. C., Ratner, M., Williams, N. and Gold, G. J.: The effect of morphine on rat brain catecholamines: turnover in vivo and uptake in isolated synaptosomes. In Frontiers in Catecholamine Research, ed. by E. Usdin and S. Snyder, Pp. 1039-1042, Pergamon Press, Elmsford, New York, 1973.

Clouet, D. H. and Ratner, M.: Catecholamine blosynthesis in brains of rats treated with morphine. Science 168: 854856,1970 .

Collias, N.: Aggressive behavior among vertebrate animals. Physiol. Zool. 17: 83-123, 1944 .

Collier, H. O. J.: Tolerance, physical dependence and receptors. Advances in Drug Research 3: 171-188, 1966.

Colpaert, F. C., Wauquier, A., Niemegeers, C. J. E. and Lal, H.: Reversal by a central anti-cholinergic drug of pimozide induced inhibition of mouse jumping in amphetamine-dopa treated mice. J. Pharm. Pharmacol. 27: 536537,1975 .

Connor, J. D.: Caudate unit response to nigra stimulation: evidence for a possible nigro-neostriatal pathway. Science 160: 899-900, 1968 . 
Connor, J. D.: Caudate nucleus neurons: correlation of the effects of substantia nigra stimulation with iontophoretic dopamine. J. Physio1. 208: 691-703, 1970.

Conover, W. J.: Practical Nonparametric Statistics. John Wiley \& Sons, New York, 1971.

Cools, A. R.: The transsynaptic relationship between dopamine and serotonin in the caudate nucleus of cats. Psychopharmacologia $\underline{36}$ : 17-28, 1974 .

Cooper, B. R., Cott, J. M. and Breese, G. R.: Effects of catecholamine-depleting drugs and amphetamine on self-stimulation of brain following various 6-hydroxydopamine treatments. Psychopharmacologia 37: 235-248, 1974.

Corrodi, H., Fuxe, K., Hamberger, B. and Ungerstedt, U.: ET 495 and brain catecholamine mechanisms: evidence for stimulation of dopamine receptors. Eur. J. Pharmacol. 20: 195-204, 1972a.

Corrod1, H., Fuxe, K., Hammer, W., Sjoquist, F. and Ungerstedt, U.: Oxotremorine and central monoamine neurons. Life Sci. 6: 2557-2566, 1967a.

Corrod1, H., Fuxe, K. and Hokfelt, T.: The effect of neuroleptics on the activity of central catecholamine neurons. Life Sci. 6: 767-774, $1967 \mathrm{~b}$.

Corrodi, H., Fuxe, K. and Lindbrink, P.: Interaction between cholinergic and catecholaminerglc neurones in rat brain. Brain Res. 43: 397-416, 1972 b.

Costa, E., Carenzi, A., Guidotti, A. and Revuelta, A.: Narcotic analgesics and the regulation of neuronal catecholamine stores. In Frontiers in Catecholamine Research, ed. by E. Usdin and S. Snyder, pp. 1003-1010, Pergamon Press, Elmsford, New York, 1973.

Costa, E., Groppett1, A. and Nalmzada, M. K.: Effects of amphetamine on the turnover rate of brain catecholamines and motor activity. Br. J. Pharmacol. 44: 742-751, 1972.

Costa, E. and Neff, N. H.: Estimation of turnover rates to study the metabolic regulation of the steady-state level of neuronal monoamines. In Handbook of Neurochemistry, vo1. 4, ed. by A. Lajtha, pp. 45-79, Plenum Press, New York, 1970 .

Costa11, B. and Naylor, R. J.: Actions of dopaminergic agonists on motor functions: In Advances in Neurology, vol. 9, ed. by D. Calne, T. N. Chase and A. Barbeau, Pp. 285297, Raven Press, New York, 1975. 
Costa11, B. and Naylor, R. J.: On catalepsy and catatonia and the predictability of the catalepsy test for neuroleptic activity. Psychopharmacologia 34: 233-241, 1974.

Costall, B. and Naylor, R. J.: The role of telencephalic dopaminergic systems in the mediation of apomorphine stereotyped behavior. Eur. J. Pharmacol. 24: 8-24, 1973 .

Costa11, B., Naylor, R. J. and 01ley, J. E.: Catalepsy and circling behaviour after intracerebral injections of neuroleptic, cholinergic and anticholinergic agents into the caudate-putamen, globus pallidus and substantia nigra of rat brain. Neuropharmacology 11: 645-663, 1972 .

Cotzias, G. C., Van Woert, M. H. and Schiffer, L. M.: Aromatic amino acids and modification of Parkinsonism. New Eng. J. Med. 276: $374-378,1971$.

Coyle, J. T. and Snyder, S. H.: Antiparkinsonian drugs: 1nhibition of dopamine uptake in the corpus striatum as a possible mechanism of action. Science 166: 899-901, 1969.

Crabtree, J. M. and Moyer, K. E.: Sex differences in fighting and defense induced in rats by shock and d-amphetamine during morphine abstinence. Physiol. Behav. 11: 337-343, 1973 .

Davis, W.M. and Khalsa, J. H.: Some determinants of aggressive behavior induced by morphine withdrawal. Psychon. Sci. 24: $13-15,1971$.

Decsi, L., Vaszeg1, M. K. and Mehes, J.: Direct chemical stimulation of various subcortical brain areas in unrestrained cats. In Recent Developments of Neurobiology in Hungary, vol. 2, ed. by K. Lissak, Pp. 182-211, Akademia1 Kiado, Budapest, 1969.

Dlabac, A.: Apomorphine-induced aggressivity in rats and its alterations. Activas Nerv. Sup. 15: 133, 1973.

Dobrin, E. I. and Mares, S. E.: Effect of morphine on serum gonadotrophin levels. In Drug Addiction, vol. 4, New Aspects of Analytical and Chemical Toxicology, ed. by J. M. Singh and H. La1, PP. 69-77, Stratton Intercontinental Book Corp., New York, 1974.

Dominic, J. A. and Moore, K. E.: Supersensitivity to the central stimulant action of adrenergic drugs following discontinuation of a chronic diet of $\alpha$-methyltyrosine. Psychopharmacologia 15: 96-101, 1969. 
Domino, E. F. and Wilson, A. E. Enhanced brain acetylcholine utilization during morphine withdrawal in the rat. Nature 243: 285-286, 1973 .

Elchelman, B.: The catecholamines and aggressive behavior. In Chemical Approaches to Brain Function, ed. by $S$. Ehrenpreis and I. J. Kopin, vol. 5, pp. 109-129, Academlc Press, New York, 1973.

Elchelman, B. S. and Thoa, N. B.: The aggressive monoamines. B1o1. Psych1at. 6: 143-164, 1973.

Ernst, A. M.: Mode of action of apomorphine and dexamphetamine on gnawing compulsion in rats. Psychopharmacologia 10: $316-323,1967$.

Ernst, A. M.: Relation between the action of dopamine and apomorphine and their 0-methylated derivatives upon. the C.N.S. Psychopharmacologia I: 391-399, 1965.

Everett, G. M. and Borcherding, J. W.: L-DOPA: effect on concentrations of dopamine, norepinephrine and serotonin in brains of mice. Science 168: 849-850, 1970.

Faul1, R. L. M. and Laverty, R.: Changes in dopamine levels in the corpus striatum following lesions in the substantia nigra. Exp. Neurol. 23: 332-340, 1969.

Ferris, R. M., Tang, F. L. M. and Russell, A. V.: In vitro evidence for a presynaptic action of apomorphine. Pharmacologist 16: $328,1974$.

Fibiger, H. C. and Grewal, D. S.: Neurochemical evidence for denervation supersensitivity: the effect of unilateral substantia nigra lestons in apomorphine-induced increases in neostriatal acetylcholine levels. Life Sci. 15: 57-63, 1974 .

Fibiger, H. C., Lytle, L. D. and Campbe11, B. A.: Cholinergicmodulation of adrenergic arousal in the developing rat. J. Comp. Phys1o1. Psychol. 72: 384-389, 1970 .

Fielding, S. and Lal, H.: Screening tests using higher animals. In Neuroleptics, ed. by S. Fielding and H. Lal, Pp. 64-75, Futura Press, Mt. Kisco, New York, 1974.

Fjalland, B. and Moller-Nielsen, I.: Methylphenidate antagonism of haloperidol, interaction with cholinergic and anticholinergic drugs. Psychopharmacologia 34: 111-118, 1974 a. 
Fja11and, B. and Moller-Nielsen, I.: Enhancement of methy1phenidate-induced stereotypies by repeated administration of neuroleptics. Psychopharmacologia 34: 105-109, $1974 \mathrm{~b}$.

Florea, J.and Thor, D. H.: Drug withdrawal and fighting in rats. Psychon. Sci. 12: 33, 1968.

Fog, R., Randrup, A. and Pakkenburg, H.: Lesions in corpus striatum and cortex of rat brains and the effect of pharmacologically induced stereotyped, aggressive and cataleptic behaviour. Psychopharmacologia 18: 346-356, 1970 .

Fukui, K. and Takagi, H.: Effect of morphine on the cerebral contents of metabolites of dopamine in normal and tolerant mice: its possible relation to analgesic action. Br. J. Pharmaco1. 44: 45-51, 1972 .

Fuxe, K.: Cellular localization of monoamines in the median eminence and in the infundibular stem of some mamals. Acta Physio1. Scand. 묘: 383-384, 1963 .

Fuxe, K. and Hokfelt, T.: Catecholamines in the hypothalamus and the pituitary gland. In Frontiers in Neuroendocrinology, ed. by W. F. Ganong and L. Martini, pp. 47-96, Oxford University Press, New York, 1969.

Fuxe, K. and Hokfelt, T.: Further evidence for the existence of tubero-infundibular dopamine neurons. Acta Physiol. Scand. 66: 245-246, 1966 .

Fuxe, K., Hokfelt, T. and Nilsson, 0.: Castration, sex hormones and tubero-infundibular dopamine neurons. Neuroendocrinology 5: 107-120, 1969.

Fuxe, K., Hokfelt, T. and Ungerstedt, U.: Distribution of monoamines in the mammalian central nervous system by histochemical studies. In Metabolism of Amines in the Brain ed. by G. Hooper, pp. 10-22, Macmillan, London, 1969.

Fuxe, K., Hokfelt, T. and Ungerstedt, U.: Morphological and functional aspects of central monoamine neurons. Int. Rev. Neurobiol. 13: 93-121, 1970 .

Fuxe, K. and Ungerstedt, U.: Action of caffeine and theophy1lamine on supersensitive dopamine receptors: considerable enhancement of receptor response to treatment with dopa and dopamine receptor agonists. Med. Biol. 52: 4854,1974 . 
Gauchy, C., Ag1d, Y., Glowinsk1, J. and Cheramy, A.: Acute effects of morphine on dopamine synthesis and release and tyrosine metabolism in the rat striatum. Eur. J. Pharmac01: 22: $311-319,1973$.

Gerlach, J., Reisby, N. and Randrup, A.: Dopaminergic hypersensitivity and cholinergic hypofunction in the pathophyslology of tardive dyskinesias. Psychopharmacologia 34: $21-35,1974$.

Geyer, M. A. and Segal, D. S .: Shock-induced aggression: opposite effects of intraventriculariy infused dopamine and norepinephrine. Behav. B101. 10: 99-104, 1974.

Gianutsos, G., Drawbaugh, R. B., Hynes, M. D. and La1, H.: The morphine withdrawal syndrome in the rat. In Methods In Narcotic Research, ed. by S. Ehrenpreis and E. A. Neldle, pp. 293-309, Marce1 Dekker, New York, 1975.

Gianutsos, G., Hynes, M. D., Pur1, S. K., Drawbaugh, R. B. and Lal, H.: Effect of apomorphine and nigrostriatal lesions on aggression and striatal dopamine turnover during morphine withdrawal: evidence for dopaminergic supersensitivity in protracted abstinence. Psychopharmacologla 34: $37-44,1974$.

Glanutsos, G, and La1, H.: Aggression in mice after p-chloro amphetamine. Res. Comm. Chem. Path. Pharmaco1. 10: $379-383,1975$.

Glick, S. D. and Cox, R. S.: Self-administration of haloperidol in rats. Life Sci. 16: 1041-1046, 1975.

Glick, S. D., Greenstein, S. and Waters, D. H.: Lateral hypothalamic lestons and striatal dopamine levels. Life Sc1. 14: 747-750, 1974 .

Goldstein, A. and Schulz, R.: Morphine-tolerant longitudinal muscle strip from guinea pig 1leum. Br. J. Pharmacol. 48: $655-666,1973$.

Goldstein, M., Freedman, L. S. and Backstrom, T.: The Inhibition of catecholamine biosynthesis by apomorphine. J. Pharm. Pharmaco1. 22: 715-717, 1970.

Grabowska, M., Antkiewicz, L., Maj, J. and Michaluk, J.: Apomorphine and central serotonin neurons. Pol. J. Pharmaco1. 25: 29-39, 1973 .

Grabowska, M and Michaluk, J.: On the role of serotonin in apomorphine-induced locomotor stimulation in rats. Pharmaco1. Biochem. Behav. 2: 263-266, 1974. 
Gudelsky, G. A., Thornburg, J. E: and Moore, R. E.: Blockade of $\alpha$-methy 1 tyrosine-induced supersensitivity to apomorphine by chronic administration of L-DOPA. Life Sc1. 16: 1331-1338, 1975 .

Gunne, L. M.: Catecholamines and 5-hydroxytryptamine in morphine tolerance and withdrawal. Acta Physiol. Scand. 58 supp1. 204: 1-91, 1963 .

Gunne, L. M., Jonsson, J. and Fuxe, K.: Effects of morphine intoxication on brain catecholamine neurons. Eur. J. Pharmacol. $\underline{5}$ : $338-342,1969$.

Guyenet, P. G., Javoy, F., Ag1d, Y., Beaujouan, J. C. and Glowinsk1, J.: Dopamine receptors and cholinergic neurons in the rat striatum. In Advances in Neurology, vol. 9, Dopaminergic Mechanisms, ed. by D. Calne, T. N. Chase and A. Barbeau, Pp. 43-51, Raven Press, New York, 1975 .

Gyorgy, L., Pfelfer, K. A. and Haftman, B.: Modification of certain central nervous effects of haloperidol during long-term treatment in the mouse and rat. Psychopharmacologia 16: 223-233, 1969 .

Harnack, E.: Uber die Wirkungen des Apomorphines am Saugethier und am Frosch. Nauyn Schmiedebergs Arch. Expt1. Patho1. Pharmaco1. 2: 254-306, 1874 .

Hasselager, E., Rollnski, Z, and Randrup, A.: Speciflc antagonism by dopamine inhibitors of items of amphetamine induced aggressive behaviour. Psychopharmacologia 24: 485495,1972 .

Haubrich, D. R. and Blake, D. E.: Modification of serotonin metabolism in rat brain after acute or chronic administration of morphine. Biochem. Pharmaco1. 22: 2753-2759, 1973.

Haubrich, D. R. and Goldberg, M. E.: Homovanillic acid concentration in rat brain: effect of a choline acetyltransferase inhibitor and comparison with cholinergic and dopaminergic agents. Neuropharmacology 14: 211214,1975 .

Haubrich, D. R. and Reid, W. D.: Effects of pilocarpine or arecoline administration on acetylcholine levels and serotonin turnover in rat brain. J. Pharmacol. Exp. Ther. 181: 19-27, 1972 .

Himmelsbach, C. K.: Studies of the relation of drug addiction to the autonomic nervous system: results of cold pressor test.J. Pharmaco1. Exp. Ther. 73: 91-98, 1941. 
Hokfelt, T.: The possible ultrastructural identification of B72 tubero-infundibular dopamine containing nerve endings in the median eminence of the rat. Brain Res. $\underline{5}$ : $121-123,1967$.

Hokfelt, T., LfungdahI, A., Fuxe, K. and Johansson, O.: Dopamine nerve terminals in the rat limbic cortex: aspects of the dopamine hypothesis of schizophrenia. Science 184: $177-179,1974$.

Ho1lander, M. and Wolfe, D. A.: Nonparametric Statistical Methods, John Wiley \& Sons, New York, 1973.

Hollister, A. S., Breese, G. R. and Cooper, B. R.: Compar1son of tyrosine hydroxylase and dopamine-beta-hydroxylase inhibition with the effects of various 6-hydroxydopamine treatments on amphetamine induced motor activity. Psychopharmacologia 36: 1-16, 1974.

Hornykiewicz, 0.: Dopamine (3-hydroxytyramine) and brain function. Pharmacol. Rev. 18: 925-964, 1966.

Hughes, J.: Isolation of an endogenous compound from the brain with pharamcological properties similar to morphine. Brain Res. 88: 295-308, 1975.

Hynes, M. D., Anderson, C., Gianutsos, G. and Lal, H.: Effects of haloperidol, methyl tyrosine and morphine on recovery from lesions of lateral hypothalamus. Pharmacol. Blochem. Behav. (In press).

Hytte1, J.: Endogenous levels and turnover of catecholamines in mouse brain after repeated administration of haloperido1. Psychopharmacolog1a 36: 237-241, 1974.

Iorio, L. C., Deacon, M. A. and Ryan, E. A.: Blockade by narcotic drugs of naloxone-precipltated jumping in morphine-dependent mice. J. Pharmacol. Exp. Ther. 192: $58-63,1975$.

Iversen, S. D. and Creese, I.: Behavioral correlates of dopaminergic supersensitivity. In Advances in Neurology, vol. 9, Dopaminergic Mechanisis, ed. by D. Calne, T. N. Chase and A. Barbeau, pp. 81-92, Raven Press, New York, 1975 .

Iwamoto, E. T., Ho, I. K. and Way, E. L.: Elevation of brain dopamine during naloxone-precipitated withdrawal in morphine dependent mice and rats. J. Pharmacol. Exp. Ther. 187: $558-567,1973$. 
Iwatsubo, K. and Clouet, D. H. : Dopamine-sensitive adenylate cyclase of the caudate nucleus of rats treated with morphine or haloperidol. Biochem. Pharmacol. (In press).

Jaffe, J. H. and Sharpless, S. K.: Pharmacological denervation supersensitivity in the central nervous system. A theory of physical dependence. Assoc. Nerv. Ment. Dis. 46: $226-246,1968$.

Janssen, P. A. J.: Synopsis: Dexetimide - R 16470. Janssen Pharmaceutica, Apri1; 1971.

Janssen, P. A. J.: The pharmacology of haloperidol. Int. J. Neuropsychiat. 3: 10-18, 1967.

Janssen, P. A. J., Jageneau, A. H. and Niemegeers, C. J. E.: Effects of various drugs on isolation-induced fighting behavior of male mice. J. Pharmacol. Exp. Ther. 129: $471-475,1960$.

Janssen, P. A. J. and Niemegeers, C. J. E.: The peripheral and central anticholinergic properties of benzetimide (R4929) and other atropine-like drugs as measured in a new anti-p1locarpine test in rats. Psychopharmacologia 11: $231-254,1967$.

Janssen, P. A. J., Niemegeers, C. J. E. and Schellekens, K. H. L.: Is it possible to predict the clinical effects of neuroleptic drugs (major tranquilizers) from animal data. I. "Neuroleptic activity spectra" for rats. Arzneimitte1 Forsch. 15: 104-117, 1965.

Janssen, P. A. J., Niemegeers, C. J. E., Schellekens, K. H. L., Demoen, P., Lenaerts, F. M., Van Neuten, J. M., Vain Wijngaarden, $I$, and Brugmans, J.: Benzetimide and its optical 1somers. Arzneimittel Forsch. 21: 13651373,1971 .

Johnson, J. C., Ratner, M., Gold, G. J. and Clouet, D. H.: Morphine effects on the level and turnover of catecholamines in rat brain. Res. Comm. Chem. Path. Pharmacol. 9: $41-53,1974$.

Kar11, P.: The Norway rat's killing response to the white mouse: an experimental analysis. Behaviour 10: 81-103, 1956.

Kebabian, J. W., Petzold, G. I. and Greengard, P.: Dopaminesensitive adenylate cyclase in caudate nucleus of rat bratn and 1ts similarity to the "dopamine receptor." Proc. Nat. Acad. Sct. 69: 2145-2149, 1972. 
Klawans, H. L.: The pharmacology of tardive dyskinesias. Amer. J. Psychiat. 130: 82-86, 1973.

Klawans, H. L.: The pharmacology of Parkinsonism. Dis. Nerv. Sys. 29: $805-816,1968$.

Klawans, H. L., Goetz, C. and Westhelmer, R.: Pathophyslology of schizophrenia and the striatum. D1s. Nerv. Sys. 33: $711-719,1972 \mathrm{a}$.

Rlawans, H. L. and Rubovits, R.: An experimental model of tardive dyskinesias. J. Neura1. Trans. 33: 235-246, 1972 .

Klawans, H. L., Rubovits, R., Patel, B. C. and Weiner, W. J.: Cholinergic and anticholinergic influences on amphetamine-induced stereotyped behavior. J. Neurol. Sc1. 17: 303-308, $1972 b$.

Roe, B. K.: Effects of neuroleptic drugs on brain catecholamines. In Neuroleptics, ed. by S. Flelding and H. Lal, pp. 131-172, Futura Publishing Co., Mt. Kisco, New York, 1974.

Koe, B. K. and Weissman, A.: p-Chlorophenylalanine: a specIfic depletor of brain serotonin. J. Pharmacol. Exp. Ther. 154: 49-516, 1966 .

Koslow, S. H., Racagni, G. and Costa, -E.: Mass fragmentographic measurement of norepinephrine, dopamine, serotonin and acetylcholine in seven discrete nuclei of the rat te1-diencephalon. Neuropharmacology 13: 1123-1130, 1974.

Kostowski, W., Gumulka, W. and Czonkowski, A.: Reduced cataleptogenic effects of some neuroleptics in rats with lesioned midbrain raphe and treated with p-chlorophenylalanine. Bra1n Res. 48: 443-446, 1972.

Kuschinsky, K.: Does chronic morphine treatment Induce a supersensitivity of dopamine receptors in rat brain? Psychopharmacologia 42: 225-229, 1975 .

Kuschinsky, K.: Evidence that morphine increases dopamine utilization in corpora striata of rats. Experientia 29: $1365-1366,1973$.

Kuschinsky, $\mathbb{K}$. and Hornyklewlcz, 0.: Morphine catalepsy $1 n$ the rat: relation to striatal dopamine metabolism. Eur. J. Pharmaco1. 19: 119-122, 1972 . 
Ladinsky, H., Consolo, S. and Garattini, S.: Increase in striatal acetylcholine levels in vivo by piribedil, a new dopamine receptor stimulant. Life Sc1. 14: 1251-1260, 1974 .

Lahti, R. A., McAllister, B. and Wozniak, J.: Apomorphine antagonism of the elevation of homovanillic acid induced by antipsychotic drugs. Life Sc1. 11 (part 1): $605-613,1972$.

La1, H.: Morphine-withdrawal aggression. In Methods in Narcotic Research, ed. by S. Ehrenpreis and E. A. Neidle, pp. 171-183, Marcel Dekker, New York, 1975.

Lal, H., DeFeo, J. J,, Pitterman, A., Patel, G. and Baumel, I.: Effects of prolonged social deprivation or enrichment on neuronal sensitivity for CNS depressants and stimulants. In Drug Addiction, vol. 1, ed. by J. M. Singh, L. H. Miller and H. Lal, PP. 255-266, Futura Publishing Co., Mt. Kisco, New York, $1972 a$.

La1, H., Gianutsos, G. and Puri, S. K.: A comparison of narcotic analgesics with neuroleptics on behavioral measures of dopaminergic activity. Life Sc1. 17: 29-34, $1975 \mathrm{a}$.

La1, H., Nesson, B. and Smith, N.: Amphetamine-induced aggression in mice pretreated with dihydroxyphenylalanine (DOPA) and/or reserplne. B1o1. Psychiat. 2: 299301,1970 .

La1, H., O'Brien, J., Pitterman, A., Gianutsos, G. and Reddy, C.: Aggression after amphetamines and dihydroxypheny1alanine. Federation Proc. 13: 529, 1972 b.

La1, H., O'Brien, J. and Pur1, S. K.: Morphine-withdrawal aggression: sensitization by amphetamine. Psychopharmacologia 22: 217-223, 1971 .

Lal, H., Wauquier, A. and Niemegeers, C. J. E. : Characteristics of narcotic dependence by oral ingestion of fentany1 solution. Pharmacologist $17237,1975 \mathrm{~b}$.

Langer, S. Z., Draskoczy, P. R. and Trendelenburg, U.: Time course of the development of supersensitivity to various amines in the nictitating membrane of the pithed cat after denervation or decentralization. J. Pharmacol. Exp. Ther. 157: 255-273, 1967.

Langer, S. Z . and Trendelenburg, U.: The onset of denervation supersensitivity. J. Pharmacol. Exp. Ther. 151: $73-86,1966$. 
Levitt, M., Spector, S., Sjoerdsma, A. and Udenfriend, S.: Elucidation of the rate-limiting step in norepinephrine biosynthesis in the perfused guinea-pig heart. J. Pharma co1. Exp. Ther. 148: 1-8, 1965.

Lindva11, 0. and Bjorklund, A.: The organization of the ascending catecholamine neuron systems in the rat brain as revealed by the glyoxylic acid fluorescence method. Acta Physiol. Scand. supp1. 412: 1-47, 1974.

Lippa, A. S., Antelman, S., Fisher, A. and Canfield, D.: Neurochemical mediation of reward: a significant role for dopamine. Pharmacol. Blochem. Behav. 1: 23-28, 1973.

Lloyd, K. G., Stadler, H. and Bartholini, G.: Dopamine and acetylcholine neurons in the striatal and $11 \mathrm{mblc}$ structures: effect of neuroleptic drugs. In Frontiers in Catecholamine Research, ed. by E. Usdin and S. Snyder, pp. 777-779, Pergamon Press, Elmsford, New York, 1973.

Loh, H. H., Hitzemann, R. J. and Way E. L.: Effect of acute morphine administration on the metabolism of brain catecholamines. Life Sci. 12 (part 1): 33-41, 1973.

Lorenz, K.: On Aggression, Harcourt, Brace \& World, New York, 1966.

Lycke, E., Modigh, K. and Roos, B. E.: Aggression In mice associated with changes in the monoamine metabolism of the brain. Experientia 25: 951-953, 1969.

Mabry, P. D. and Campbe11, B. A.: Serotonergic inhibition of catecholamine-1nduced behavioral arousal. Brain Res. 49 : $381-391,1973$.

Maj, J., Baran, L., Grabowska, M. and Sowinska, H. : Effect of clonidine on the 5-hydroxytryptamine and 5-hydroxyindoleacetic acid brain levels. Blochem. Pharmacol. 22: $2679-2683,1973$.

Mann, S. and La1, H.: Enhancement of drug (apomorphine or amphetamine) induced aggression in rats withdrawn from chronic exposure to ethanol inhalation. Federation Proc. 34: 720,1975 .

Marsha11, I. and Smith, C. B.: Acute and chronic morphine treatment and the hydroxylation of [1-14C]-L-tyrosine in the mouse brain. Br. J. Pharmacol. 50: 428-430, 1974.

Martin, W. R. and Sloan, J. W.: The pathophyslology of morphine dependence and its treatment with opiold antagonists. Pharmakopsychiat. Neuro-Psychopharmako1. 1: 260$270,1971$. 
Martin, W. R., Wikler, A., Eades, C. G. and Pescor, F. T.: Tolerance to and physical dependence on morphine in rats. Psychopharmacolog1a 4: 247-260, 1963.

Matthysse, S.: Antipsychotic drug action: a clue to the neuropathology of schizpphrenia. Federation Proc. 32: $200-205,1973$.

Maynert, E. W. and Klingman, G. I.: Tolerance to morphine. I. Effects on catecholamines in the brain and adrenal glands. J. Pharmaco1. Exp. Ther. 135: 285-295, 1962.

McGeer, P. L., Grewaal, D. S. and McGeer, E. G.: Influence of noncholinergic drugs in rat striatal acetylcholine leve1s. Brain Res. 80: 211-217, 1974.

McKenzie, G. M.: Role of the tuberculum olfactorium in stereotyped behavior induced by apomrophine in the rat. Psychopharmacolog1a 23: 212-219, 1972 .

Mckenzie, G. M.: Apomorphine-induced aggression in the rat. Brain Res. 34: 323-330, 1971 .

Mclean, J. R, and McCartney, M.: Effect of d-amphetamine on rat brain noradrenaline and serotonin. Proc. Soc. Exp. B101. Med. 107: 77-79, 1961 .

McLellan, H. and York, D.: The action of dopamine on neurons of the caudate nucleus. J. Phys1o1. 189: 393-402, 1967.

Mclennan, A.: The release of acetylcholine and 3-hydroxytyramine from the caudate nucleus. J. Physio. 165: 98116,1964 .

Mclennan, A.: The release of dopamine from the putamen. Experientia 21: 725,1965 .

Mennear, J. H.: Interactions between central cholinergic agents and amphetamine in mice. Psychopharmacologia 7: $107-114,1965$.

Miczek, K. A.: Intraspecies aggression in rats: effects of d-amphetamine and chlordiazepoxide. Psychopharmacologia 39: 275-301, 1974 .

Mishra, R. K., Gardner, E. L., Katzman, R. and Makman, M. H.: Enhancement of dopamine-stimulated adenylate cyclase activity in rat caudate after lesions in substantia nigra: evidence for denervation supersensitivity. Proc. Nat. Acad. Sc1. $\underline{71}: 3883-3887,1974$. 
Moore, K. E.: Development of tolerance to the behavioral depressant effects of $\alpha$-methyltyrosine. J. Pharm. Pharmacol. 20: 805-807, 1968 .

Moore, K. E., McCarthy, L. E. and Borison, H, L.: Blood glucose and brain catecholamine levels in the cat following the injection of morphine into the cerebrospinal fluld. J. Pharmacol. Exp. Ther. 148: 169-175, 1965.

Moore, R. Y., Bhatnagar, R. K. and Heller, A.: Anatomical and chemical studies of a nigro-striatal projection in the rat. Brain Res. 30: 119-135, 1971.

Morpurgo, C.: Aggressive behavior induced by large doses of 2-(2,6-dichloropheny1-amino)-2-imidazo1ine hydrochloride (ST 155) 1n.mice. Eur. J. Pharmacol.3: 374-377, 1968.

Morpurgo, C. and Theobald, W.: Influence of antiparkinson drugs and amphetamine on some pharmacological effects of phenothiazine derivatives used as neuroleptics. Psychopharmacologia 6 : 178-191, 1964.

Moyer, R. E.: Kinds of aggression and their physiological bases. Comm. Behav. B1o1. 2A: 65-87, 1968 .

Mullin, W. J. and Phillis, J. W.: Acetylcholine release from the brain of unanaesthetized cats following habituation to morphine and during precipitation of the abstinence syndrome. Psychopharmacolog1a 36: 85-99, 1974.

Myers, R. D.: Drug and Chemical Stimulation of the Brain, Van Nostrand Reinhold, New York, 1974.

Myers, R. D.: Emotional and autonomic responses following hypothalamic chemical stimulation. Canad. J. Psychol. 18: $6-14,1964$.

Neff, N. H. and Costa, E.: The influence of monoamine oxidase inhibitors on catecholamine synthesis. Life Sci. 5: $951-959,1966$.

Niemegeers, C. J. E., Verbruggen, F. J., Van Nueten, J. M. and Janssen, P. A. J.: Spiroxamide (R5188): a new compound producing morphine-like and chlorpromazine-1ike effects in animals. Int. J. Neuropharmacol. 2: 349354,1964 .

Nistri, A., Bartholini, A., Defenu, G. and Pepeu, G.: Investigations into the release of acetylcholine from the cerebral cortex of the cat: effects of amphetamine, of scopolamine and of septal lesions. Neuropharmacology 11: $665-674,1972$. 
Nyback, H., Borzeck1, Z. and Sedvail, G.: Accumulation and dfsappearance of catecholamines formed from tyrosine${ }^{14} \mathrm{C}$ in mouse brain: effect of some psychotropic drugs. Eur. J. Pharmaco1. 4 : 395-403, 1968 .

Nyback, H., Schubert, J. and Sedvall, G.: Effect of apomorphine and pimozide on synthesis and turnover of labelled catecholamines in mouse brain. J. Pharm. Pharmacol. 22: $622-624,1970$.

O'Keefe, R., Sharman, D. F. and Vogt, M.: Effects of drugs used in psychoses on cerebral dopamine metabolism. Br. J. Pharmacol. 38: 287-304, 1970 .

01tsman, G. A. and Harvey, J. A.: "LH syndrome" and brain catecholamines. Physiol. Behav. $\underline{8}: 69-78,1972$.

Patni, S. K. and Dandiya, P. C.: Apomorphine induced biting and fighting behaviour in reserpinized rats and an approach to the mechanism of action. Life Sci. 14:737745,1974 .

Paton, W. D. M.: A pharmacological approach to drug dependence and drug tolerance. In Scientific Basis of Drug Dependence, ed. by H. Steinberg, pp. 31-47, Grune \& Stratton, New York, 1969.

Persson, T.: Drug induced changes in $\mathrm{H}^{3}$ catecholamine accumulation after $\mathrm{H}^{3}$ tyrosine. Acta Pharmacol. Toxicol. 28: $378-390,1970$.

Persson, T. and Waldeck, B.: Further studies on the possible interaction between dopamine and noradrenaline containing neurons in the brain. Eur. J. Pharmacol. 11: 315320,1970 .

Phillips, A. G., Brooke, S. M. and Fibiger, H. C.: Effects of amphetamine isomers and neuroleptics on self-stimulation from the nucleus accumbens and dorsal noradrenergic bundle. Brain Res. 85: 13-22, 1975.

Phillips, A. G. and Fibiger, H. C.: Dopaminergic and noradrenergic substrates of positive reinforcement: differential effects of $D-$ and $L$ - amphetamine. Sclence 179: $575-577,1973$.

Poirer, L. J. and Sourkes, T. L.: Influence of the substantia nigra on the catecholamine content of the striatum. Brain 88: 181-192, 1965 . 
Portig, P. J. and Vogt, M.: Release into the cerebral ventricles of substances with possible transmitter function in the caudate nucleus. J. Physio1. 204: 687-715, 1969.

Price, M. T. C. and Fibiger, H. C.: Apomorphine and amphetamine stereotypy after 6-hydroxydopamine lesions of the substantia nigra. Eur. J. Pharmacol. 29: 249-252, 1974.

Puri, S. K., Cochin, J. and Volicer, L.: Effects of morphine sulfate on adenylate cyclase and phosphodiesterase activities in rat corpus striatum. Life Sci. 16: 759-768, 1975 .

Puri, S. K. and Lal, H.: Tolerance to the behavioral and neurochemical effects of haloperidol and morphine in rats chronically treated with morphine or haloperidol. N. S. Arch. Pharmaco1. 282:155-170, 1974 .

Puri, S. K. and Lal, H.: Reduced threshold to pain-induced aggression specifically related to morphine dependence. Psychopharmacologia 35: 237-242, $1974 \mathrm{~b}$.

Puri, S. K and La1, H.: Effect of dopaminergic stimulation or blockade on morphine withdrawal aggression. Psychopharmacologia 32: 113-118, 1973a.

Pur1, S. K and Lal, H.: Effect of apomorphine, benztropine or morphine on striatal dopamine turnover: evidence for latent supersensitivity of dopaminergic receptors in morphine dependent rats. Pharmacologist 15: 247, $1973 \mathrm{~b}$.

Puri, S, K., Reddy, C. and La1, H.: Blockade of central dopamine receptors by morphine: effect of haloperidol, apomorphine or benztropine. Res. Comm. Chem. Path. Pharmacol. $\underline{5}: 389-401,1973$.

Randrup, A. and Munkvard, I.: Relation of brain catecholamines to aggressiveness and other forms of behavioural excitation. In Aggressive Behavior, ed. by S. Garattini and E. B. Sigg, pp. 228-235, Excerpta Medica Foundation, Amsterdam, 1969.

Randrup, A. and Udsen, P.: Adrenergic mechanisms and amphetamine induced abnormal behaviour. Acta Pharmacol. 20: $145-157,1963$.

Rech, R. H. and Moore, K. E.: Interactions between d-amphetamine and $\alpha$-methyltyrosine in rat shuttle-box behavior. Brain Res. $\underline{8}$ : $398-400,1968$. 
Reid, J. L.: Dopamine supersensitivity in the hypothalamus? In Advances in Neurology, vol. 9, Dopaminergic Mechan Isms, ed. by D. Calne, T. N. Chase and A. Barbeau, pp. 73-80, Raven Press, New York, 1975.

Re1s, D. J., Hess, P. and Azmitia, E. C.: Changes in enzymes subserving catecholamine metabolism in morphine tolerance and withdrawal in rat. Brain Res. 20: 309-312, 1970 .

Rethy, C. R., Smith, C.B. and Villarreal, J. E.: Effect of narcotic analgesics upon the locomotor activity and brain catecholamine content of the mouse. J. Pharmacol. Exp. Ther. 176: 472-479, 1971 .

Rochette, L. and Bralet, J.: Effect of clonidine on the synthesis of cerebral dopamine. Blochem. Pharmacol. 24: $303-305,1975$.

Rommelspacher, H. and Kuhar, M. J.: Effects of dopaminergic drugs and acute medial forebrain bundle lesions on striatal acetylcholine levels. Life Sc1. 16: 65-70, 1975.

Roos, B. E.: Decrease in homovanil11c acld as evidence for dopamine receptor stimulation by apomorphine in the neostriatum of the rat. J. Pharm. Pharmacol. 21: 263264,1969 .

Roos, B. E.: Effects of certaln tranquilizers on the level of homovanilif acid in the corpus striatum. J. Pharm. Pharmacol. 17: 820-821, 1965 .

Rosenman, S. J. and Smith, C. B.: ${ }^{14}$ C catecholamine synthesis in mouse brain during morphine withdrawal. Nature 240: $153-155,1972$.

Roth, R. H., Walters, J. R., Murrin, L. C. and Morgenroth, V. H.: Dopamine neurons: role of $1 \mathrm{mpulse}$ flow and presynaptic receptors in the regulation of tyrosine hydroxylase. In Pre- and Postsynaptic Receptors, ed. by E. Usdin and W. E. Bunney, Pp. 5-48, Marcel Dekker, New York, 1975.

Sanders-Bush, E., Bushing, J. A. and Sulser, F.: Long term effects of p-chloroamphetamine on tryptophan hydroxylase activity and the levels of 5-hydroxyindole acetic acid in brain. Eur. J. Pharmacol. 20: 385-388, 1972. 
Sasame, H. A., Perez-Cruet, J., DiChiara, G., Tagliamonte, A., Tagliamonte, P. and Gessa, G. E.: Evidence that methadone blocks dopaminergic receptors in the brain. J. Neurochem. 19: 1953-1957, 1972 .

Sayers, A. C., Burki, H. R., Ruch, W. and Asper, H.: Neuroleptic-induced hypersensitivity of striatal dopamine receptors in the rat as a model of tardive dyskinesias. Effect of clozapine, haloperidol, loxapine and chlorpromazine. Psychopharmacologia 41: 97-104, 1975.

Scatton, B., Thierry, A. M., Glowinski, J. and Julou, L.: Effects of thioperazine and apomorphine on dopamine synthesis in the mesocortical dopaminergic systems. Brain Res. 88: $389-393,1975$.

Schee1-Kruger, J.: Central effects of anticholinergic drugs measured by the apomorphine test in mice. Acta Pharmacol. Toxicol. 38: 1-16, 1970 .

Schelkunov, E. L.: Adrenergic effects of chronic administration of neuroleptics. Nature 214: 1210-1212, 1967.

Schoenfeld, R. and Uretsky, N.: Altered response to apomorphine in 6-hydroxydopamine treated rats. Eur. J. Pharmacol. 19: 115-118, 1972 .

Scott, J. P.: Hostility and aggression in animals. In Roots of Behavior, ed. by E. L. Bliss, pp. 167-178, Harper and Row, New York, 1962 .

Scott, J. P.: Aggression, University of Chicago Press, Chicago, 1958.

Seeman, P. and Lee, T.: Antipsychotic drugs: direct correlation between clinical potency and presynaptic action on dopamine neurons. Science 188: 1217-1219, 1975 .

Seevers, M. H. and Deneau, G. A.: Physiological aspects of tolerance and physical dependence. In Physiological Pharmacology, vol. 1, ed. by W. Root and F. Hofmann, pp. 565-640, Academic Press, New York, 1963.

Segal, M., Deneau, G. A. and Seevers, M. H.: Levels and distribution of central nervous system amines in normal and morphine-dependent monkeys. Neuropharmacology 11: 211-222, 1972 .

Senault, B.: Amines cerebrales et comportement d'agressivite intraspecifique induit par l'apomorphine chez le rat. Psychopharmacologia 34: 143-154, 1974. 
Senault, B.: Effets de lesions du septum, de l'amygdale, du striatum, del a substantia nigra et de l'ablation des bulbes olfactifs sur le comportement d'agressivite intraspecifique induit par l'apomorphine chez le rat. Psychopharmacologia 28: $13-25,1973$.

Senault, B.: Influence de 1 a surrenalectomie, de 1'hypophysectomie, de la thyroidectomie, de la castration ainsi que de la testosterone sur le comportement d'agressivite intraspecifique indult par l'apomorphine chez le rat. Psychopharmacolog1a 24: 476-484, 1972 .

Senault, B.: Comportement d'agressivite intraspecifique induit par 1'apomorphine chez le rat. Psychopharmacologia 18: $271-287,1970$.

Sethy, V. H. and Van Woert, M. H.: Regulation of striatal acetylcholine concentration by dopamine receptors. Nature 251: 529-530, 1974 .

Sharpless, S. and Jaffe, J.: Withdrawal phenomena as manifestations of disuse supersensitivity. In Scientific Basis of Drug Dependence, ed. by H. Steinberg, pp. 6776, Grune \& Stratton, New York, 1969.

Singh, J. M.: Model to study methadone addiction. Pharmacolog1st 15: $242,1973$.

Singh, M. M. and Smith, J. M.: Reversal of some therapeutic effects of an antipsychotic agent by an antiparkinsonism drug. J. Nerv. Ment. Dis. 157: 50-58, 1973.

Sloan, J. W., Brooks, J. W., Eisenman, A. J. and Martin, W. R.: The effect of addiction to and abstinence from morphine on rat tissue catecholamine and serotonin levels. Psychopharmacologia 4 : 261-270, 1963.

Smelik, P. G. and Ernst, A. M.: Role of nigro-neostriatal dopaminergic fibers in compulsive gnawing behaviour in rats. Life Sc1. $\underline{5}$ : 1485-1488, 1966.

Smith, C. B.: Neurotransmitters and the narcotic analgesics. In Chemical and Biological Aspects of Drug Dependence, ed. by S. J. Mule and H. Bril1, Pp. 495-504, CRC Press, Ohio, 1972 .

Smith, C. B., Sheldon, M. I., Bednarczyk, J. H. and Villarreal, J. E.: Morphine induced increase in the incorporation of ${ }^{14} \mathrm{C}$ tyrosine into ${ }^{14} \mathrm{C}$ dopamine and $14 \mathrm{C}$ norepinephrine in the mouse brain: antagonism by naloxone and tolerance. J. Pharmaco1. Exp. Ther. 180: 547-557, 1972. 
Smith, C. B., Villarreal, J. E. and Bednarczyk, J. H.: Tolerance to morphine induced increases in $14 \mathrm{C}$ catecholamine synthesis in mouse brain. Science 170: 1106-1108, 1970 .

Snyder, S. H., Taylor, K. M., Coyle, J. T. and Meyerhoff, J. L.: The role of brain dopamine in behavioral regulation and the actions of psychotropic drugs. Amer. J. Psychiat. 127: 117-125, 1970 .

Spano, P. F. and Neff, N. H.: Procedure for the simultaneous determination of dopamine, 3-methoxy-4-hydroxypheny1acetic acid, and 3,4 -dihydroxyphenylacetic acid in brain. Ana1. Biochem. 42: 113-118, 1971 .

Spector, S., Sjoerdsma, A. and Udenfriend, S.: Blockade of endogenous norepinephrine synthesis by $\alpha$-methyl tyrosine, an inhibitor of tyrosine hydroxylase. J. Pharmacol. Exp. Ther. 147: 86-95, 1965 .

Stadler, H., Lloyd, K. G. and Bartholini, G.: Dopaminergic inhibition of striatal cholinergic neurons: synergistic blocking action of $\gamma$-butyrolactone and neuroleptic drugs. N. S. Arch. Pharmaco1. 283: 129-134, 1974 .

Stadler, H., Lloyd, K. G., Gadea-Ciria, M. and Bartholini, G.: Enhanced striatal acetylcholine release by chlorpromazine and its reversal by apomorphine. Brain Res. 55: $476-480,1973$.

Stark, P. and Henderson, J. K. : Central cholinergic suppression of hyper-reactivity and aggression in septal-1esioned rats. Neuropharmacology 11: 839-847, 1972.

Starke, K. and Montel, H.: Involvement of $\alpha$-receptors in clonidine-induced inhibition of transmitter release from central monoamine neurones. Neuropharmacology 12: 1073$1080,1973$.

Stein, L.: Chemistry of reward and punishment. In Psychopharmacology: A Review of Progress (1957-1967), ed. by D. Efron, pp. 105-123, U. S. Government Printing office, Washington, D. C., 1968 .

Stille, G., Lauener, H. and Eichenberger, E: : The pharmacology of 8-chloro-11-(4-methy 1-1-piperaziny 1$)-5$ H-dibenzo [b,e][1,4] diazepine (clozapine). Farmaco 26: 603-625, 1971 . 
Stone, C. A., Wenger, H. C., Ludden, C. T., Stavorski, I. M. and Ross, C. A.: Antiserotonin-antihistaminic properties of cyproheptadine. J. Pharmacol. Exp. Ther. 131: 73-83, 1961 .

Swonger, A. K. and Rech, R. H.: Serotonergic and cholinergic involvement in habituation of activity and spontaneous alternation of rats in a Y maze. J. Comp. Physio. Psychol. 81: 509-522, 1972 .

Takagi, H. and Nakama, M.: Effect of morphine and nalorphine on the content of dopamine in mouse brain. Jap. J. Pharmaco1. 16: 483-484, 1966 .

Tarsy, D. and Baldessarini, R. J.: Pharmacologically induced behavioral supersensitivity to apomorphine. Nature 245: $262-263,1973$.

Tassin, J. P., Thierry, A. M., Blanc, G. and Glowinski, J.: Evidence for a specific uptake of dopamine by dopaminergic terminals of the rat cerebral cortex. N. S. Arch. Pharmacol. 282: 239-244, 1974 .

Tedeschi, R. E., Tedesch1, D. H., Mucha, A., Cook, L., Matt1s, P. A. and Fellows, E. J.: Effects of various centrally acting drugs on fighting behavior of mice. J. Pharmacol. Exp. Ther. 125: 28-34, 1959 .

Thesleff, S.: Supersensitivity of skeletal muscle produced by botulinum toxin. J. Physiol. 151: 598-607, 1960.

Thierry, A. M., Blanc, G., Sobe1, A., Stinus, L. and Glowinski, J.: Dopaminergic terminals in the rat cortex. Sclence 182: 499-501, 1973a.

Thierry, A. M., Stinus, L., Blanc, G. and Glowinski, J.: Some evidence for the existence of dopaminergic neurons in the rat cortex. Brain Res. 50: 230-234, 1973b.

Thor, D. H.: Chemical induction of traumatic fighting behavior. Proc. Am. Psychol. Assoc. 4: 883-884, 1969.

Thor, D. H., Hoats, D. L. and Thor, C. J.: Morphine induced fighting and prior social experience. Psychon. Sc1. 18: $137-139,1970$.

Thornburg, J. E. and Moore, K. E.: Supersensitivity to dopamine agonists following unilateral 6-hydroxydopamineinduced striatal lesions in mice. J. Pharmacol. Exp. Ther. 192: 42-49, 1975 . 
Thornburg, J. E. and Moore, K. E.: Supersensitivity to dopaminergic agonists following withdrawal of a chronic diet containing haloperidol or pimozide. Pharmacologist 16: 307,1974 .

Thornburg, J. E. and Moore, K. E.:The relative importance of dopaminergic and noradrenergic neuronal systems for the stimulation of locomotor activity induced by amphetamine and other drugs. Neuropharmacology 12: 853-866, $1973 \mathrm{a}$.

Thornburg, J. E. and Moore, K. E.: Inhibition of anticholinergic drug-induced locomotor stimulation in mice by $\alpha$-methyltyrosine. Neuropharmacology 12: 1179-1185, $1973 \mathrm{~b}$.

Thornburg, J. E. and Moore, K. E.: Postnatal development of benztropine-induced locomotor stimulation: evidence for an anticholinergic mechanism of action. Res. Comm. Chem. Path. Pharmacol. 6: 313-320, $1973 \mathrm{c}$.

Trabucchi, M., Cheney, D., Racagni, G. and Costa, E.: Involvement of brain cholinergic mechanisms in the action of chlorpromazine. Nature 249: 664-667, 1974.

Trendelenurg, U.: Mechanisms of supersensitivity and subsensitivity to sympathomimetic amines. Pharmacol. Rev. 18: $629-640,1966$.

Trendelenburg, U.: Supersensitivity and subsensitivity to sympathomimetic agents. Pharmacol Rev. 15: 225-276, 1963.

Udenfriend, S., Creveling, C. R., Czaki, M., Daly, J.W. and Witkop, B.: Inhibitors of norepinephrine metabolism in vivo. Arch. Blochem. Biophys. 84: 249-259, 1959.

Ulrich, R. and Azrin, N. H.: Reflexive fighting in response to aversive stimulation. J. Exp. Ana1. Behav. ㅍ: 511520,1962 .

Ungerstedt, U.: Postsynaptic supersensitivity after 6-hydroxydopamine induced degeneration of the nigro-striatal dopamine system. Acta Physiol. Scand. $\underline{82}$ supp1 367: 69-93, 1971a.

Ungerstedt, U.: Adipsia and aphagia after 6-hydroxydopamine. induced degeneration of the nigro-striatal dopamine system. Acta Physiol. Scand. supp1. 368: 95-122, 1971b. 
Ungerstedt, U., Butcher, L. L., Butcher, S. G., Anden, N. E. and Fuxe, K.: Direct chemical stimulation of dopaminergic mechanisms in the neostriatum of the rat. Brain Res. 14: $461-471,1969$.

Uretsky, N. J. and Iversen, L. L.: Effects of 6-hydroxydopamine on catecholamine containing neurons in rat brain. J. Neurochem. 17: 269-278, 1970 .

Uretsky, N. J. and Schoenfe1d, R. I.: Effects of L-DOPA on the locomotor activity of rats pretreated with 6-hydroxydopamine. Nature 234: 157-159, 1971.

Valze111, L.: The "isolation syndrome" in mice. Psychopharmacologia 31: $305-320,1970$.

Va1ze111, L: Drugs and aggressiveness. Adv. Pharmacol. $\underline{5}$ : $79-108,1967$.

Van Rossum, J. M. and Hurkmans, J. A.: Mechanism of action of psychomotor stimulant drugs (significance of dopamine in locomotor stimulant action). Int. J. Neuropharmacol. 3: $227-239,1964$.

Vetulani, J., Leith, N. J., Stawarz, R. J. and Sulser, F.: Effect of clonidine on the norepinephrine (NE)-sensitive cyclic AMP generating system in slices of rat spinal cord (SC), brain stem (BS) and limbic forebrain (LFB) and on medial forebrain bundle (MFB) stimulation. Pharmacologist 17: 196, 1975.

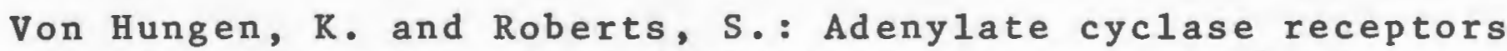
for adrenergic neurotransmitters in rat cerebral cortex. Eur. J. Biochem. 36: 391-401, 1973.

Von Volghtlander, P. F., Boukma, S. J. and Johnson, G. A.: Dopaminerglc denervation supersensitivity and dopamine stimulated adeny 1 cyclase activity. Neuropharmacology 12: 1081-1086, 1973 .

Von Voightlander, P. F., Losey, E. G. and Triezenberg, H. J.: Increased sensitivity to dopaminergic agents after chronic neuroleptic treatment. J. Pharmaco1. Exp. Ther. 193: $88-94,1975$.

Von Volghtlander, P. F. and Moore, K. E.: Involvement of nigro-striatal neurons in the in vivo release of dopamine by amphetamine, amantadine and tyramine. J. Pharmaco1. Exp. Ther. 184: 542-552, 1973a. 
Von Volghtlander, P. F. and Moore, K. E.: In vivo release of $\mathrm{H}^{3}$ dopamine from the brain during the administration of haloperidol. Res. Comm. Chem. Path. Pharmacol. 5: 223$232,1973 \mathrm{~b}$.

Von Voightlander, P. F. and Moore, K. E.: Turning behavior of mice with unilateral 6-hydroxydopamine lesions in the striatum: effects of apomorphine, L-DOPA, amantadine, amphetamine and other psychomotor stimulants. Neuropharmacology 12: 451-462, $1973 \mathrm{c}$.

Von Voightlander, P. F. and Moore, K. E.: Nigro-striatal pathway: stimulation evoked release of ${ }^{3} \mathrm{H}$ dopamine from caudate nucleus. Brain Res. 35: 580-583, 1971a.

Von Volghtlander, P. F. and Moore, K. E. : The release of $\mathrm{H}^{3}-$ dopamine from rat brain following electrical stimulation of the substantia nigra and caudate nucleus. Neuropharmacology 10: $733-741,1971 \mathrm{~b}$.

Walters, J. R., Roth, R. H. and Aghajanian, G. K.: Dopaminergic neurons: simflar biochemical and histochemical effects of $\gamma$-hydroxybutyrate and acute lesions of the nigro-striatal pathway. J. Pharmacol. Exp. Ther. 186: $6.30-639,1973$.

Wauquier, A. and Niemegeers, C. J. E.: Intracranial selfstimulation in rats as a function of various stimulus parameters. II. Influence of haloperidol, pimozide and pipamperone on medial forebrain bundle stimulation with monopolar electrodes. Psychopharmacologia 27: 191-202, 1972 .

Wauquier, A., Niemegeers, C. J. E. and La1, H.: Differential antagonism by the anticholinergic dexetimide of inhibitory effects of haloperidol and fentanyl on brain selfstimulation. Psychopharmacologia 41: 229-235, 1975.

Wauquier, A., Niemegeers, C. J. E. and Lal, H.: Differential antagonism by naloxone of inhibitory effects of haloperidol and morphine on brain self-stimulation. Psychopharmacologia 37: 303-310, 1974 .

Way, E. L., Loh, H. H. and Shen, F.: Morphine tolerance and physical dependence and synthesis of 5-hydroxytryptamine. Science 162: 1290-1292, 1968.

Wei, E., Loh, H. H. and Way, E. L.: Quantitative aspects of precipitated abstinence in morphine-dependent rats. J. Pharmacol. Exp. Ther. 184: 398-403, 1973. 
Weiner, W. J., Goetz, C. and Klawans, H. L.: Serotonergic and antiserotonergic influences on apomorphine-induced stereotyped behaviour. Acta Pharmacol. Toxicol. $\underline{36}$ : $155-160,1975$.

Weiner, W. J., Goetz, C., Westhelmer, R. and Klawans, H. L.: Serotonergic and antiserotonergic influences on amphetamine-induced stereotyped behavior. J. Neurol Sci. 20: $373-379,1973$.

Weissman, A.: Iumping in mice elicited by $\alpha$-naphthyloxyacetic ac1d. J. Pharmaco1. Exp. Ther. 184: 11-17, 1973.

Welch, B. L. and Welch, A. S.: Some aspects of brain biochemistry correlated with general nervous reactivity and aggressiveness. In Animal Aggression: Selected Readings, ed. by C. H. Southwick, pp. 187-200, Van Nostrand Reinhold, New York, 1970.

Williams, B. J. and Pirch, J. H.: Correlation between brain adenyl cyclase activity and spontaneous motor activity in rats after chronic reserpine treatment. Brain Res. 68: $227-234,1974$.

Winer, B. J.: Statistical Principles In Experimental Design, second edition, McGraw-H111, New York, 1971.

Wurtman, R. J., Larin, F., Mastafapour, S. and Fernstrom, J. D.: Brain catechol synthesis: control by brain tyrosine concnetration. Science 185: 183-184, 1974 .

Yarbrough, G. C.: Supersensitivity of caudate neurones after repeated administration of haloperidol. Eur. J. Pharmacol. 31: 367-369, 1975 .

Yarbrough, G. C.: Actions of acetylcholine and atropine on cerebral cortical neurons in chronically morphinetreated rats. Life Sc1. 15: 1523-1529, 1974.

Yarbrough, G. C., Buxbaum, D.M. and Sanders-Bush, E.: Increased serotonin turnover in the acutely morphine treated rat. Life Sc1. 10: 977-983, 1971.

Yen, C. Y., Stanger, R. L. and Millman, N.: Ataractic suppression of lsolation induced aggressive behavior. Arch. Int. Pharmacodyn. 123: 179-185, 1959.

Yokel, R. A. and Wise, R. A.: Increased lever pressing for amphetamine after pimozide in rats: implications for a dopamine theory of reward. Science 187: 547 - 549, 1975 . 
York, D. H.: Possible dopaminergic pathway from substantia nigra to putamen. Brain Res. 20: 233-249, 1970 .

Yunger, L. M., McMaster, S. E. and Harvey, J. A.: Neurotoxic effects of p-chloroamphetamine (p-CA) on perikarya of raphe neurons. Pharmacologist 16: 244, 1974.

Zigmond, M. J. and Stricker, E. M.: Deficits in feeding behavior after intraventricular injection of 6-hydroxydopamine in rats. Science 177: 1211-1214, 1972 .

Zivkovic, B., Guldotti, A. and Costa, E.: Effects of neuroleptics on striatal tyrosine hydroxylase: changes in affinity for the pteridine cofactor. Molec. Pharmacol. 10: $727-735,1974$. 